\title{
La divinazione nei Documenti d'Amore: tra prassi giuridica e disciplina della parola
}

\begin{abstract}
La pubblicazione dei Documenti d'Amore per cura di Federico Ubaldini mostra, fin dalle sue intenzioni, la volontà di analizzare l'opera di Francesco da Barberino per il suo apporto linguistico. Nel contributo si prende in esame come alcuni aspetti, ovvero la disciplina della parola e la predicazione, si intrecciano alla divinazione nelle sue varie forme, un'altra questione fondamentale e analizzata in più luoghi dell'opera barberiniana, che oscilla costantemente tra i poli veritas/falsitas, e sottigliezza/grossezza. Dapprima, si procederà a un'analisi dello statuto giuridico di tali tecniche, analizzando i richiami al Corpus iuris canonici e alla patristica puntualmente evocati nella glossa latina; in secondo luogo, ci si concentrerà sullo statuto dell'oniromanzia, cosa che porta le artes divinandi a una continua ridefinizione tra testo latino e volgare e a un loro inquadramento nella prassi pubblica della predicazione; infine, ci si concentrerà sullo statuto dell'astrologia giudiziaria all'interno dei vari livelli di cultura e di pubblico implicati da Francesco da Barberino tanto nei Documenti, quanto nel complementare Reggimento. L'intento è quello di mostrare come l'opera barberiniana nel suo complesso agisca su vari fronti, tanto come riflessione teorico-dottrinale, quanto come manuale precettistico-formale, sfruttando pienamente le potenzialità linguistiche del volgare, del latino e dell'apparato figurativo.
\end{abstract}

Federico Ubaldini's edition the Documenta Amoris illustrates his wish to provide a linguistic analysis of Francesco Barberino's work. This contribution analyses how some of these aspects intertwine with divination in its various forms, which is another important aspect of Barberino's writings that constantly oscillates between the poles veritas/falsitas and thinness/thickness. The contribution studies a) the legal statute of such techniques, b) the statute of oneiromancy, and c) the statute of judicial astrology within the various levels of culture and public that Barberino implicates both in his Documenta and in the complementary Reggimento. The main objective is to show how Barberino's work acted on several fronts, making broad use of the linguistic potential of both the vernacular and Latin and of the figurative means at his disposal.

Parole chiave: Francesco da Barberino, Divination, Preaching, Judicial Astrology, Oneiromancy, Fortune 
«Omnis mundi creatura

quasi liber, et pictura

nobis est, et speculum.

Nostrae vitae, nostrae mortis, nostri status, nostrae sortis

fidele signaculum».

Alano di Lilla, Omnis mundi creatura, carmen, vv. 1-6

\section{Introduzione}

Pubblicando nel 1640 l'editio princeps dei Documenti d'Amore ${ }^{1}$ di Francesco da Barberino il nobile senese Federico Ubaldini, conte di Urbania e segretario del cardinale Francesco Barberini, sottolineò come la monumentale opera del notaio valdelsano avesse l'intento di voler insegnare «l'arte di renderci amabili con le belle maniere, e con i saggi avvisi, i quali ci conducono per quella strada per cui eternandosi la Fama, veniamo ad essere in ogni secolo felici». ${ }^{2}$ Tuttavia,

$1 \mathrm{Al}$ fine di permettere il reperimento dei passi menzionati su entrambe le edizioni dei Documenti d'Amore, si citerà il testo da Francesco da Barberino, I Documenti d'Amore / Documenta Amoris (ed. Albertazzi), ma tra parentesi verranno sempre indicati il volume e la pagina di riferimento nell'edizione I Documenti d'Amore di Francesco da Barberino (ed. Egidi). Si sono resi necessari alcuni interventi di ripristino delle lezioni di Barb. lat. 4076, che ho visionato in riproduzione digitale, specialmente per quanto riguarda le fonti citate nella glossa latina, dove Albertazzi si discosta dal manoscritto preferendogli la fonte, se esplicitamente menzionata (i criteri sono enunciati in Francesco da Barberino, I Documenti d'Amore / Documenta Amoris, vol. I, p. XIV). Tutti gli interventi in questione saranno di volta in volta segnalati e motivati in nota. Ho inoltre ritoccato la punteggiatura in alcuni casi e scelto, in conformità con la dichiarata fedeltà al codice, di non accogliere le integrazioni di Albertazzi in tutti quei casi in cui esse sono motivate solo dal restauro della fonte latina. Per il Reggimento traggo il testo dalla problematica edizione Francesco da Barberino, Reggimento e costumi di donna (ma si tengano presenti le numerosissime riserve, per un sunto delle quali rimando a Giunti, Il Reggimento di Francesco da Barberino, pp. 43-74; Ead., «Né parlerai rimato», pp. 71-111, specialmente le pp. 71-78). Per le traduzioni latine del corpus di Aristotele cfr. il database Aristoteles Latinus, mentre per quanto riguarda i richiami al testo greco cfr. Aristotle, Parva naturalia e Aristotelis Fragmenta selecta; infine, per i commenti allo Stagirita si cita da CLCAG. Il Corpus iuris canonici verrà citato seguendo i criteri esposti in Indices titulorum et legum, vol. 1, p. V, traendo il testo del Decretum di Graziano (= Decr.) e delle Decretali da Corpus iuris canonici; per i riferimenti al Corpus iuris civilis adotto i criteri redatti in Indices titulorum et legum, vol. 2, p. XI, ovvero: D = Digesta, in Corpus Iuris Civilis, vol. 1; C = Codex, in Corpus Iuris Civilis, vol. 2.

2 Dalla lettera di dedica a Carlo, Maffeo e Niccolò Barberini premessa a Federico Ubaldini, Documenti d'amore. Si veda anche Barberini, Francesco Barberini e l'edizione seicentesca. Per la biografia e le opere dell'Ubaldini rimando a Mezzanotte, Contributo alla biografia, ma cfr. anche Vitaletti, Intorno a Federico Ubaldini, pp. 489-506; Izzi, Ubaldini, Federigo. 
agli occhi di un erudito secentesco pienamente inserito nelle dinamiche della curia romana, quale era l'Ubaldini, i Documenti d'Amore si presentavano degni di nota almeno per due altre ragioni. Proprio nel 1640, infatti, egli intraprendeva la stesura di una dettagliata storia della famiglia Barberini, rilavorata lungo tutta la sua vita e mai portata a termine, ${ }^{3}$ e individuava erroneamente in Francesco da Barberino un illustre antenato del Cardinale, per cui la pubblicazione dei Documenti aveva anche carattere encomiastico e doveva rendere omaggio alla «gloria di questa Casa». ${ }^{4}$ L'Ubaldini, inoltre, perseguiva l'intento, facilmente rintracciabile nella struttura dell'edizione, di far «ancora apparire qual fosse la prima età della nostra lingua, e chi cominciasse primieramente a sollevarla», ${ }^{5}$ cosa perfettamente in linea con l'opera di riscoperta linguistica e filologica della lirica delle Origini che caratterizzò l'attività del senese, di cui ci resta traccia in numerosi codici della Biblioteca Apostolica Vaticana da lui annotati e trascritti. ${ }^{6}$

Proprio in virtù dell'interesse per gli autori medievali e del giudizio sulla

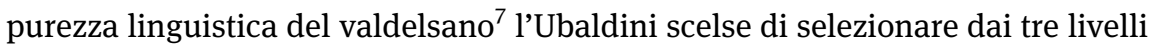
di scrittura dei Documenti d'Amore solo il testo volgare, non pubblicando quindi

3 Di essa ci restano frammenti e singole sezioni in alcuni codici barberiniani, ovvero i mss. segnati Barb. lat. 4726, Barb. lat. 4727, Barb. lat. 4728, Barb. lat. 4901, Barb. lat. 4881, per i quali si rinvia di nuovo a Mezzanotte, Contributo alla biografia, p. 496, n. 2.

4 «Per la testimonianza che ne rendono tant'huomini di conto antichi e moderni, e per esser M. Francesco della Casa Barberina, fattosi il Mondo curioso delle sue rime, io ho attribuito il poterle pubblicare a mia somma ventura» (dall'avvertenza A' lettori, in Federico Ubaldini, Documenti d'amore). Cfr. anche Prandi, Vincenzo di Beauvais e Francesco da Barberino, pp. 134-135.

5 Avvertenza A'lettori, Federico Ubaldini, Documenti d'amore.

6 Si vedano ad esempio gli appunti sulla Commedia di Dante studiati da Vitaletti, Annotazioni alla Divina Commedia di Federico Ubaldini; lo zibaldone Barb. lat. 3999 dove, alle cc. 78r-81v, Federico Ubaldini trascrive la tenzone tra Dante e Forese Donati, traendo i primi quattro sonetti dal codice Chig. L.VIII.305 e gli ultimi due dal Chig. L.IV.131, oppure le annotazioni, datate 1642, al Tesoretto di Brunetto Latini nel codice Chig. L.VII. 249 (c. 133v) dove se ne annuncia la pubblicazione, confluita nell'edizione Le rime di M. Francesco Petrarca estratte da un suo originale. Cfr. anche Del Lungo, Federico Ubaldini e le Vite Ubaldiniane; Mezzanotte, Federico Ubaldini e gli studi provenzali.

7 «A noi basti d'accennare che nel presente libro si mostra, com'io diceva, l'età più tenera della nostra favella toscana, e quali fossero le nascenti bellezze, che poscia acquistando molto di vigore e di grazia, l'hanno resa non indegna di comparire nel teatro dell'Universo al pari della Greca, e la Latina facondia. E certo se riguardiamo attentamente queste rime, presso che non c'incontreremo in niuna voce, o modo di parlare che non sia di quelli, che con tanta leggiadria il Petrarca, il Boccaccio, et anche il gran Poeta Dante seppero così destramente intramettere negli scritti, che con applauso commune fino al dì d'oggi sono e letti et imitati dagl'intendenti. [. . .] Anzi ne i Documenti si sentirà da queste orecchie delicate l'istesse durezze, che sogliono esser in coloro che non havendo ancora la favella intiera, tentano di pure esprimere i concetti dell'animo» (A'lettori, in Federico Ubaldini, Documenti d'amore). 
né l'autotraduzione latina né le glosse, e pose a chiusura della sua edizione una lista di autori italiani e provenzali e una Tavola delle voci e maniere di parlare più considerabili usate nell'opera. ${ }^{8}$ L'editore secentesco aveva dunque individuato una delle colonne portanti dei Documenti, ovvero l'attenzione dedicata dal suo autore ai fatti linguistici, ${ }^{9}$ un fenomeno che viene declinato dal Barberino in modi diversi. Egli, infatti, struttura l'opera come un Bildercodex in cui il livello testuale si richiama costantemente a quello figurativo rendendo l'autore «equilibratore dei rapporti testo-immagine» ${ }^{10}$ e la scrittura, aggiungo, iconica e figurabile, ${ }^{11}$ ma vi include al contempo diversi excursus sulla doctrina dicendi che spaziano dal trattatello metrico contenuto nella parte seconda dell'opera, ${ }^{12}$ ai frequentissimi rimandi alla tradizione precettistica in cui campeggia la figura di Albertano da Brescia, fino all'impiego massivo di tecniche retoriche della divulgazione pastorale attinte dalle artes praedicandi. ${ }^{13}$

Federico Ubaldini si rivolge dunque ai Documenti d'Amore come a una fonte dalla quale trarre informazioni linguistiche e lessicali nonché la gloriosa genealogia della famiglia Barberini. Se quindi una lettura del poema come documento al

8 Rispettivamente in corrispondenza delle pp. 377 e 385, non numerate. Per un giudizio sulla struttura dell'edizione dell'Ubaldini si veda Antognoni, Le glosse ai 'Documenti d'Amore', p. 78. $9 \mathrm{Si}$ tratta di un aspetto messo in luce anche dai contemporanei dell'autore, come ad esempio Filippo Villani che definisce Francesco da Barberino «semipoeta» ma al contempo ne sottolinea l'impiego del volgare. Cfr. Philippi Villani, De origine civitatis Florentie, pp. 143-144 e 400-401.

10 Ciccuto, Francesco da Barberino: un pioniere del 'Bildercodex', p. 86. Ma cfr. anche Nardi, Le illustrazioni dei 'Documenti d'amore', pp. 78-79: «L'immagine, dunque, è, insieme, elemento introduttivo, didascalico e sintetizzante rispetto alla parte letteraria che, a sua volta, assume a questa stessa funzione divenendo il tramite per mezzo del quale si fornisce una chiave di lettura interpretativa di quella iconica».

11 Ma per Goldin Folena i Documenti non rappresentano un caso di visibile parlare e «le miniature del Barb. lat. 4076 più che commento sono emanazione del testo, qua e là suo necessario complemento, perché talora esse possono esprimere, significare, più che le parole stesse, anche se ad ogni miniatura il Barberino fa seguire la sua puntuale decodificazione, vale a dire, nella terminologia dell'autore, la sua descriptio» (Goldin Folena, Il commento nella pagina autografa, pp. 277-278). Su posizioni affini anche Ciociola, «Visibile parlare», p. 20.

12 Le due glosse metriche sono contenute in Doc. Am., II, sub Industria, doc. vI, v. 3128 (vol. II, pp. 263-264), ovvero nel proemio alla sezione dei 'mottetti', e in Doc. Am., VII, sub Prudentia, doc. IX, v. 5190 (vol. III, pp. 146-148). Cfr. Antognoni, Le glosse ai 'Documenti d'Amore'; Gilardi Zanone, In margine alle chiose dei 'Documenti d'Amore', pp. 65-81; Camboni, Il sonetto delle origini, pp. 13-34; Ead., Cantus/Cantilena, pp. 9-13; Abramov-van Rijk, Parlar cantando, pp. 67-75; Panzera, Francesco da Barberino tra Andrea Cappellano e Averroè, pp. 100-108.

13 Non trascurabile il legame che Francesco da Barberino intrattiene con l'ars dictaminis, recentemente messo in luce da Montefusco, Bischetti, Prime osservazioni, pp. 198-205; per la rilevanza lessicale dei Documenti d'Amore si veda ora Verlato, Schede di lessico. 
contempo storico e linguistico è stata già tentata, ciò che potrebbe sensibilmente rivalutare il ruolo intellettuale del Barberino come abile utilizzatore di letteratura latina e volgare è la realizzazione di un repertorio esaustivo delle fonti impiegate nella coppia Reggimento-Documenti e una problematizzazione delle stesse nelle macroquestioni che modellano in filigrana l'intera opera letteraria del valdelsano, sebbene importanti sondaggi abbiano già fatto luce sul suo scrittoio. ${ }^{14}$ I Documenti non sono semplicisticamente quel manifesto del volgare illustre che l'Ubaldini voleva leggervi proprio perché la coesistenza di cultura latina, cultura in lingua d'oc e in lingua di sì non può essere messa in secondo piano, e se tale coesistenza ha valore strutturante nei tre livelli testuali dell'opera, diventa ancor più rilevante quando si analizza come lo stesso tema o la stessa problematica siano smembrati non solo nei diversi piani di scrittura, ma anche nella pluralità di fonti a cui il valdelsano attinge nel processo argomentativo.

L'approccio alla divinazione mi pare che sia un'utile cartina al tornasole nel tentativo di circoscrivere l'operato del valdelsano come auctor e la sua maniera di modellare le auctoritates per più di una ragione. Nei Documenti, infatti, Francesco rivela solide conoscenze dell'inquadramento giuridico, dottrinale e culturale della predizione del futuro, cosa che si ripercuote sull'architettura complessiva dell'opera attraverso il ricorso al linguaggio profetico o la stessa chiusa affidata ad Eternità. Inoltre, il percorso che la divinazione instaura nel testo volgare e nella glossa dei Documenti si articola attraverso molteplici rimandi che egli modula in base alle proprie esigenze comunicative, cosa che permette di avanzare alcune importanti considerazioni su ulteriori livelli di lettura riscontrabili nel testo oltre a quelli esplicitamente invocati dall'autore. ${ }^{15}$ Infine, nella ricchissima miniera delle glosse si affacciano vivide tracce della quotidianità intellettuale e culturale di un giurista-poeta del primo Trecento, in cui testi accademici e patristici convivono con l'opera evangelizzatrice dei predicatori e con l'impatto che essa ebbe sulle piazze, mentre sullo sfondo si intravvedono gli echi delle condanne inquisitoriali dell'aristotelismo radicale e gli effetti dell'anti-intellettualismo duecentesco che faceva capo a Brunetto. La divinazione rappresentava, in sostanza, un

14 Mi riferisco in particolare al gruppo di ricerca guidato da Billanovich negli anni Settanta per il quale si veda Billanovich, Prandi, Scarpati, Lo «Speculum» di Vincenzo di Beauvais. Anche l'edizione curata nel 2008 da Marco Albertazzi, al di là dei suoi effettivi limiti, ha permesso di fare passi in avanti attraverso l'inserimento della punteggiatura e dei richiami in nota alle fonti citate.

15 «Si sa bene peraltro che il B. non copia mai. Egli tiene molto alla sua originalità, onde trasforma gli elementi altrui, talora condensa idee e fatti, talaltra svolge e commenta. Se noi non possedessimo il commento, non giungeremmo mai a formarci un'idea del materiale imponente che il B. ha utilizzato per l'opera sua» (Renier, Recensione a A. Thomas, Francesco da Barberino et la littérature provençale, p. 97). 
argomento di estrema attualità nelle accademie fin dalla metà del secolo precedente e subirà un radicale processo di rinnovamento grazie a Dante, con tappe che sono già delineabili nei passaggi che conducono dal Convivio al Paradiso. Francesco da Barberino si trova quindi a un crocevia sia cronologicamente, sia culturalmente, e la sua attività come notaio episcopale e inquisitore per i francescani rende tale percorso ancora più denso per cui, tra le numerose piste possibili, la divinazione si configura come una tra le più ricche e indicative nel testare la tenuta del complesso progetto enciclopedico e didattico del Barberino.

Sono tuttavia necessarie alcune precisazioni di carattere metodologico: in primis, intendo come divinazione il complesso di téchnai e di artes che presiedeva alla predizione del futuro, ovvero sia sistemi come la geomanzia, l'aruspicina e la negromanzia, ma anche pratiche come l'oniromanzia e discipline vere e proprie, dotate di un riconoscimento nell'insegnamento accademico, come l'astrologia giudiziaria. Si escluderanno pertanto da questa analisi il profetismo tout court e l'apocalittica, pure importantissimi nell'opera del valdelsano, ma difficilmente isolabili nei Documenti come sezioni a cui viene riservata un'esposizione più o meno autonoma. In secondo luogo, bisogna tenere presente che il commento possiede un carattere frammentario e variegato, «così complesso e composito che appare subito evidente la mancanza di un legame di necessità col testo di partenza» ${ }^{16}$ ma esso è, al contempo, artefice dello «straordinario progetto editoriale» ${ }^{17}$ dei Documenti. Per questo motivo l'analisi terrà in particolare considerazione il testo latino, malgrado non sia facile individuare in esso una trattazione sistematica della questione, a cui tuttavia si accenna in più luoghi, spesso in relazione a contesti distanti tra loro. Il criterio organizzatore del presente saggio saranno dunque le fonti impiegate dall'autore di volta in volta, in quanto esse mi paiono essenziali e dirimenti nel definire i punti di contatto o di distacco con il coevo inquadramento della questione.

Il lavoro sarà suddiviso in tre macrosezioni. Nella prima, partendo dal consueto binomio tra Fortuna e libero arbitrio, tratterò di rituali divinatori come l'aruspicina, che Francesco da Barberino associa alla superstizione sulla base di Agostino, recuperato mediante il Corpus iuris canonici di Graziano. In questo caso si sottolineerà l'impalcatura giuridico-dottrinale di questa porzione dei $\mathrm{Do}$ cumenti, da cui traspaiono l'impronta del doctor in utroque iure ma anche quella degli ensenhamens provenzali e della letteratura precettistica in generale. Nella seconda parte si approfondirà quindi il nesso tra predizione del futuro e peccatum linguae e i suoi risvolti nell'oniromanzia, mostrando come la predicazione

16 Goldin Folena, Il commento nella pagina autografa, p. 272.

17 Ivi, p. 273. 
in pubblico possieda il rischio di essere associata al mendacium e si opponga alla parola divina, intesa come Verbum e Veritas. Il recupero barberiniano degli autori patristici e dell'aristotelismo e il contesto storico delle condanne parigine dell'averroismo saranno fondamentali per stabilire rudimentali avvisaglie di una teoria della ricezione in divenire all'interno dei Documenti. L'importanza della divinazione astrologica come argomento di pubblica orazione sarà dunque l'oggetto della terza parte dove si evidenzieranno le aperture di Francesco da Barberino all'astrologia giudiziaria come disciplina erudita, da impiegare solo di fronte ai sottili e da non destinare agli ignoranti, i grossi, più volte chiamati in causa lungo tutta l'opera. Ne risulta un punto di vista poliedrico, che in taluni casi segue fedelmente le direttive agostiniane e del Decretum o, in generale, le maggiori auctoritates sulla questione, salvo poi staccarsene quando il Barberino ha bisogno di piegare la trattazione a finalità didattiche, anche a costo di aggirare il problema della conciliazione tra libero arbitrio e determinismo che invece acquisiva sempre più rilevanza nella lirica fiorentina coeva.

\section{Il ruolo della Fortuna e le tecniche divinatorie tra diritto canonico e patristica}

Con i Documenti d'Amore Francesco da Barberino intende realizzare una raccolta di insegnamenti rivolta a un pubblico maschile al fine di produrne l'educazione nei costumi della cortesia e l'innalzamento spirituale, un'operazione già intrapresa per l'uditorio femminile con il Reggimento e costumi di donna, la cui composizione incornicia cronologicamente quella dei Documenti. ${ }^{18}$ La trattazione ha un andamento progressivo e procede dalla prima parte indirizzata ai novizi fino alla conclusione, in cui si affrontano questioni teologiche e dottrinali. All'interno della prima parte, sotto il magistero di Docilità, Francesco da Barberino inserisce alcune riflessioni preliminari sul ruolo della Fortuna negli atti umani, in particolare nei documenti XxIII e XXIV: nel primo caso l'autore dichiara di voler esporre "como 'l signor dêa tractar lo servente», ${ }^{19}$ dopo aver racchiuso nel documento precedente i precetti che devono osservare i servitori. Le norme sono destinate ai «signor' noviçi», ${ }^{20}$ e tra le primissime raccomandazioni

18 Cfr. Ortiz, Le imitazioni dantesche, pp. 231-268; Cristiani, La questione cronologica, pp. 3-21; Margueron, Francesco da Barberino; Pasquini, Francesco da Barberino.

19 Doc. Am., I, sub Docilitate, doc. XXIII, v. 1424 (vol. I, p. 286).

20 Ivi, v. 1428 (vol. I, p. 287). 
il valdelsano fa proprio riferimento alla maniera in cui questi devono rivolgersi ai loro sottoposti:

\author{
Singnor noviç<i $>0$ convien poner cura \\ che la sua parladura, \\ l'andar, e ciascun acto in cominciare, \\ sia fuor di grosseggiare: \\ a poco a poco sallisca al suo grado, \\ faccia gran viste rado; \\ per ogni ciancia comandar si guardi. \\ Se pur s'adira, tardi, \\ né con rimor, né con parlar villano: \\ sia viepiù dolce e piano \\ che non era davanti signoria. \\ Guàrdisi tuttavia \\ di non dispregio dar al suo minore: \\ ch'egli è troppo maggiore, \\ e più notato <è > in lui viç<i $>0$ cotale. \\ E pensi sempre quale \\ era davanti el volger de la rota; \\ com'ella è quasi mòta \\ subitamente per ciascuno in terra. ${ }^{21}$
}

Nella lunga glossa il Barberino chiama in causa numerose auctoritates sulla questione del sermo humilis e dell'arroganza, tra cui Agostino, Boezio e Aristotele, mentre per quanto riguarda l'atto del «grosseggiare», reso con «extra pompas» nell'autotraduzione latina, si richiama ad un altro luogo dell'opera in cui tratta dei difetti maschili, menzionando tra essi proprio la pomposità. ${ }^{22}$ Dopo aver descritto la mansuetudine e come essa debba applicarsi al rapporto con i servitori, Francesco introduce una lunga trattazione sui rivolgimenti della Fortuna, in quanto essa sarebbe responsabile nell'aver elevato i primi e posto in basso chi è in condizione di servitù. Il testo latino affronta la questione a partire dai classici, entrando in conflitto con la riflessione senecana sull'operato della provvidenza, esposta nel primo libro dei Dialogi e nelle lettere a Lucilio, ${ }^{23}$ dove

21 Ivi, vv. 1434-1452 (vol. I, pp. 288-289).

22 Si tratta di Doc. Am., II, sub Industria, doc. v, reg. LXIIII (vol. II, pp. 140-141). L'uso del termine da parte di Francesco da Barberino viene registrato nel TLIO come forma sostantivata dell'aggettivo pomposo, con significato «che manifesta arrogante superiorità; baldanzoso, inorgoglito», come infatti si ricava dalla glossa latina.

23 Lucius Annaeus Seneca, De providentia, I, I, pp. 114-16: «Quaesisti a me, Lucili, quid ita, si providentia mundus ageretur, multa bonis viris mala acciderent. Hoc commodius in contextu operis redderetur, cum praeesse universis providentiam probaremus et interesse nobis deum; sed quoniam a toto particulam revelli placet et unam contradictionem manente lite integra sol- 
Seneca si chiede come sia possibile che agli uomini buoni accadano eventi spiacevoli, ${ }^{24}$ ma si richiama implicitamente anche alla tradizione agostiniana che apre il De libero arbitrio, che sarà fondamentale per la riflessione dei teologi medievali sul tema. ${ }^{25}$ Pur inserendo la trattazione sulla Fortuna in un contesto cortese che si richiama ai rapporti sociali vigenti nella società coeva, il valdelsano mette a confronto le maniere in cui essa è stata rappresentata nei testi antichi, fino a fornirne egli stesso una raffigurazione: nel codice Barb. lat. $4076,{ }^{26}$ princi-

vere, faciam rem non difficilem, causam deorum agam». L'interrogativo si ripete lungo tutto il dialogo, posto che Seneca dà per assodata la dimensione trascendente e dunque difende la sua causa a partire dal punto di vista degli dei. Il De providentia, inoltre, condivide con l'opera di Francesco da Barberino anche l'evidente impostazione giuridica: Seneca, infatti, fin dalle prime battute struttura il ragionamento sulla falsa riga di una causa iudicialis, in cui il compito dell'autore è quello di difendere la posizione degli dei, un espediente in cui si riversano gli effetti della sua lunga esperienza come avvocato e che lo accomuna al valdelsano. Albertazzi segnala a questo proposito anche il passo senecano Ad Lucilium, VII, 66, 22: «Agendum pone ex alia parte virum bonum divitiis abundantem, ex altera nihil habentem, sed in se omnia: uterque aeque vir bonus erit, etiam si fortuna dispari utetur, Idem, ut dixi, in rebus iudicium est quod in hominibus: aeque laudabilis virtus est in corpore valido ac libero posita quam in morbido ac vincto».

24 Una simile riflessione domina anche $C v$, IV, XI, in cui sono evidenti anche le reminiscenze scritturali. Cfr. il par. 11, per il quale Ageno individua l'ipotesto di Matth., VI, 19-34: «E dico che più volte alli malvagi che alli buoni pervegnono apunto li procacci: ché li non liciti alli buoni mai non pervegnono, però che li rifiutano. E quale buono uomo mai per forza o per fraude procaccerà? Impossibile sarebbe ciò, ché solo per la elezione della illicita impresa più buono non sarebbe. E li liciti rade volte pervegnono alli buoni, perché, con ciò sia cosa che molta sollicitudine quivi si richeggia, e la sollicitudine del buono sia diritta a maggiori cose, rade volte sofficientemente quivi lo buono è sollicito».

25 Cfr. Bertuzzi, Il dibattito sul libero arbitrio, pp. 81-83.

26 Essendo contenuta all'interno della glossa latina la miniatura è assente nel codice Barb. lat. 4077, che tramanda solo il testo volgare e una piccola porzione dell'autotraduzione. La possibile autografia (o idiografia) dei due principali mss. latori dei Documenti, ovvero il Barb. lat. 4076 e il Barb. lat. 4077, e del loro apparato figurativo, è stata assai discussa dalla critica. L'idea dell'autografia integrale del primo codice, l'unico che riporta interamente il testo e le miniature, si deve a Francesco Egidi, che avanza tale tesi nella prefazione alla sua edizione (vol. IV, pp. XXI-XXIII), ma contro di essa si vedano innanzitutto Petrucci, Minuta, autografo, libro d'autore, pp. 409-410; Id., Scrivere il testo, pp. 224-225; Id., Minima barberina; Panzera, Per l'edizione critica, pp. 101-102, dove si segnalano anche due ulteriori testimoni; Supino Martini, Per la tradizione manoscritta. Un elenco riassuntivo del testimoniale che attesta l'attività letteraria del valdelsano è nella scheda approntata da Claudio Lagomarsini per TraLiRo, online all'url: http://www.mirabileweb.it/authorrom/francesco-da-barberino-n-1264-m-aprile-1348-author/TRALIRO_239704. Sull'apparato illustrativo si vedano anche Goldin, Testo e immagine; Ead., Il commento nella pagina autografa; Nardi, Le illustrazioni dei 'Documenti d'amore', pp. 75-92; Ciociola, Scrittura per l'arte, arte per la scrittura, pp. 570-572. Per lo status quaestionis sull'autografia delle miniature rinvio innanzitutto a Supino Martini, Per la tradizione manoscritta, p. 947, n. 9, e a Ciccuto, Francesco da Barberino: un pioniere 
pale latore dell'apparato iconografico dei Documenti, l'excursus è infatti corredato da una miniatura i cui elementi vengono descritti minuziosamente dall'autore. ${ }^{27}$ Essa contiene la «natura naturans», ovvero la potenza divina, ritratta mentre dà indicazioni alla «natura naturata», l'uomo, descritto come «volentem et obbedientem» nel manovrare la ruota «comprehendentem situm stellarum cum omnibus que infra celum sunt tantum» ${ }^{28}$ (Fig. 7).

Chiamando in causa questioni come la possibilità per l'uomo di decidere autonomamente del proprio destino o la dipendenza degli atti umani da fattori esterni Francesco da Barberino si ricollega a un tema che ha larghissimo sviluppo nella letteratura e nel pensiero medievali, ovvero l'operato della Fortuna e la possibilità per l'uomo di contrastarne le decisioni attraverso l'esercizio del libero arbitrio. La posizione del valdelsano risente della lettura dei primi canti della Commedia e, in particolare, di Inf. VII, ${ }^{29}$ un'ipotesi che non pare troppo azzardata se si considerano le numerosissime tracce che legano i Documenti al poema dantesco, a partire dal cosiddetto ‘argomento barberiniano' per la datazione della Commedia. ${ }^{30}$

del 'Bildercodex', pp. 83-88, con importanti acquisizioni sul lavoro di équipe che produsse la mise en page del Barb. lat. 4076; MacLaren, Shaping the Self in the Image of Virtue. Indispensabile in questo senso anche lo studio parallelo dell'Officiolum, per il quale si vedano almeno Sutton, The lost 'Officiolum'; Bertolo, Nocita, Apocalissi figurata; Id., L'Officiolum' ritrovato di Francesco da Barberino; Blume, Francesco da Barberino. The Experience of Exile. Sulle ipotesi riguardanti il rapporto tra le illustrazioni di Barb. lat. 4077 e il codice Strozzi 146 della Biblioteca Medicea Laurenziana di Firenze, prezioso testimone miniato del Tesoretto di Brunetto Latini, rimando infine a Degenhart, Schmitt, Corpus der Italienischen Zeichnungen, pp. 40-42; Ciardi Dupré Dal Poggetto, Nuove ipotesi di lavoro, pp. 94-96. Da ultimo, vedi il contributo di Bischetti nel presente volume.

27 Cfr. Egidi, Le miniature dei codici barberiniani, pp. 92-94; Goldin Folena, Il commento nella pagina autografa, pp. 276-279.

28 Doc. Am., I, sub Docilitate, doc. XxIII, v. 1450b (vol. I, p. 292). Cfr. la presentazione della ruota: «Nota tamen quod hanc fortune figuram, quam infra subicio, pro natura naturata, ipsi nature naturanti subdite, et omnino in singulis obbedienti, resummo. Ut satis tam ex figuris ipsis quam ex circumpositis descriptionibus etiam sine glosis istis circumspectus lector et considerator poterit plenius de omnibus informari. Vide igitur quod fortunas sequi secundum quod ipsi primi, nisi ita intellexissent summebant, errare est» (ivi, p. 291).

29 Sul rapporto tra questo passo e Inf. VII qualche accenno è in Indizio, L'argomento barberiniano, p. 351.

30 Per il dibattutissimo 'argomento barberiniano' cfr. Indizio, Gli argomenti esterni, pp. 224-234, che contesta e riordina le tesi precedenti, con particolare riferimento a Egidi, L'argomento barberiniano; Vandelli, L'argomento barberiniano; Petrocchi, Intorno alla pubblicazione. Le conclusioni di Indizio sulla datazione della Commedia vengono contestate da Fenzi, Ancora a proposito dell'argomento barberiniano, contributo, quest'ultimo, a cui nuovamente risponde Indizio, L'argomento barberiniano. Per i contatti prettamente testuali tra i due poeti cfr. Melodia, Dante $e$ 
L'accostamento tra la trattazione del giurista valdelsano e Inf. VII dimostra, tuttavia, una certa indipendenza di pensiero rispetto alla descrizione dantesca della Fortuna, modellata sub specie Boetii ${ }^{31}$ come dispensatrice di beni e ricchezze (vv. 61-66), ma al contempo elevata a «general ministra e duce» (v. 78) della provvidenza di Dio, in contrasto con le formulazioni agostiniane del De civitate Dei dove si negava la possibilità di una natura divina della stessa. ${ }^{32}$ Dante, facendone un'intelligenza dipendente dal volere celeste, assume quindi una posizione intermedia, ma dichiara al contempo che gli sforzi dell'uomo non possono influire in nessun modo sul suo operato. ${ }^{33}$ Si tratta di un primo accenno al problema della conciliazione tra Virtù e Fortuna, su cui l'Alighieri tornerà prima in Purg. XVI nell'incontro con Marco Lombardo e poi in Par. VIII, a proposito di Carlo Martello, distinguendo il ruolo degli astri nella definizione della personalità umana e quello del libero arbitrio, che ha il potere di indirizzare l'agire degli individui verso il bene e dunque di contrastare le inclinazioni negative. ${ }^{34}$ Tuttavia, l'arbitrium non è esente nello stesso Dante dalle sue impli-

Francesco da Barberino. Cfr. anche Goldin Folena, Il commento nella pagina autografa, pp. 268-271; Bertolo, Nocita, L'Officiolum' ritrovato di Francesco da Barberino, pp. 110-111.

31 Cfr. Severino Boezio, Consolatio philosophiae, IV, vI, 7-8 e II, II, 6-7. Cfr. inoltre il commento di Graziolo Bambaglioli a Inf. VII in cui si ribadisce appunto come la Fortuna abbia la possibilità di influire sull'ottenimento dei beni temporali: «Similiter autem, dicit auctor, ipsa providentia Dei prefecit et ordinavit fortunam tamquam magistram et ducem ad permutationem istorum bonorum temporalium; ex quo hec temporalia bona, honores divitie potentie principatus et alia temporalia transitoria, de uno in alium hominem et de uno in alium sanguinem transferuntur. Et adversus hanc transmutationem fortune non potest alicuius mortalis prudentia se tueri, et sic ex istorum translatione bonorum aliqui regunt et florent alii mendicant et dolent, huius fortune iudicium occultum et investigabile prosequentes» (Graziolo Bambaglioli, Commento all'«Inferno» di Dante, pp. 57-58). Non posso qui addentrarmi nella copiosissima bibliografia dedicata alle fonti di Inferno VII e al rapporto con Boezio e per brevità rimando solo a Bommarito, Boezio e la fortuna di Dante; Desideri, "Et indefessa vertigo"; Mineo, Fortuna, libertà e volontà.

32 Agostino, De civitate Dei, IV, 18, in CCSL, vol. XLVII, pp. 112-113. Ma si veda anche l'anonimo compilatore delle Chiose ambrosiane, secondo il quale le formulazioni di Inf. VII deriverebbero proprio dall'Ipponense (Le chiose ambrosiane alla Commedia, pp. 28-29).

33 Inf. VII, 85-96: «Vostro saver non ha contasto a lei: / questa provede, giudica, e persegue / suo regno come il loro li altri dèi. / Le sue permutazion non hanno triegue: / necessità la fa esser veloce; / sì spesso vien chi vicenda consegue. / Quest'è colei ch'è tanto posta in croce / pur da color che le dovrien dar lode, / dandole biasmo a torto e mala voce; / ma ella s'è beata e ciò non ode: / con l'altre prime creature lieta / volve sua spera e beata si gode».

34 Un esempio della popolarità di tale questione è rappresentato anche dalla tenzone tra Iacopo de' Garatori da Imola e Pietro Alighieri, in cui l'Alighieri minore risponde all'amico chiarendo la concezione paterna del libero arbitrio in rapporto al determinismo astrologico. La tenzone, trasmessa dal ms. 445 della Biblioteca Capitolare di Verona, è edita da Crocioni, Le 
cazioni prettamente giuridiche, nel suo costituire una libertà di scelta indirizzata dalla ragione, e infatti tale discrezionalità è alla base sia della collocazione di molti personaggi all'interno della Commedia sia del percorso intellettuale del Dante agens. ${ }^{35}$ A maggior ragione, quindi, la valutazione dell'arbitrium tiene conto della letteratura giuridica in un autore di formazione notarile come il Barberino, e infatti nei Documenti la Fortuna non sarebbe affatto un'entità separata, dotata dunque di caratteristiche divine, ma piuttosto il principio che domina i rivolgimenti della ruota, colei che appunto giudica e dirige gli avvenimenti, avendo nella natura naturans il suo fondamento razionale:

Quare vel illas primas figuras et antiquas intelligas sano modo, ut ipsa fortuna rotam volvens summatur pro naturata natura, et fateamur illam esse subiectam imperio et totali dispositioni naturantis nature, scilicet Dei, quod quicquid faciat, faciat secundum Dei mandatum quod provenit secundum merita humana in hominibus et voluntatem Dei [. . .]. Ea autem que supra celum sunt et in celo, ut sanctorum ordo et angelorum corus et similia, sunt ex ipsa Dei dispositione in suo posita statu. Et attende in huius rote volubilitate quod ipsa natura naturata, elementa et que infra celum sunt dirigit divine potestatis, arbitrio semper salvo. In humanis autem creaturis potestatem non habet dandi gradus vel status seu tollendi, sed secundum merita et demerita optinet quisque locum primum recepturus vel penam. ${ }^{36}$

Francesco da Barberino, in sostanza, non critica tanto la casualità nell'operato della Fortuna che Dante aveva esposto in Inf. VII, quanto la possibilità per l'uomo di procacciarsi una buona sorte attraverso il merito personale e l'agire virtuoso, giudicati irrilevanti da Dante a questa altezza ma fondamentali nella trattazione barberiniana. ${ }^{37}$ In questo senso anche la riflessione sulla divinazione rientra nel merito dell'opposizione tra l'iniziativa personale e volontaria e

rime di Pietro Alighieri, pp. 85-89 ma si veda anche Ciociola, Rassegna stabiliana, pp. 100-101. Ancora sull'evoluzione del pensiero dantesco nelle tre cantiche cfr. Le chiose ambrosiane alla Commedia, pp. 28-29: «Loquitur enim Dantes de fortuna tripliciter: hic more paganorum qui eam pro dea colebant, ut recitat Augustinus De civitate Dei libro IIII, in Purgatorio more philosofico secundum Aristotilem De bona fortuna; in Paradiso more theologico secundum beatum Thomam de Aquino. Et sic in Inferno ostedit <se esse> mere poetam, in Purgatorio philosophum, in Paradiso theologum, per quam distinctionem excusatur in multis casibus in quibus errasse videtur».

35 «La visione di Dante del libero arbitrio diverge da quella della maggioranza dei pensatori. La sua è una visione decisamente intellettualistica, che identifica la libertà di scelta con il governo della volontà da parte della ragione» (Steinberg, Dante e i confini del diritto, pp. 74-75). Ma si veda anche Vanni Rovighi, Arbitrio, in ED, vol. I, pp. 345-348.

36 Doc. Am., I, sub Docilitate, doc. XXIII, v. 1450b (vol. I, pp. 292-293).

$37 \mathrm{Si}$ veda anche oltre: «Sed quo ad nostra salvationem, dampnationem, exaltationem et depressionem creatori nostro aut bona merita proximos nostros faciunt aut mala disiungunt. Ita et in terrenis virtutes nostrum statum exaltant, et deprimunt vitia iuxta dispositionem cuiuslibet et cautelam, Dei in omnibus iudicio antemisso» (ivi, v. 1450b, [vol. I, pp. 293-294]). 
i mutamenti della ruota della Fortuna, proprio perché il determinismo astrologico e la predizione si pongono in contrasto con entrambi i termini del binomio Virtù/Fortuna. La possibilità di scrutare gli avvenimenti futuri, infatti, può essere ammissibile solo in termini di prescienza divina, secondo formulazioni che avevano caratterizzato il dibattito tra agostiniani e scolastica nel XIII secolo e che troveranno piena affermazione con Gioacchino da Fiore. ${ }^{38}$ Quando il problema della divinazione si sposta dal piano del trascendente a quello dell'esperienza, esso implica tuttavia il rischio che all'uomo non sia permesso indirizzare autonomamente il proprio destino attraverso l'esercizio del libero arbitrio. Al contempo, se l'operato della sorte diventa prevedibile e regolato in maniera deterministica, immancabilmente risulta impossibile la sua conciliazione con la Fortuna, sia se quest'ultima viene intesa come intelligenza divina, sia se ad essa si attribuisce il significato boeziano di entità che presiede alla distribuzione di beni e ricchezze, in quanto gli astri assolverebbero esattamente al suo stesso compito. Il valdelsano, infatti, prende esplicitamente posizione sulla predizione del futuro nel documento XXIV di questa prima sezione, in un'argomentazione in cui si biasimano coloro che ricorrono alla pratica dell'augurio come seguaci di dottrine pagane e idolatri. Tale giudizio viene confermato anche in alcune sezioni del Reggimento, ${ }^{39}$ ed è derivato nelle sue implicazioni giuridiche dal Corpus iuris canonici e messo in pratica dallo stesso Francesco durante la sua attività di giudice inquisitoriale sotto il pontificato di Giovanni XXII, con condanne che colpirono celebri personaggi della Firenze trecentesca, tra cui l'astrologo Cecco d'Ascoli. ${ }^{40}$ Nel testo volgare dei Documenti le posizioni dell'autore appaiono già molto chiare e sono

38 Cfr. Bertuzzi, Il dibattito sul libero arbitrio.

39 Si vedano ad esempio i precetti che associano superstizione, inganno e disciplina della parola in Regg., XV, p. 170: «Non far le tuo perdonanze maiori / che sien di veritade / e non usare accattando bugie, / e non andar faccendo brievi o scritte / o indivine o fatture o malie, / e non ti far più inferma che sia, / né muta se tu puoi parlare aperto».

40 Per i documenti che attestano l'attività di giudice inquisitoriale si vedano Davidsohn, Un libro di entrate e spese; Biscaro, Inquisitori ed eretici a Firenze (1319-1334). Cfr. anche Marruzzo, Composizione e significato de «I Documenti d'amore», pp. 245-249; Giansante, Marcon, Giudici e poeti toscani a Bologna, pp. 18-19; Steinberg, Accounting for Dante, pp. 59-60. La condanna al rogo di Cecco d'Ascoli potrebbe essere tuttavia frutto di una precisa politica dei francescani fiorentini e specialmente dell'inquisitore Accursio Bonfantini, più che di una reale ostilità di Francesco da Barberino e degli altri giudici nei confronti dell'astrologia giudiziaria (cfr. Parmeggiani, Consiliatores dell'Inquisizione fiorentina); sull'atteggiamento nei confronti di Cecco d'Ascoli mi permetto di rinviare a Ferrilli, Cino da Pistoia, Francesco da Barberino e l'astrologia giudiziaria. 
esposte ricorrendo alla retorica degli ensenhamens che, come si è detto, domina specialmente questa prima parte dell'opera: ${ }^{41}$

Dico di quegli appresso,

e blasmo gl'indivini et an' coloro

che sperimenti loro

fanno, e dimostran saver che non sanno.

Questo è gran viço e inganno;

e quei del primo senton del pagano;

e in gran periglio stàno,

che mante volte però morti vidi.

Altre volte m'avidi

di certa gente ch'àn fede cristiana

et usan la pagana,

credendo non errar, ma che convegna.

Vedi un ch'al Sol si segna,

e leva sù, e fàlli certo honore,

se solo al Creatore

egli à respecto, che fe' lui, e quello

puoi dir che ben faccia ello.

In altra guisa, paganiça e falla:

tal' usança lassàlla

in tutto lodo, eçiamdio nel buono.

Ch'alcun[i] prendon non buono

exemplo, e te non manca Dio adorare.

Per simil dêi pigliare

e de la Luna e degli altri pianeti.

D’ogn'altra cosa sièti

regula simil, fuorché Dio e i suoi.

Adora dove vuoi,

ché in ogni parte e loco trovi Idio.

Dunqua qui ti prego io

che non ti curi più de l'Oriente,

che invèr <de > l'Occidente

far le tue oration, come t'occorre

così nel lecto porre. ${ }^{42}$

Nel testo volgare gli indovini sono rappresentati come detentori di una sapienza che rientra nel dominio della falsitas, propugnatori di «gran viço e inganno»e condannabili non solo per le loro credenze, ma anche per la capacità di diffon-

41 Sul rapporto tra i Documenti e gli ensenhamens provenzali cfr. Segre, Le forme e le tradizioni didattiche, t. 1, pp. 94-96; t. 2, pp. 139-141 (in particolare n. 2746); Ortiz, Francesco da Barberino e la letteratura didattica neolatina.

42 Doc. Am., I, sub Docilitate, doc. XxIv, vv. 1633-1665 (vol. I, pp. 321-326). 
dere false dottrine presso le folle e propagare conseguentemente il vizio. L'associazione tra paganesimo e divinazione è deprecabile da un lato perché assegna all'uomo una facoltà che appartiene a Dio, ovvero la possibilità di determinare gli eventi futuri, ma anche in quanto la profezia declamata pubblicamente si traduce in esercizio della parola e del linguaggio, nelle «orazioni» che lo stesso Francesco da Barberino ricorda fuggevolmente e che nel caso della divinazione sono classificabili come mendacium. Fin qui, dunque, le affermazioni del notaio valdelsano sembrano pienamente rispondenti a quanto San Paolo aveva affermato nella prima lettera ai Corinzi, dove appunto la profezia veniva esaminata nei suoi risvolti pratico-oratori e legata a doppio filo al peccatum linguae:

Sectamini caritatem aemulamini spiritalia magis autem ut prophetetis qui enim loquitur lingua non hominibus loquitur sed Deo nemo enim audit Spiritu autem loquitur mysteria nam qui prophetat hominibus loquitur aedificationem et exhortationem et consolationes qui loquitur lingua semet ipsum aedificat qui autem prophetat ecclesiam aedificat volo autem omnes vos loqui linguis magis autem prophetare nam maior est qui prophetat quam qui loquitur linguis nisi si forte ut interpretetur ut ecclesia aedificationem accipiat nunc autem fratres si venero ad vos linguis loquens quid vobis prodero nisi si vobis loquar aut in revelatione aut scientia aut prophetia aut in doctrina [. . .] ita et vos per linguam nisi manifestum sermonem dederitis quomodo scietur id quod dicitur eritis enim in aera loquentes tam multa ut puta genera linguarum sunt in mundo et nihil sine voce est [. . .] nam si orem lingua spiritus meus orat mens autem mea sine fructu est quid ergo est orabo spiritu orabo et mente psallam spiritu psallam et mente [. . . in lege scriptum est quoniam in aliis linguis et labiis aliis loquar populo huic et nec sic exaudient me dicit Dominus itaque linguae in signum sunt non fidelibus sed infidelibus prophetia autem non infidelibus sed fidelibus si ergo conveniat universa ecclesia in unum et omnes linguis loquantur intrent autem idiotae aut infideles nonne dicent quod insanitis si autem omnes prophetent intret autem quis infidelis vel idiota convincitur ab omnibus diiudicatur $a b$ omnibus occulta cordis eius manifesta fiunt et ita cadens in faciem adorabit Deum pronuntians quod vere Deus in vobis est [. . .] prophetae duo aut tres dicant et ceteri diiudicent quod si alii revelatum fuerit sedenti prior taceat potestis enim omnes per singulos prophetare ut omnes discant et omnes exhortentur et spiritus prophetarum prophetis subiecti sunt non enim est dissensionis Deus sed pacis sicut in omnibus ecclesiis sanctorum [. . .] si quid autem volunt discere domi viros suos interrogent turpe est enim mulieri loqui in ecclesia an a vobis verbum Dei processit aut in vos solos pervenit si quis videtur propheta esse aut spiritalis cognoscat quae scribo vobis quia Domini sunt mandata si quis autem ignorat ignorabitur itaque fratres aemulamini prophetare et loqui linguis nolite prohibere omnia autem honeste et secundum ordinem fiant. ${ }^{43}$

43 I Cor, XIV , 1-6; 9-10; 14-15; 21-25; 29-33; 35-40. Ma per l'interpretazione di questo passo sono fondamentali le osservazioni di Tommaso d'Aquino: «Respondeo dicendum quod prophetia primo et principaliter consistit in cognitione: quia videlicet cognoscunt quaedam quae sunt procul remota ab hominum cognitione. Unde possunt dici prophetae a phanos, quod est apparitio: quia scilicet eis aliqua quae sunt procul, apparent. Et propter hoc, ut Isidorus dicit, in 
Nel passo biblico si fa riferimento all'atto della locuzione come momento che segue immediatamente la profezia e che possiede risvolti sia a livello dottrinale, sia giuridico. Le medesime istanze vengono tradotte anche nei Documenti d'Amore, dove il tentativo di inquadrare la divinazione da un punto di vista linguistico-legale condiziona notevolmente la selezione barberiniana delle fonti. Infatti, nella glossa latina ai versi sugli indovini la predizione del futuro presenta principalmente due diverse connotazioni: in un primo momento, di carattere linguistico ed enciclopedico, l'autore parte dall'etimo del termine auguria ${ }^{44}$ e passa in rassegna i vari sistemi divinatori; successivamente egli affronta la questione a livello teologico, stabilendo l'inconciliabilità di tali pratiche con la dottrina cristiana. La glossa rivela quindi gli interessi linguistici del valdelsano sia su un piano prettamente etimologico e nominalistico, sia per le concrete applicazioni della divinazione in un più ampio contesto di oratoria pubblica e civile, che risente con ogni probabilità dell'attività notarile dell'autore e che ha un modello di riferimento nel causidicus Albertano.

La commistione tra teologia, dottrina giuridica e oratoria emerge anche dalle auctoritates che il Barberino elegge nel rigettare la divinazione, tra cui spicca, non a caso, proprio Agostino, recuperato, come si vedrà a breve, per via indiretta dal Decretum di Graziano. Gli scritti del vescovo Ipponense sono fondamentali da questo punto di vista per due ragioni. In primo luogo, opere come il De mendacio, il Contra mendacium e il De Trinitate costituivano i testi capitali sui quali si fondava la riflessione filosofica medievale sulla menzogna, special-

libro Etymol. "in veteri testamento appellabantur videntes: quia videbant ea quae ceteri non videbant, et prospiciebant quae in mysterio abscondita erant”. Unde et gentilitas eos appellabat vates, a vi mentis. Sed quia, ut dicitur I ad Cor. XII, "unicuique datur manifestatio Spiritus ad utilitatem"; et infra, XIV, dicitur, “Ad aedificationem Ecclesiae quaerite ut abundetis”: inde est quod prophetia secundario consistit in locutione, prout prophetae ea quae divinitus edocti cognoscunt, ad aedificationem aliorum annuntiant, secundum illud Isaiae XXI: "Quae audivi a Domino Exercituum, Deo Israel, annuntiavi vobis”. Et secundum hoc, ut Isidorus dicit, in libro Etymol., possunt dici prophetae "quasi prae-fatores, eo quod porro fantur", idest, a remotis fantur, "et de futuris vera praedicunt”. Ea autem quae supra humanam cognitionem divinitus revelantur, non possunt confirmari ratione humana, quam excedunt: sed operatione virtutis divinae, secundum illud Marci ult.: "Praedicaverunt ubique, Domino cooperante et sermonem confirmante sequentibus signis". Unde tertio ad prophetiam pertinet operatio miraculorum, quasi confirmatio quaedam propheticae annuntiationis. Unde dicitur Deut. ult.: "Non surrexit propheta ultra in Israel sicut Moyses, quem nosset Dominus facie ad faciem, in omnibus signis atque portentis"» (Tommaso d'Aquino, Summa Theologiae, IIa, IIae, q. 171, a. 1, co. [t. X, p. 366]).

44 «Auguria: ides 'avium garria', quia ipsi primo et adhuc aliqui ad voces avium super eos volantium de futuris iudicare nitebantur» (Doc. Am., I, sub Docilitate, doc. XXIv, v. 1632 (vol. I, p. 325). Nel testo ho ripristinato volantium, di Egidi e di Barb. lat. 4076, c. 30rb, al posto dell'erroneo vulantium di Albertazzi. 
mente per quanto riguarda la distinzione tra Verbo umano, di per sé potenzialmente soggetto all'errore, e Verbum divino, a cui vanno attribuiti i caratteri della veritas. ${ }^{45}$ Ma Agostino era l'autore di riferimento nelle varie collectiones canonistiche per l'associazione tra pratiche divinatorie e magia, e grazie alla loro rilevanza giuridica numerosi brani e incipit dell'Ipponense confluiscono anche nei Documenti, sapientemente arricchiti dal valdelsano attraverso dettagli tratti dalla propria biografia. Tale attitudine è evidente nella glossa ai versi del doc. XXIV poc'anzi menzionati in cui, raccogliendo alcune opinioni popolari riguardanti il legame tra volo degli uccelli e possibilità di prevedere gli eventi futuri («vidi dicere»), si affronta in termini giuridico-dottrinali la condanna degli indovini:

Dicitur in Canone XXvI questione vI “Admoneant”, et verba sunt Augustini: «Admoneant sacerdotes fideles populos, ut noverint magicas artes incantatoresque quibuslibet infirmitatibus hominum nichil posse remedii conferre, non animalibus languentibus claudicantibusve, vel etiam moribundis quicquam mederi; sed hec esse laqueos et insidias antiqui hostis, quibus ille perfidus, genus humanum decipere nititur, et si quis hec exercuerit, clericus, degradetur, laicus, anathemathiçetur». Sed hoc non facit, ut videtur ad licteram precedentem, immo facit propter aliquos quos vidi dicere, quod si quarundam avium multitudo veniebat super tettum alicuius anno illo moriebatur; et si inter animalia in campo, moriebatur etc. Et adhuc aliqui corvorum eventum malum signum iudicant et multa similia. ${ }^{46}$

45 «Se infatti la corrispondenza Verbo divino/verbo interiore fonda la possibilità per l'uomo di attingere la verità e anche di tradurla esteriormente attraverso il linguaggio, la distanza che comunque separa il nostro verbo dal Verbo di Dio giustifica da sola la possibilità dell'errore e della menzogna. [. . .] Al tempo stesso il mendacium si definisce come colpa morale a partire da quella institutio che, privilegiando fra tutti i segni la parola, le ha assegnato la funzione di veicolare e tradurre esattamente il verbo interiore» (Casagrande, Vecchio, I peccati di lingua, p. 255). Le formulazioni agostiniane saranno riprese anche nelle summae giuridiche, come ad esempio in Ivo Carnotensis, Panormia, VIII, 124-134 (in PL, vol. 161, coll. 1333-1338), dove vengono riportati exempla ed excerpta dell'Ipponense sul mendacium, poi confluiti in Decr., C. 22, q. 2, cc. 3-22 (passim), nonché altri brani in cui si trattano le differenti tipologie di peccato di lingua.

46 Doc. Am., I, sub Docilitate, doc. XXIV, v. 1632 (vol. I, pp. 325-326). Nel brano appena citato ho emendato magicos, claudicatibusve e muribundis del testo di Albertazzi ripristinando le lezioni magicas, claudicantibusve e moribundis del Barb. lat. 4076, c. 30rb, corrette grammaticalmente anche in Egidi. Preciso inoltre che Albertazzi riconduce tale brano al Decretum di Ivo di Chartres, XI, 65 che, nell'edizione di Migne, presenta alcune divergenze rispetto al testo barberiniano, come ad esempio incantatationesque e quidquam mederi (cfr. Ivo Carnotensis, Decretum, XI, 65, in $P L$, vol. 161, t. I, coll. 759-760). Tuttavia, considerando la massiccia presenza di Graziano in questa sezione dei Documenti, mi sembra più probabile che Francesco stia citando da questa collectio canonistica e, in particolare, da Decr., C. 26, q. 7, c. 15 (Infirmitatibus hominum incantationes nichil remedii prestant, vol. I, col. 1045), opera in cui confluisce lo stesso Decretum di Ivo. Il debito barberiniano nei confronti del Corpus iuris canonici, del quale si discuterà più approfonditamente nelle prossime pagine, finora è stato messo in luce solo da Panzera, Francesco da Barberino tra Andrea Cappellano e Averroè, pp. 83-95 (in particolare pp. 92-93). 
La struttura delle glosse barberiniane è dunque pensata per assolvere a svariati compiti che travalicano la mera funzione di commento all'autotraduzione del testo volgare, ${ }^{47}$ ponendosi piuttosto come una «summa o collectio di auctoritates, sulla quale però interferiscono digressioni, considerazioni, racconti, aneddoti, ecc., che [le] danno qua e là sapore di un genere più umile». ${ }^{48}$ Tale attitudine enciclopedica, evidente in questo brano che attinge alla collectio di Graziano, viene infatti mantenuta anche nei passi successivi, dove sono riportati nuovamente gli incipit di alcuni canoni del Decretum contigui a quello menzionato nell'inserto precedente, ma ugualmente debitori della dottrina agostiniana sugli auguri:

Ad istam autem facit magis illud Augustini: «Non observetis dies, qui dicuntur Egiptiaci, aut Kalendas Ianuarii, in quibus cantilene quedam et commesationes, ad <invicem $>$ dona donantur, quasi anni principio, boni facti augurio, aut aliquos menses, aut tempora, aut dies, et annos, aut lune solisque cursum» etc. Et subdit penas ad idem vide capitulum "Non licet" et capitulum "Siquis Kalendas Ianuarii ritu paganorum" etc. ponuntur causa et questione predicta. ${ }^{49}$

Mi sembra evidente che l'autore compili tali sezioni della glossa avendo sottomano l'opera di Graziano, e proprio dal Decretum egli ricava l'attribuzione delle leggi Admoneant e Non observetis al vescovo di Ippona. Malgrado tali estratti siano entrati a tutti gli effetti nella raccolta canonistica sotto il nome di Agostino, essi vengono citati anonimamente in altre fonti di cui lo stesso giurista si era servito nell'allestimento del corpus canonistico: l'Admoneant è infatti riferito ad Agostino da Ivo di Chartres ${ }^{50}$ e Burcardo di Worms, ${ }^{51}$ mentre gli atti del Concilio di Tours $^{52}$ e i Capitularia di Benedetto Diacono ${ }^{53}$ non menzionano l'autore. Le fonti del canone Non osbervetis sono invece riconducibili al Polycarpus di Gregorio da

47 Sui rapporti tra testo volgare, autotraduzione e commento latino cfr. Goldin, Autotraduzione latina.

48 Goldin Folena, Il commento nella pagina autografa, p. 272. Si vedano anche Jacobsen, Francesco da Barberino Man of Law, 15 (1986), p. 96; 16 (1987), pp. 92-93; Panzera, Francesco da Barberino tra Andrea Cappellano e Averroè, pp. 173-175 e p. 194.

49 Doc. Am., I, sub Docilitate, doc. XxIv, v. 1632 (vol. I, p. 326). Segnalo che nel testo citato ho ritoccato la punteggiatura. Il primo passo corrisponde a Decr., C. 26, q. 7, c. 16 (Dies Egiptiaci, et Ianuarii kalendae non sunt observandae, vol. I, coll. 1045-1046). Considerando che l'incipit «Siquis Kalendas» è riferibile a Decr., C. 26, q. 7, c. 14 (Anathema sit qui ritu paganorum kalendas observat, vol. I, col. 1045), è possibile riconoscere nella legge menzionata come «Non licet» una citazione del canone immediatamente precedente, che tratta il medesimo argomento, ovvero Decr., C. 26, q. 7, c. 13 (Kalendarum observationes agere non licet, vol. I, col. 1044).

50 Ivo Carnotensis, Decretum, XI, 65, in PL, vol. 161, t. I, coll. 759-760.

51 Burchardus Wortatiensis, Decretum, X, 40, in PL, vol. 140, col. 839.

52 Conc. Turon. (813), XLII, in MGH, Concilia, t. II, Concilia Aevi Karolini, t. I, p. 292.

53 Benedictus Diaconus, Capitularia, Additam III, c. 93, in PL, vol. 97, coll. 882-883. 
San Crisogono, ${ }^{54}$ che lo assegna ad Agostino, ma Friedberg, editore del Corpus iuris canonici, avverte che «certum est haec non esse Augustini». ${ }^{55}$ Nei passi successivi della glossa si nota che Francesco da Barberino mantiene lo stesso atteggiamento nei confronti degli inserti agostiniani del Decretum, scegliendo di privilegiare il peso dell'auctoritas dell'Ipponense e nascondendo la fonte canonistica a cui sicuramente egli aveva continuato ad attingere:

Et dicit Augustinus in Hencheridion: «Quis existimaret quam magnum peccatum sit dies observare et menses et annos et tempora, sicut observant qui certis diebus sive mensibus sive annis volunt vel nolunt aliquid inquohare, eo quod secundum varias doctrinas hominum fausta vel infausta existiment tempora, nisi huius mali magnitudinem ex timore Apostoli pensaremus, qui talibus ait: “Timeo vos, ne forte sine causa laboraverim in vobis?"». Et idem super Epistolam ad Galathas: «Intelligat lector ad tantum periculum anime pertinere superstitiosas temporum observationes, ut dicat Apostolus: "Timeo . . ."»; et infra, ut supra: «Quod quamvis tanta celebritate et auctoritate per orbem terrarum in Ecclesiis legatur, plena sunt tamen» etc. ${ }^{56}$

La glossa contiene un riferimento ad Enchiridion, XXI, 79, dove a sua volta viene menzionato Galat., IV, $11,{ }^{57}$ nonché ulteriori rinvii alle Expositiones agostiniane che commentano il medesimo passo biblico; ${ }^{58}$ tali brani, tuttavia, risultano nuovamente citazioni tratte in blocco da luoghi contigui della collectio di Graziano, ${ }^{59}$ come dimostrano sia la struttura dei richiami, sia l'individuazione della fonte agostiniana. ${ }^{60}$ Il costante ricorso alla raccolta canonistica, impiegata

54 Die Kanonessammlung Polycarpus des Gregor von S. Grisogono, Quellen und Tendenzen, von Uwe Horst, VI, 11, 12, in MGH (online all'URL: http://www.mgh.de/datenbanken/leges/ka nonessammlung-polycarp/).

55 Decr., C. 26, q. 7, c. 16, vol. I, coll. 1045-1046, nota 140, dove si menzionano come fonte anche i Capitula di Martino di Braga (c. 71, 73 e 75), per i quali si veda Martini Episcopi Bracarensis, Opera omnia, pp. 80-144. Cfr. anche Kéry, Canonical collections of the Early Middle Ages, pp. 8-9. Nessuna menzione riguardo alle fonti dei due canoni nella Glossa ordinaria di Giovanni Teutonico e Bartolomeo da Brescia.

56 Doc. Am., I, sub Docilitate, doc. Xxıv, v. 1632 (vol. I, pp. 326-327). Ho emendato vanas del testo di Albertazzi, che riprende letteralmente la citazione da Agostino, ripristinando varias del Barb. lat. 4076, c. 30rb e già in Egidi, in cui la $r$ è palesemente abbreviata mediante titulus tremulatus. Albertazzi ripristina il testo della citazione di Agostino, ma la sostituzione di vanas con varias esprime in realtà un giudizio di valore sulle dottrine intorno ai giorni fausti e infausti e potrebbe avere anche qualche importanza nella ricostruzione della fonte da cui il Barberino cita.

57 Cfr. Agostino, Enchiridion, XXI, 79, in CCSL, vol. 46, p. 93.

58 Cfr. Agostino, Expositio Epistolae ad Galatas, 35, in CSEL, vol. 84, pp. 103-104.

59 Decr., C. 26, q. 7, c. 17, vol. I, col. 1046.

60 Si notino i due brani citati in Doc. Am., I, sub Docilitate, doc. xxIv, vv. 1634-1635 (vol. I, pp. 327-328) come di paternità agostiniana: l'indicazione del primo (incipit: «Intelligi voluit 
a tutti gli effetti come una summa enciclopedica, è con ogni evidenza condizionato non solo dalla necessità di disporre di un repertorio di auctoritates sul tema, ma anche dall'attività di giurista del Barberino, dimostrando al contempo l'interesse dell'autore nell'individuare gli aspetti legali e dottrinali della divinazione. Non a caso, poco oltre il valdelsano riporta quei passi del Decretum che

Dominus etiam illa que a divinantibus») si ricava da Decr., C. 26, q. 2, c. 5 (vol. I, col. 1021), dove Friedberg rinvia ad Agostino, Quaestiones in Deuteronomium, XIX (Quaestionum in Heptateuchum, V, in CCSL, vol. 33, p. 287), ma in questo caso Albertazzi emenda noluit del Barb. lat. 4076 e di Egidi, correggendo in voluit, sulla base del Decretum e del testo di Agostino. Il secondo passo che Francesco da Barberino introduce con «Et idem in libro De natura demonum dicit: "Igitur genus divinationis a Persis dicitur esse allatum ferunt"» costituisce la rielaborazione di De civitate Dei, VII, 35 (cfr. CCSL, vol. 47, pp. 215-216), ma anche del De magorum prestigiis di Rabano Mauro, debitore di Isidoro (cfr. Padovani, Il diritto, un passato “monumentalizzato"?, p. 65), sebbene Albertazzi preferisca rinviare a Ivo di Chartres (Ivo Carnotensis, Decretum, XI, 68, in PL, vol. 161, t. I, col. 761), che tuttavia presenta alcune divergenze con il testo riportato nei Documenti. Ma è il valdelsano stesso alla fine della citazione ad informarci che il brano è tratto da Decr., C. 26, qq. 3-4, c. 1 (vol. I, col. 1024), una sezione dell'opera di Graziano fondamentale anche in virtù degli incipit riportati contestualmente che fanno riferimento a due canoni contigui. Il primo, ovvero Decr., C. 26, qq. 3-4, c. 2, Quot modis demones futura prenoscant (vol. I, coll. 1025-1026), viene citato dal Barberino anche come «Sciendum» (ma Albertazzi modifica l'intitolazione del manoscritto e di Graziano stesso in quod modis e in nota rinvia non alla raccolta canonistica, bensì alla sua fonte, ovvero Agostino, De divinatione demonum, IV, 8, in CSEL, vol. 41, pp. 606-607); il secondo, Decr., C. 26, qq. 3-4, c. 3, Quod ex corporeis motibus internas animae cogitationes diabolus conprehendat, res occultissima est (vol. I, col. 1026), è richiamato da Francesco con l'incipit «Quodam loco», e riporta un passo agostiniano che Graziano recupera da Retractationes, II, 30 (in CCSL, vol. 57, p. 114), a sua volta dipendente da Agostino, De divinatione demonum, V, 9 (in CSEL, vol. 41, pp. 607-608). Per quanto riguarda gli incipit che Francesco da Barberino menziona nelle righe immediatamente successive si noti inoltre come egli mascheri ancora la fonte canonistica, privilegiando l'auctoritas dell'Ipponense: il valdelsano riunisce infatti le citazioni attribuendole al De doctrina christiana malgrado esse siano perfettamente rintracciabili nell'opera di Graziano. Ciò accade per l'incipit del canone «Illud», corrispondente a Decr., C. 26, q. 2, c. 6, tratto a sua volta da Agostino, De doctrina christiana, II, xIX, 29-II, XxIII, 36 (in CCSL, vol. 32, pp. 53-59), oppure per il canone «Illos», che si trova in Decr. C. 26, q. 2, c. 8 e in Conf., IV, III, 4 (in CCSL, vol. 27, p. 41), nonché il successivo «Si de area», in Decr., C. 26, q. 2, c. 10 e tratto da Epist., XLVII, 3 (in CCSL, vol. 31, p. 205), mentre per l'incipit «Sed et illud», corrispondente a Decr., C. 26, q. 2, c. 9, Graziano menziona il canone come tratto da San Girolamo, sebbene tra tutti i riferimenti al Decretum contenuti in questa sezione dei Documenti l'autore preponderante nelle menzioni esplicite resti comunque Agostino. Nelle righe immediatamente successive Francesco da Barberino continua a citare da loci attigui del Decretum: ad esempio in Doc. Am., I, sub Docilitate, doc. XXIv, v. 1636 (vol. I, p. 328) si riferisce a Decr., C. 26, q. 5, c. 14 (Nec mirum, vol. I, coll. 1032-1036), mentre gli incipit di Doc. Am., I, sub Docilitate, doc. XXIv, v. 1639 (vol. I, p. 328) si ritrovano in Decr., C. 26, q. 5, c. 1 (Si quis ariolos, vol. I, col. 1027), C. 26, q. 5, c. 2 (Qui divinationes, vol. I, col. 1027), C. 26, q. 5, c. 3 (Non liceat, vol. I, coll. 1027-1028). 
stabiliscono quali siano le pratiche da considerarsi lecite e illecite, accettando quindi la condanna della magia che procede dagli incantesimi:

Et dic quod quedam sortes sunt licite quedam illicite. Illicite sunt que fiunt per magicas incantationes vel ad exercendas vanitates, vel que fiunt ad inquirendum aliqua occulta (ut XXVI questione prima "Hii qui”). Et capitulum illud que autem causa necessitatis fiunt non sunt illicite, ut si contentio esset de electione aliquorum et esset peritus uterque in omnibus exemplo Mathye, possunt fieri sortes ut eadem causa et questione non exemplo, et questione $\mathrm{v}$ non licet. Cum enim non superest humanum auxilium, tunc demum possumus recurrere ad divinum XxII, questione II queritur. Et in dubiis secundum leges ad sortes decurritur Digestis “De iudiciis" sed cum ambo Codice "Comunia de legatis”, "Si duobus”. ${ }^{6}$

Il brano a cui Francesco da Barberino accenna tramite l'incipit «Hii qui» corrisponde a Decr., C. 26, q. 2, c. 3 (Ad secularia negocia divina oracula non sunt convertenda), ${ }^{62}$ tratto nuovamente da Agostino, e riflette sull'opportunità di ricavare auspici sul futuro attraverso la lettura e l'esegesi dei Testi Sacri. In questo caso Agostino condanna la pratica, ritenuta tuttavia meno grave rispetto al ricorso ai demoni, sostenendo che quanto scritto nei Vangeli non sia applicabile alla vita terrena, bensì a quella dopo la morte, e denunciando implicitamente la diffusissima tendenza a ricercare nella Bibbia presagi riguardanti la fine dei tempi e l'interpretazione della storia presente, passata e futura. ${ }^{63} \mathrm{Il}$ canone, qui ricordato sommariamente, viene riportato per intero poco dopo dal valdelsano, che rende esplicita la doppia fonte agostiniana e canonistica, ${ }^{64}$ mentre per quanto riguarda l'accenno all'apostolo Mattia («exemplo Mathye»), anch'esso completato dalla citazione integrale del brano, il Barberino introduce il passo come tratto da Beda. ${ }^{65}$ In realtà il raffronto tra il testo dei Documenti e quello delle Expositiones

61 Doc. Am., I, sub Docilitate, doc. XxIv, v. 1640 (vol. I, p. 329). Ho ritoccato la punteggiatura e i segni di paragrafo, in conformità con Barb. lat. 4076, c. 30va.

62 Nell'edizione di Friedberg, vol. I, col. 1021. Il riferimento è ad Agostino, Epist., LV, 37 in CCSL, vol. 31, p. 264.

63 Su tale argomento si veda Potestà, L'ultimo messia.

64 «Hii qui de paginis evangelicis sortem eligunt, etsi optandum est, ut id potius faciant, quam ad demonia consulenda concurrant, tamen ista michi displicet consue $<\mathrm{tu}>\mathrm{do}$, ad negotia secularia et ad vite huius vanitatem divina oracula velle convertere» (Doc. Am., I, sub Docilitate, doc. XxIv, v. 1640 [vol. I, p. 330]). Nel brano in questione ho modificato la punteggiatura ed eliminato le integrazioni di Albertazzi basate sul testo della fonte canonistica, ripristinando le lezioni di Egidi e di Barb. lat. 4076, c. 30va. Ho inoltre corretto la forma displicet tradita dal codice contro l'erroneo displicit di Egidi e Albertazzi, ho aggiunto la necessaria integrazione su consue $<t u>d o$, che nel codice si trova trascritto (con)suedo come segnala anche Egidi in nota, e ho infine preferito sciogliere negotia anziché negocia.

65 «Et Beda Super Actus apostolorum: "Non exemplo Mathie [inquid] vel quod Ionas profeta sorte deprehensus sit indifferenter sortibus est credendum, cum privilegia singulorum, ut Jeronimus ait, comunem legem omnino facere non possint. Siqui tamen necessitate aliqua com- 
super Actus Apostolorum mette in luce notevoli divergenze, specialmente perché il passo menzionato dal Barberino riunisce due luoghi non contigui di Beda, ma corrisponde esattamente a Decr., C. 26, q. 2, c. 4 (Exemplo Matthiae vel Ionae non est sortibus indifferenter credendum), ovvero al canone immediatamente successivo a «Hii qui» nella collectio di Graziano, ivi attribuito proprio al Venerabile. ${ }^{66}$ Per quanto riguarda invece i richiami al Corpus iuris civilis, il Barberino consiglia di ricorrervi solo in caso di dubbio, privilegiando dunque la risoluzione giuridica delle questioni relative alla divinazione mediante il diritto canonico. ${ }^{67}$

Per questi motivi, se il debito nei confronti di Graziano è palese, restano tuttavia da indagare le ragioni della mise en abîme della raccolta canonistica a favore del ricorso alla fonte agostiniana. Come l'analisi finora ha messo in evidenza, il pensiero barberiniano sulla divinazione è modellato integralmente su testi patristici e giuridici; tale binomio sancisce il valore normativo degli scritti di Agostino anche in un'opera come i Documenti, che possiede ben altre finalità rispetto a commenti ausiliari, tra cui la Glossa ordinaria di Giovanni Teutonico e Bartolomeo da Brescia, strumento privilegiato per l'esegesi del Corpus iuris canonici tra i giuristi attivi nel Trecento nello studium felsineo, come dimostra la mole di testimoni bolognesi. ${ }^{68}$ La variatio nell'esplicitazione dei riferimenti, che privilegia appunto talvolta Graziano, più spesso l'Ipponense, rappresenta inoltre il tentativo di Francesco da Barberino di collocare l'autoesegesi latina in un terreno a metà tra lettera-

pulsi Deum putant sortibus exemplo apostolorum esse consulendum, videant hoc ipsos apostolos non nisi collecto fratrum cetu et precibus ad Deum fusis agisse"» (ibid.). La citazione è tratta da Beda Venerabilis, Expositio Actuum Apostolorum, I, 26 (in CCSL, vol. 121, pp. 14-15).

66 La citazione è in Doc. Am., I, sub Docilitate, doc. xxIv, v. 1640 [vol. I, p. 330], mentre per il Decretum si veda nell'edizione di riferimento vol. I, col. 1021. Si noti però che nella sua edizione dei Documenti Albertazzi preferisce rinviare ancora a Ivo Carnotensis, Panormia, VIII, 78 (in $P L$, vol. 161, coll. 1325-1326), dove tuttavia è ben esplicita la fonte bediana.

67 Gli incipit sono riferibili a D. 5. 1. (De iudiciis, vol. 1, pp. 73-77) e a C. 6. 43.3 (Si duobus, vol. 2, pp. 274-275).

68 In merito alla Glossa ordinaria è stato osservato che essa circolava a Bologna nella redazione del cosiddetto "tipo laurenziano", per il quale cfr. Kuttner, Repertorium der Kanonistik (1140-1234), pp. 103-115 (per la tradizione manoscritta) e 116-122; Id., Bernardus Compostellanus antiquus, pp. 288-292; Kuttner, Smalley, The Glossa Ordinaria to the Gregorian Decretals; Condorelli, Bartolomeo da Brescia, p. 182. Ma per il testimoniale della Glossa resta fondamentale lo studio di von Schulte, Die Glosse zum Decret Gratians. Si noti, inoltre, che la celebre biblioteca di Santa Croce, che contribuì alla formazione dei laici fiorentini tra cui lo stesso Dante, crebbe proprio intorno a un codice contenente il Decretum di Graziano con la glossa di Bartolomeo da Brescia (si tratta del ms. Plut. I sin. 1 della Biblioteca Medicea Laurenziana di Firenze, comprato nel 1246 da fra' Guido della Frassa). Cfr. Davis, The Early Collection of Books of S. Croce; Brunetti, Gentili, Una biblioteca nella Firenze di Dante, p. 30; Zanni, Una ricognizione per la biblioteca di Dante, p. 174. 
tura ed enciclopedismo. Essa non è infatti né una mera accumulazione di citazioni canonistiche, né un calco pedissequo di brani agostiniani, ma sottolinea piuttosto la capacità dell'autore di fare luce su una questione dottrinale complessa attraverso la doppia lente del giurista e del letterato, come dimostrano anche gli excursus aneddotici che sono parte integrante della glossa stessa.

Da queste prime porzioni di testo è possibile ricavare alcune considerazioni sul pensiero del valdelsano riguardo alla predizione del futuro. In prima istanza, Francesco da Barberino individua nella divinazione una forma di idolatria contraria alla legge e da considerarsi blasfema, e in questo senso l'omogeneità contenutistica dei canoni menzionati supporta e completa le affermazioni dei vv. 1637-1638 del testo volgare, dove gli indovini e gli auguri sono condannati a livello dottrinale e accostati a coloro che propugnano una falsa sapienza pagana. In secondo luogo, la lettura oracolare dei Vangeli si lega necessariamente all'esegesi pubblica delle Scritture, che in questo caso è finalizzata alla divulgazione dei presagi sul futuro che gli indovini sono in grado di riscontrarvi. Tale pratica viene dunque accostata ad altre forme di superstizione messe in atto da coloro che pronunciano orazioni, come rivelano i vv. 1661-1664 («Dunqua qui ti prego io / che non ti curi più de l'Oriente, / che invèr <de> l'Occidente / far le tue oration») e la relativa glossa, dove si prendono di mira simili atteggiamenti che caratterizzerebbero specialmente l'operato dei religiosi. ${ }^{69}$ Il legame tra la predizione del futuro e la sua 'dicibilità' in un contesto pubblico è dunque ben delineato, e sarà a questo tipo di impiego che bisognerà fare riferimento per una trattazione più organica della questione.

\section{Peccatum linguae e performatività: la predicazione e l'oniromanzia}

Scorrendo quei loci dei Documenti in cui si riflette sulla pubblica orazione e sull'oggetto dei discorsi dei predicatori è possibile isolare due differenti piani che, intersecandosi tra loro, fanno luce sulla condanna barberiniana della divinazione. L'atto della predicazione comprende infatti un primo momento, che corrisponde all'inventio, riguardante la preparazione del discorso, ovvero la scelta

69 Cfr. Doc. Am., I, sub Docilitate, doc. xxIv, v. 1651 (vol. I, p. 330): «Nam cum tibi sit facultas licite et non suspecte orare, bene facis, si mali consuetudinis non sis causa». Si noti inoltre che Francesco da Barberino rimanda a Doc. Am., I, sub Docilitate, doc. IX (vol. I, pp. 141-149), luogo in cui vengono illustrati nello specifico numerosi rituali propiziatori e precetti riguardanti l'oratoria, con particolare attenzione nei confronti dell'oratoria religiosa. 
degli argomenti e degli exempla, mentre il secondo si concentra sugli effetti dell'actio, la proclamazione pubblica, esaminando quali siano le conseguenze provocate da un discorso fazioso e dottrinalmente erroneo sulle varie tipologie di uditorio. Presupposto comune è la ricerca della veritas, sia per quanto riguarda il non forzare la lettura dei testi e dei segni che fornirebbero indicazioni sugli avvenimenti futuri, sia per il dovere morale di non indurre in errore coloro che rappresentano il pubblico della predicazione. Secondo il valdelsano, quindi, il discorso andrebbe strutturato in maniera non faziosa, modulando gli exempla e le citazioni contestualmente e prestando particolare attenzione all'uditorio, composto dai sapienti, capaci di decifrare le sottigliezze dell'oratore, ma anche dagli incolti, di fronte ai quali l'eloquio andrebbe semplificato e reso non capzioso:

Non dece disputar fra gente grossa

di cosa ch'error possa

ne le lor menti forse generare;

né ancor seminare

perle tra lor, né fave tra sottili, né delicati cibi ai bassi e vili. ${ }^{70}$

In linea con gli interessi linguistici e formali che permeano i Documenti, Francesco da Barberino delinea in questo caso anche una rudimentale teoria della ricezione in cui si distinguono nettamente la «gente grossa» e i «sottili» e che, indirettamente, stabilisce le effettive qualità dell'oratore. ${ }^{71}$ In tale binomio è possibile intravvedere gli effetti del passaggio della categoria filosofica della sottiglianza a contesti più ampi, ${ }^{72}$ il contrasto tra religione popolare e religione colta ma anche un tentativo di adattare la materia al destinatario, la stessa tematica che nel Reggimento assume caratteri prettamente linguistici con la scelta del volgare. ${ }^{73}$

70 Doc. Am., II, sub Industria, doc. v, reg. XviI, vv. 2331-2336 (vol. II, pp. 108-109).

71 La dicotomia è riproposta anche nel Reggimento, fin dal Proemio, pp. 1-2: «E io risposi: 'Io hoe un(o) fedel(e) servo; / Francesco ha nome, nacque in una selva / c'ha nome Barberino; / è molto grosso, ma molto èe fedele, / e a lui non bisogna sottigliezza / poi voi gli date vostra informagione; / sì ch'io gli parlerò, e poi inmantanente / sarò davanti alla vostra eccellenzia / colla risposta ch'allora convegna».

72 Sul tema in ambito romanzo si veda Bruni, Semantica della sottigliezza.

73 «La lingua del Reggimento non vuol essere una lingua ideale, un archetipo, ma uno strumento che sia capace di offrire al testo una possibilità comunicativa propria, una lingua i cui caratteri non sono ben definiti, ma che vanno giudicati sul metro essenzialmente del loro potenziale di convinzione. [. . . ] La scelta del volgare è suggerita dalle ragioni stesse dell'esposizione: convincere per educare» (Guimbard, Francesco da Barberino e la scelta del volgare, p. 11). 
Nei versi appena menzionati e nella relativa glossa Francesco da Barberino riassume sotto forma di precetti l'atteggiamento che l'oratore deve assumere nei confronti dell'uditorio, menzionando il caso del predicatore Albericus dela Caprafica, di cui mi pare non resti traccia al di là della menzione nei Documenti. ${ }^{74}$ Come è evidente dalla glossa barberiniana, l'oggetto dei sermoni di Alberico consisteva nella confutazione di alcuni errori dottrinali di celebri filosofi, tra cui le teorie deterministiche dell'astrologo arabo Alkindi nonché il pensiero di Averroè e di Avicenna. La possibilità di incorrere nel mendacium, di per sé contrario alla speculazione intorno alla veritas, sarebbe dunque uno dei rischi della predicazione avente come oggetto le 'favole', affermazioni non verificabili e passibili di fraintendimento, e che dunque contravvengono a livello dottrinale all'assimilazione tra Dio come Verbo e Verità. Le diffusissime teorie deterministiche nonché le pratiche divinatorie rappresentano in questo senso un'intricata questione da dirimere: la predizione del futuro, riguardando avvenimenti possibili ma non ancora accaduti, rischia quindi di configurarsi come un discorso già menzognero nella sua strutturazione argomentativa, avendo come oggetto una materia non ascrivibile al dominio della veritas. In secondo luogo, quando l'orazione trova realizzazione performativa nell'actio, i suoi effetti negativi possono riverberarsi sull'uditorio generando ulteriormente errore, un aspetto al quale Francesco da Barberino presta particolarmente attenzione, come si è già notato. L'esempio di Alberico della Caprafica dimostra quindi sia l'inefficacia della confutazione, sia la sua perniciosità se rivolta a un pubblico 'grosso', un'insidia che risiede nella strutturazione stessa della predicazione popolare, che incarna «la volontà di trasmissione e diffusione di una parola evangelica che non resti mera esortazione e vuota forma di ammonimento, ma diventi, piuttosto, esemplarità e prassi di vita». ${ }^{75}$

Sebbene inventio e actio siano due momenti inscindibili nel determinare la correttezza giuridica e dottrinale dell'orazione, per cercare di fornire qualche linea guida su come essi si intreccino alla predizione del futuro li analizzerò ora separatamente, prima prestando attenzione alle maniere in cui il predicatore costruisce il discorso oratorio e, in secondo luogo, al binomio grossezza/sotti-

74 Così anche per Canteins, Francesco da Barberino: l'homme et l'oeuvre, p. 134. Il toponimo Caprafica potrebbe corrispondere all'antico nome di Capraccia, cittadina nei pressi di Orvieto e ora facente parte del comune di Bagnoregio. Cfr. Capocaccia, Macchioni, Statuto della città di Bagnoregio, p. 176; Macchioni, Storia civile e religiosa della città di Bagnoregio Altri riscontri del toponimo conducono verso la chiesa di Santo Stefano "in Caprafice" a Roma, ma il nome sarebbe una corrutela da "in Capite Africae” (cfr. Gatti, Del Caput Africae, pp. 207-208), mentre più numerose sono le località denominate Capraficus, di cui ben due in Abruzzo.

75 Manselli, Il soprannaturale e la religione popolare, pp. 87-88. 
gliezza, che sarà dirimente per l'impiego dell'astrologia giudiziaria. Partendo dalla complessa questione della veritas, Francesco da Barberino poteva trovare una classificazione del peccato di lingua non solo nel sopracitato Agostino, che aveva contribuito alla sua stessa definizione, ${ }^{76}$ ma anche nello Speculum di Vincenzo di Beauvais, un'opera di cui egli si era servito a più riprese nell'allestimento dei Documenti, come ha dimostrato Maria Prandi. ${ }^{77}$ Tuttavia, alla copiosa letteratura enciclopedica e dottrinale sul tema Francesco da Barberino preferisce un ammaestramento tratto dagli scritti della Contessa di Dia, la trobairitz menzionata più volte sia nei Documenti, sia nel Reggimento: ${ }^{78}$

Quesitum fuit a Comitissa de Dia que posset dari regula optima, brevis et aperta militibus ad bellandum; et illa interrogavit: "De quo bello queritis?". Et querens iterum quesivit: "Quot sunt bella?”. Dixit illa: “Duo”, et querens "Que ?”. Dixit ipsa: "Bellum armigerum et bellum verbale; et armigeri aliud ad mortem, aliud ad valendum; verbalis autem aliud ad solatium, aliud ad convincendum. De armigero ad mortem tolle regulam unam: vincat curialitatem vita. De armigero autem ad valendum tolle secundam regulam: preama et preamate amore potius vale quam presis. De verbali ad solatium tolle tertiam: vinci magis quam vincere altercationibus cura. De verbali ad convincendum fac partes II: ut prima si fueris cum irato iratus et veritas est tecum, verbis claris et paucis tene partem tuam, donec in astantes fidem tue veritatis inducas, quo facto in alia cum aliis te convertas. Et in hoc et eodem, si veritas contra te, in casu quo te ipsum publicari non decet, post aliquam resistentiam irato cede. Secunda, si iratus cum non irato, te ipsum contine ac expecta tibi obviam rationem. Tertia si non iratus cum irato: in casu isto, aut est amicus aut non sic. Amicum quippe te convenit expectare; alii autem propter iram, proposita plana voce tua defensione cede. Quod si omnino perstiterit, loquens cum astantibus de aliis da sermonem, quasi verba eius contempnere, si tuus non est superior, videaris. De superiori autem, inquid illa, "in quo gradu singulas intelligas dominas, tibi regulam trado talem: iratis deferas, non iratis assurgas, vinci semper et non vincere queras. Hoc quippe modo gratias iuvenes acquirunt crudelium dominarum et crudelitatem virorum temperant asperorum. Hec nanque, licet longa sint, posita in tractatibus suis, hic breviter collecta sufficiant" ${ }^{79}$

76 Come si è notato in precedenza, la strutturazione del mendacium all'interno del peccatum linguae risentiva delle formulazioni agostiniane, per le quali si vedano De mendacio, XIV, 25 (in CSEL, vol. 41, pp. 444-446); Casagrande, Vecchio, I peccati di lingua, pp. 257-259.

77 Cfr. Prandi, Vincenzo di Beauvais e Francesco da Barberino; Panzera, Francesco da Barberino tra Andrea Cappellano e Averroè, pp. 139-160. Per il riferimento a Vincenzo di Beauvais si veda Spec. Nat., XXX, cap. 92, De peccato cordis et oris, p. 2285.

78 Cfr. Regg., V, pp. 74-76; VII, pp. 119-120; Thomas, Francesco da Barberino et la littérature provençale, pp. 117-127 (ma si veda anche la recensione Renier al volume di Thomas, pp. 103-104). Sulla Contessa di Dia cfr. anche Rieger, Trobairitz, pp. 108-137.

79 Doc. Am., VI, sub Spe, doc. IV, v. 4146 (vol. III, pp. 27-28). Querens, mancante nel testo di Albertazzi, è stato integrato sulla base di Barb. lat. 4076, c. 68rb. e, sempre sulla base del codice, è stata ripristinata la forma perstiterit. 
L'episodio fa riferimento ad alcuni trattati della Contessa non pervenutici e di cui i Documenti costituiscono l'unica testimonianza indiretta. In essi sono contenuti insegnamenti per il giovane cavaliere riguardanti il bellum armigerum e il bellum verbale, distinguendo in quest'ultimo caso tra la contesa portata avanti per svago e quella che intende convincere l'interlocutore. Presupposto comune per i bellatores nelle armi e nelle parole deve essere il rispetto dei dettami della cortesia, mentre la disputa verbale volta a convincere l'interlocutore deve avere come prerogativa la moderazione dell'ira con riguardo alla veridicità delle tesi sostenute. La distinzione operata tra il comportamento del cavaliere che porta avanti un'argomentazione corretta («veritas est tecum»), al quale viene suggerito di trascinare il contendente dalla propria parte con calma e fermezza, e colui che espone un ragionamento falso («veritas contra te»), il quale dopo un breve confronto dovrebbe cedere al proprio interlocutore, mostra chiaramente come la veridicità dell'argomentazione costituisca in tal caso una ratio organizzatrice anche da un punto di vista comportamentale in questioni ben lontane dalla predicazione religiosa. In sostanza la Veritas, prevedendo una realizzazione fattuale mediante il Verbum, possiede in sé sia la connotazione terrena di ars loquendi, sia quella di attributo divino, ed è tramite la definizione delle sue caratteristiche che è possibile rintracciare se e in quale misura la divinazione possa essere configurata come pratica che rispetta la rettitudine. Il valdelsano si sofferma sulla sua definizione sostanziale in due occasioni che ne mettono in luce la doppia natura umana e divina, ovvero nella seconda parte dei Documenti, sotto il magistero di Industria, e nella chiusa dell'opera, dominata da Etternitas. Nel primo caso è lo stesso Francesco a individuare una terna precettistica di regulae raggruppabili per unità tematica («tres iste regule due precedentes et ista tractum habent in veritatis favorem»): ${ }^{80}$ in esse è evidente l'intenzione di fornire ragguagli sugli argomenti dottrinalmente aderenti alla rettitudine e su come essi debbano essere modulati nell'atto dell'insegnamento e della predicazione:

Tutto che verità già non si muti, né sia bisogno di lei colorare; ciascun è da laudare che parla quella e dimostra et insegna: ma ben convien a .llui nel cor la tegna.

Megli'è per verità morte patire, che per contraro dire aver qualunque temporale stato: ch'ogni mal acquistato o poco dura o dà morte finale;

80 Doc. Am., II, sub Industria, doc. v, reg. LXXII, v. 2650 (vol. II, p. 171). 
e perché morte indugi non ti vale.

Dunqua è la morte cotal più d'amare,

che doppo vita ti face durare.

Non ogni cosa ch'è vera si vuole

in popol predicare,

né l'amico blasmare

del viç<i>o occulto, alchun altro presente:

ma solo spesso farnel conoscente. ${ }^{81}$

I versi in questione vengono glossati ricorrendo al Corpus iuris civilis e interpretati, di conseguenza, nelle loro implicazioni giuridiche; non è escluso, dunque, che in tal modo l'autore abbia intenzione di coniugare oratoria religiosa e oratoria civile, quest'ultima intesa come prerogativa dei giuristi a cui pure lo stesso notaio valdelsano apparteneva. Nel commento alle regulae appena menzionate l'autore rinvia a dei loci contigui che insistono sugli aspetti teologico-filosofici e sull'inscindibilità tra Veritas e Verbum con riferimento alle auctoritates patristiche. Ad esempio, nella regola LXX Francesco afferma che tratterà oltre della sostanza della veritas, e precisamente in Doc. Am., IX, sub Iustitia, doc. I, ${ }^{82}$ dove notiamo l'affiorare di citazioni da Anselmo d'Aosta, Agostino, Bernardo di Clairvaux e Riccardo di San Vittore, tra gli altri:

De hac veritate dicit Anselmus in libro De veritate: «Quia veritas est rectitudo sola mente perceptibilis»; et Augustinus in Soliloquiis: «Veritas est id quod est»; et idem in libro De vera religione: «Vera in tantum vera sunt; in quantum sunt»; et idem ibidem: «Veritas est lux intelligibilis»; et idem: «Veritas est, qua hostenditur id quod est». Et Hylarius: «Veritas est declaratum esse». Augustinus autem contra Academicos libro I, capitulo III inquid: «Hominis finis est, perfecte querere veritatem». Et idem ibidem: «Nam via que ducit ad veritatem, nulla, ut oppinor, intelligitur melius quam diligens inquisitio veritatis». Huius «veritatis» ut dicit Bernardus in tractatu De gradibus humilitatis - «agnitio consistit in tribus gradibus. Inquirimus namque veritatem in nobis, ipsis in proximis, et in sui natura. In nobis, nosmet ipsos diiudicando: in proximis, eorum malum compatiendo: in sui natura mundo corde contemplando». Et infra: «Ad primum adscendimus per laborem humilitatis, ad secundum per affectum compassionis, ad tertium per excessum contemplationis». ${ }^{83}$

81 Doc. Am., II, sub Industria, doc. v, reg. LXX, vv. 2637-2641; reg. LXXI, vv. 2642-2649; reg. LXXII, vv. 2650-2654 (vol. II, pp. 170-172).

82 «De ista veritate habes infra in parte viII, documento primo, et eius figuram infra circa finem libri» (Doc. Am., II, sub Industria, doc. v, reg. LXX, v. 2367 [vol. II, p. 170]).

83 Doc. Am., IX, sub Iustitia, doc. I, vv. 6433-6434 (vol. III, pp. 290-291). I versi commentati sono: «Vedranno palesi a tutti gli lor falli, / ché verità gli à scritti per mostralli». Si noti inoltre che in questa occasione il valdelsano rimanda anche al documento successivo («et de ista veritate super hoc documento quod adhuc totum prohemium est, antequam ad verba iustitie que incipiunt infra proximo documento aliqua referamus»), un richiamo che era anche nella glossa alla regula LXII, v. 2650. Nel testo latino ho ritoccato lievemente la punteggiatura ed eliminato le integrazioni di Albertazzi, non corrispondenti al testo di Barb. lat. 4076, c. 88rb. 
La rosa di autori a cui Francesco si affida caratterizza la Veritas nella sua sostanza, come entità bastante a sé stessa e attributo divino. Già in Doc. Am., II, sub Industria, doc. v, reg. LXx, v. 2637, l'autore aveva menzionato una figura della veritas che sarebbe stata inserita alla fine dell'opera, e il medesimo richiamo si ha anche nella chiosa della sezione sotto il magistero di Giustizia, in cui il valdelsano descrive più dettagliatamente la rappresentazione allegorica di una donna con il corpo parzialmente incastonato in un masso e avente tra le mani un libro che ne ribadisce la fermezza:

Istius veritatis figuram habes infra iuxta finem libri que amorem adsociat ad claudendum librum, que figura fixa est in quodam saxo ad denotandum quod moveri non potest, librum tenet apertum, in quo scriptum est: «Quecumque sunt hic sunt et ego semper maneo». Et de eadem veritate loquitur hic liber. Nam bona et mala tenebit scripta coram Deo in die iudicii, et methaphora est. Et quod dicit «Ego semper maneo», si intelligas perpetuo, dic quod de Deo qui veritas est loquitur si durante vita nostra dic quod solum de veritate in rebus iuxta distintionem que supra de iustitia fit. ${ }^{84}$

La miniatura in questione si trova a c. 98v del Barb. lat. 4076, contestualmente alla chiusa di Doc. Am., XII, sub Etternitate, doc. unicum, e ai vv. 6999-7004. Essa presenta due livelli figurativi: nel primo e più alto vi è dipinta un'allegoria di Amore alato nell'atto di chiudere il libro dei Documenti; l'immagine sovrasta quattro altre figure, ovvero, nell'ordine, la Sollecitudine, la Perseveranza, la Verità e la Fortezza. In tale rappresentazione allegorica la Verità segue esattamente i dettami che Francesco da Barberino aveva precedentemente annunciato (Fig. 13). ${ }^{85}$ Nei versi corrispettivi si afferma che la conclusione dell'opera non può essere affidata a Eternità, l'allegoria che presiede l'ultimo documento e che costituisce un'innovazione rispetto al sistema di virtù derivato, come ha dimostrato Marruzzo, da Alano di Lilla e Guglielmo di Conches. ${ }^{86}$ La chiusa dell'opera viene quindi affidata al principale locutore dei Documenti, ovvero Amore, da intendersi non in senso cortese o carnale, bensì come rappresentazione dell'amore divino, come si specifica già nel proemio dell'opera ma anche in quest'ultima sezione: ${ }^{87}$

84 Ivi, vv. 6433-6434 (vol. III, p. 293).

85 Cfr. Egidi, Le miniature dei codici barberiniani, p. 88. La stessa illustrazione è anche nel Barb. lat. 4077, c. 87v. Sulle miniature raffiguranti Amore nel Barb. lat. 4076 cfr. Dunlop, Painted Palaces, pp. 132-137.

86 Marruzzo, Composizione e significato de «I Documenti d'amore», pp. 240-242.

87 «Il testo divulgato da Amore può essere considerato come l'equivalente degli insegnamenti affidati ai libri sapienziali della Bibbia, oppure a raccolte come i Disticha Catonis. [. . .] Nel poema volgare la figura di Amore non è immediatamente svelata come allegoria cristologica, ma è anzi presentata con i tratti feudali del 'signore' («signor cortese» in VIII Pr. 1). Nelle parole di Eternità, che lo celebra come colui «che fece il fermamento / pianeti, stelle e ciascun elemento» (XII i 41-42), è la dichiarazione più esplicita della sua natura divina» (Panzera, Francesco da Barberino tra 
Io sola Etternità chiuder non posso questo libro, ch'è mosso dal mio signor Amore. A .llui convien l'onore, ch'à'l poder e la força.

Et esso il chiude, ch'a ben non si sforça.
Dicit quod ipsa sola claudere, idest conclusionem dare libro non posset. [. . .] Item et alia ratione quia nichil boni perficitur sine Deo, unde ipsa sola idest sine hoc divino amore librum claudere nequivisset. ${ }^{88}$

Il rapporto biunivoco che Amore e Verità intrattengono tra loro e con l'architettura complessiva dell'opera fornisce chiari indizi sulla maniera in cui l'autore intende inquadrare i Documenti: ponendo il proprio libro tra le mani di un'allegoria cristologica sorretta dalle virtù il valdelsano configura al contempo la forma-libro dei Documenti e il suo contenuto in quanto modelli di perfetta coesione tra rectitudo e ars loquendi, dove gli insegnamenti di Amore vengono sorvegliati e legittimati dalla Veritas a livello formale e dottrinale. Tale caratterizzazione fa da contrappeso agli argomenti trattati nell'ultima sezione dell'opera in cui si compie il trionfo di Eternità, una donna raffigurata a c. 96r come una sorta di sirena le cui pinne si biforcano e formano un cerchio ininterrotto che ne avvolge la figura a mo' di manto, sul quale vengono disegnate le stelle, segno che la condizione di perpetuitas della vita oltre la morte può essere conosciuta solo in cielo. ${ }^{89} \mathrm{Di}$ conseguenza, la curiositas umana rispetto ai disegni divini e ai misteri della natura va bandita,

Andrea Cappellano e Averroè, p. 45). Ma si veda anche Nardi, Le illustrazioni dei 'Documenti d'amore’, p. 80: «Nel Barberino, dunque, si annulla la dicotomia amore spirituale-Eros, non perché ci sia una fusione tra i due, adottata solo per la rappresentazione visiva, ma perché il secondo termine viene completamente annullato dalla condanna del poeta, che non si pone neanche il problema se ci possa essere una fusione fra i due. Un Amore, dunque, tutto positivo e spirituale, intriso di attributi divini e di allusioni cristiane». Sugli intertesti scritturali e profetici nel valdelsano si veda ora Brilli, Fontes Baratto, Montefusco, Sedurre l'imperatore, pp. 44-59.

88 Doc. Am., XII, sub Etternitate, doc. unicum, vv. 6999-7004 (vol. III, p. 397 e 399).

89 Per un'accurata ricostruzione della fortuna rappresentativa di Eternità si veda Petrucci Nardelli, Minima barberina. II, pp. 1010-1014; cfr. anche Supino Martini, Per la tradizione manoscritta, p. 947; Panzera, Francesco da Barberino tra Andrea Cappellano e Averroè, pp. 194-195; MacLaren, Shaping the Self in the Image of Virtue, pp. 93-94. L'eccezionalità nella rappresentazione di Eternità come donna-sirena nei Documenti d'amore è già precocemente rilevata in Ripa, Iconologia overo Descrittione di diverse imagini, pp. 140-141; per una storia del motivo iconografico della sirena e della sua trasformazione formale da donna-uccello a donna-pesce cfr. Leclercq-Marx, La syrène dans la pensée et dans l'art e, in particolare, nella sezione IV, il par. dal titolo Les sirènes et l'élement aérien. Leur rapport avec les anges, la musique des sphères, les vents et le Zodiaque. 
ed è sotto questo auspicio, che molto deve ai testi profetici e alla letteratura escatologica, che Francesco da Barberino sceglie di chiudere i Documenti, ovvero segnalando come la speculazione filosofica su questioni imperscrutabili sia una forma di traviamento, capace di allontanare l'uomo dalla ricerca della verità e dal raggiungimento della felicità:

Iste usque in finem dat nobis bonum consilium: micte archana Dei celum inquirere quid sit. Et illud Apostoli: «Non plus sapere quam opportet sapere sed sapere ad sobrietatem». Quid enim «Licet nescias, que ratio effundat oceanum, - ut Seneca inquid - vel quid sit quod gemelorum conceptum separare, partum coniungat, cur simul natis sint facta diversa: non tibi multum licebit transire quod non licet scire, non prodest». Circa hec dicit Ambrosius in Exameron: «Quid michi querere que sint <eius> mensure terre circuitus, quam geometre centum octoginta milibus stadiorum extimaverunt? Libenter fateor me $<$ nescire > quod nescio, immo scire quod scire nichil proderit». [. . . ] Et Augustinus, super Genesi, libro II dicit de forma et figura celi multi disputant quas res, maiores nostri obmiserunt auctores, discentibus ad beatam vitam non ad futuras occupationes, quod peius est, multum pretiosa, et rebus salubribus impendenda temporum spatia». ${ }^{90}$

Nel lungo elenco di mirabilia, per il quale il Barberino attinge a fonti di carattere diverso, ${ }^{91}$ si ricorre alla preterizione per enumerare gli argomenti che non appartengono al campo dello scibile e del predicabile. Riguardo invece alla sapienza di pertinenza dell'uomo egli si rifà all'auctoritas di Agostino, riportando prima un passo del De libero arbitrio in cui è palese il limite imposto alla conoscenza umana («Eos sapientes vocat, quos veritas vocari iubet, et qui regno mentis omnis libidinis subiuga$\mathrm{t}<$ ione pacati $>$ sunt») $)^{92}$ e, successivamente, un commento ad Ecclesiaste, I, 17-18 contenuto nel De doctrina christiana, in cui l'Ipponense rivendica la necessità di allontanare l'interesse per le cose temporali per dirigersi verso la vera scienza, che deve tendere all'amore di Dio e alla liberazione dell'uomo dagli affanni. ${ }^{93}$

90 Doc. Am., XII, sub Etternitate, doc. unicum, v. 6964 (vol. III, pp. 380-381). In questo caso ho modificato la punteggiatura e non ho accolto l'intervento di Albertazzi <et> occupantes, ripristinando occupationes di Egidi e di Barb. lat. 4076, c. 97ra.

91 Un approfondimento sulla questione è stato promesso da Panzera, Francesco da Barberino tra Andrea Cappellano e Averroè, p. 202; ma si vedano le osservazioni di Montefusco, Rencensione a Panzera, Francesco da Barberino tra Andrea Cappellano e Averroè, p. 298.

92 Doc. Am., XII, sub Etternitate, doc. unicum, v. 6994 (vol. III, p. 383). Ho espunto dal testo alcune integrazioni di Albertazzi prese in blocco dal testo agostiniano ma non tradite dal codice, mentre ho lasciato quelle plausibili e difficilmente leggibili sulle riproduzioni del manoscritto. Ho tuttavia modificato voco in vocat (ma nel ms. la forma è voca) e id est in et qui, poiché Francesco da Barberino riporta il discorso di Agostino in terza persona mentre Albertazzi inserisce direttamente un virgolettato contenente la citazione, ma non corrispondente al testo di Barb. lat. 4076, c. 97rb. Il passo di Agostino si trova in De libero arbitrio, I, IX, 19 (in CCSL, vol. 29, p. 224).

93 Cfr. Agostino, De doctrina christiana, II, vII, 10 (in CCSL, vol. 32, p. 37). 
L'interazione tra testo volgare, glossa latina e miniatura rende quindi palese quale sia il motivo ispiratore dei Documenti d'Amore e quale debba essere la ratio nello strutturare gli ammaestramenti del libro, da un punto di vista di correttezza dottrinale e di predicabilità delle immagini, fisiche o mentali, nell'orazione pubblica. ${ }^{94}$ Tuttavia, a differenza di ciò che accadeva per tecniche divinatorie profondamente radicate quali l'auspicio e l'augurio, assimilabili di fatto alla magia e alla superstizione sulla base, come si è visto, di un'ampia serie di fonti patristiche e canonistiche, il problema della sovrapponibilità tra Veritas e Verbum assume risvolti ben diversi quando il valdelsano affronta altre situazioni che prevedono la predizione del futuro, come ad esempio accade per il sogno premonitore. Come è noto, il tema ha una larghissima fortuna nel Medioevo, trovando la sua legittimazione già nei sogni biblici, ${ }^{95}$ nonché in opere che diverranno capitali nello sviluppo di un'onirologia cristiana come il Commentarius al ciceroniano Somnium Scipionis di Macrobio, il De spiritu et anima di Agostino e il Policraticus di Giovanni di Salisbury. ${ }^{96}$ Il problema della conciliazione tra somnium e veritas è quindi cruciale, specialmente se si considera che il cristianesimo aveva bandito l'oraculum, ovvero il sogno proveniente direttamente da Dio e riservato spesso a personalità illustri, che in tal modo ricevevano indicazioni sugli avvenimenti futuri. La veridicità del sogno si articola dunque sia sul piano della realtà fattuale, ovvero della effettiva possibilità che quanto predetto si verifichi nella realtà, sia nella sua interpretazione onirocritica, specialmente quando essa viene esplicitata di fronte a un pubblico o assume risvolti letterari. ${ }^{97}$ La posizione del valdelsano in merito appare chiara fin dal testo volgare:

\footnotetext{
Non ti dormir a fidança che Dio

ti porti al nido per cibo la manna, ché tal pensiero inganna

molti, che poi negligença disface.

Fa' como saggio hom face,

che pensa tutto davanti bisogna:

non si confida trovar ciò che sogna. ${ }^{98}$
}

94 «Un confronto significativo [. . . ] si può trovare nell'ambito della predicazione, che pure fa ricorso sovente alle immagini, concrete o di fantasia, a fini persuasivi: anche l'itinerario morale dei DA si compie attraverso delle stazioni visive che propongono immagini mentali di sicura memorabilità» (Panzera, Francesco da Barberino tra Andrea Cappellano e Averroè, p. 70).

95 Cfr. Le Goff, Le christianisme et les rêves (IIe-VIIe siècles), pp. 216-218.

96 Si veda Le Goff, Sogni, pp. 1089-1090.

$97 \mathrm{gSu}$ quest'ultimo aspetto si veda in particolare Manselli, Il sogno come premonizione, pp. 219-244. Tra i numerosi contributi in merito segnalo solo Gregory, I sogni e gli astri, pp. 111-148; Le Goff, I sogni nella cultura e nella psicologia collettiva; Schmitt, Medioevo "superstizioso"; Kruger, Dreaming in the Middle Ages; Keshiako, Dreams and Visions in the Early Middle Ages.

98 Doc. Am., II, sub Industria, doc. v, reg. XCII, vv. 2756-2762 (vol. II, pp. 191-192). 
Francesco da Barberino redarguisce coloro che, addormentandosi, aspettano l'intervento divino per indirizzare le proprie azioni, esortandoli conseguentemente a prendere decisioni senza considerare le premonizioni oniriche. Si tratta di un ammonimento talmente pregnante da essere riprodotto fedelmente anche nel Reggimento, dove viene indirizzato alle donne che non riescono ad avere figli, affinché accettino serenamente il volere divino ed evitino di rintracciare segnali di una eventuale maternità futura nei sogni. ${ }^{99}$ Malgrado la risemantizzazione precettistica del Reggimento, nei Documenti è ancora una volta la glossa a chiarire quali siano i risvolti di una regula che poteva essere declinata in varie direzioni. Il notaio valdelsano vi passa in rassegna le fonti classiche sulla questione, tra le quali mi sembrano significative le menzioni di Avicenna, autore a cui egli aveva attinto ampiamente per le sezioni pediatriche del Reggimento, ${ }^{100}$ e di Aristotele, che farebbero propendere per una tendenza barberiniana all'onirologia di stampo aristotelico:

«De sompniis die quod non sunt omnia sompnia vera, neque sunt huius quod multum sit curandum de eis virtus est ymaginativa - dicitur in vi Naturalium Avicenne - non semper representat quod emanat de celestibus. Illi autem sunt homines verorum sonniorum - dicitur ibi - qui sunt magis temperate complexionis vide ibi». Et nota hic loquendi modum dormiente comparat negligenti. «Idest non vigilanti ad providendum ad hoc quod - dicit Phylosophus in De sonno et vigilia - videtur autem inquid sonnus vigilie quidem esse privatio nam extrema semper in aliis et in naturalibus circa idem subsceptibile videntur fieri et eiusdem esse passiones. Vigilare autem ei quod est dormire contrarium est. Et necesse est omni inesse alterum». Et dicitur in eodem: «Dormientes quidem consumuntur vigilantes vero non. Ibidem de divinatione vero sonniorum que in sonnis fit dicitur accidere a sonniis nec contempnere ydoneum nec omnino suadere. Nam quod omnes quidem vel plures existimant habere aliquam significationem sompnia prestant fidem, tanquam ab experientia factum vel dictum, et quod de quibusdam fit divinatio in sompniis non incredibile habet autem aliam rationem. Ideo et de aliis sompniis similiter utique quis arbitratur nullam vero rationabilem videre causam secundum quam utique fiat hoc credere facit: nam Deum esse mictentem fatuis et non opportunis et prudentissimis et quidlibet mictere inconveniens. Ablata vero que a Deo nulla causa aliorum convenienter videtur esse causa». Hec ibi vide "De previdentia" de qua agitur in hac regula vide infra in principio VII partis Prudentie in glosa et ibi plene. ${ }^{101}$

99 Regg., XVI, p. 205.

100 Cfr. Panzera, Francesco da Barberino tra Andrea Cappellano e Averroè, pp. 136-145.

101 Doc. Am. II, sub Industria, doc. v, reg. XCII, vv. 2756-2762 (vol. II, pp. 191-194). Nel testo di Albertazzi ho modificato il riferimento ad Avicenna da v a vi, ripristinando la lezione del manoscritto che rinvia al sesto libro del De Naturalibus (errore riprodotto anche in Panzera, Francesco da Barberino tra Andrea Cappellano e Averroè, p. 131), ho corretto la grafia di idoneum in ydoneum, già nel codice della Biblioteca Vaticana e in Egidi, ho inoltre sostituito consummuntur con consumuntur, errore probabilmente dovuto alla collocazione del titulus planus sulla prima - $u$-, anziché sulla seconda, il cui intervento è giustificato anche dal ripristino della fonte barberiniana per la quale si veda infra, nota 103; ho infine modificato ibidem dei divinatione in 
Il De anima di Avicenna, da cui Francesco trae il passo inserito in questa porzione di glossa, ${ }^{102}$ evidenzia alcuni punti di distacco rispetto alla teorizzazione del $D e$ somno et vigilia di Aristotele. ${ }^{103}$ Per lo Stagirita, infatti, erano importanti gli aspetti fisiologici che distinguevano il sonno dalla veglia, per cui la condizione del dormiente era descritta come un temporaneo arresto della facoltà sensitiva a favore di quella immaginativa. La divinazione tramite il sogno, considerata possibile, veniva però ridotta agli auspici di tipo medico o ai risvolti delle premonizioni nell'operato dell'uomo. In entrambi i casi la possibilità di predire avvenimenti futuri restava una mera coincidenza dipendente dalla corretta interpretazione della simbologia onirica, per cui al sogno veniva negata qualsiasi natura divina. ${ }^{104}$ Avicenna

ibidem de divinatione, quest'ultimo già nel codice e in Egidi. Si è reso inoltre necessario ritoccare l'interpunzione, poiché le virgolette di Albertazzi collocano la fine della citazione da Aristotele in corrispondenza di «hoc credere», mentre anche il periodo successivo è tratto dal $D e$ somno et vigilia e, anzi, è necessario a livello semantico. Tra i numerosi interventi che si sarebbero resi necessari ho scelto di correggere solo la scriptio continua di adeo, mantenendo intatto il testo latino anche se erroneo. Cfr. Barb. lat. 4076, cc. 47vb-48ra.

102 La citazione proviene da Avicenna, De Anima, IV, II, pp. 29-30 e 32: «Non sunt autem omnia somnia vera neque sunt huiusmodi quod multum sit curandum de eis. Virtus enim imaginativa non semper repraesentat quod emanat a caelestibus, sed tamen hoc tunc saepius agit cum ipsa virtus cessat repraesentare ea quae sunt sibi propinquiora, quedam sunt naturalia, quedam vero voluntaria. [. . .] Illi autem sunt homines verorum somniorum qui sunt magis temperatae complexionis».

103 Dalla maniera in cui Francesco da Barberino menziona Aristotele nella glossa è possibile risalire al tipo di traduzione latina che egli utilizzò e correggere in alcuni punti gli errori del manoscritto. Il primo passo menzionato (indicativamente da «sonnus vigilie» a «esse passiones») è tratto da Aristoteles, De somno et vigilia, 1 (453b25-29) e sembra poter essere ricondotto alla cosiddetta translatio vetus dello Stagirita, come sembrerebbe dimostrare la chiusa della frase, che nella translatio nova corretta da Guglielmo di Moerbeke figura come passiones esse. Il secondo periodo («vigilantes autem . . . alterum»), che compare allo stesso modo in entrambe le traduzioni, è invece tratto da Aristoteles, De somno et vigilia, 1 (454b1-3). Il lacerto «dormientes quidem consumuntur vigilantes vero non» diventa dirimente per dimostrare la dipendenza delle citazioni aristoteliche dei Documenti da un testo molto vicino alla translatio vetus. La frase è infatti tratta da

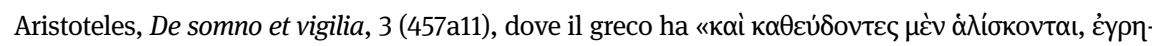

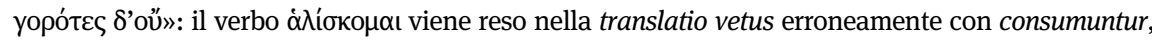
e così è riportato nella glossa di Francesco da Barberino, mentre la translatio nova con le revisioni di Guglielmo di Moerbeke presenta la forma corretta capiuntur. Infine, l'ultimo periodo è tratto in blocco dall'incipit di Aristoteles, De divinatione per somnium, 1 (462b12-24), ma con alcuni significativi scarti rispetto a entrambe le traduzioni latine. Per una panoramica generale sulle traduzioni aristoteliche durante il Medioevo cfr. Kouri, Lehtinen, Disputed Questions on Aristotle's De iuventute et senectute, pp. 365-367; Brams, La riscoperta di Aristotele in Occidente, specialmente le pp. 66-67 e pp. 105-130.

104 Il legame tra sogno premonitore e $\delta \alpha \iota \mu o ́ v ı \alpha$ è evidente soprattutto nel De divinatione per somnium: «Omnino autem quoniam et aliorum animalium sompniant quedam, a deo utique 
riprende le teorizzazioni fisiologiche aristoteliche e il dualismo vigente tra virtus ymaginativa e virtus interpretativa, ai quali aggiunge la caratterizzazione degli uomini come esseri che proiettano le loro azioni verso il futuro, laddove gli animali condurrebbero un'esistenza stanziata nel presente. ${ }^{105}$ Per questo, il brano del De anima selezionato dal Barberino e riportato in glossa in parte contraddice la selezione di passi aristotelici dei Documenti: relegando alcuni sogni nel dominio della veritas e ammettendo la loro dipendenza dalle sfere celesti, concetto che Avicenna aveva esposto a più riprese nel trattato, ${ }^{106}$ il valdelsano sembra per tali tematiche più vicino al medico arabo che allo Stagirita. ${ }^{107}$ La glossa, non casualmente, è cesellata in chiusura dall'apologo del soldato Solernio il quale avrebbe impiegato la maggior parte del suo tempo dormendo poiché riceveva in sogno l'annuncio di prodigi divini, e avrebbe deciso di arruolarsi solo in seguito a tali premonizioni, riuscendo vittorioso. ${ }^{108}$ Con tale exemplum il valdelsano sembra quindi ammettere

missa non erunt sompnia, neque facta sunt huius gratia, daimonia tamen: natura enim daimonia, non divina. Signum autem: valde enim stulti homines previdentes sunt et recte sompniantes, tanquam deo non inmittente, set quorumcumque quasi loquax natura est et melancolica, multimodas visiones vident: eo enim quod secundum plurima et multipharia moveantur cum theorematibus, existentes in hiis sicut quidam rapiunt contendentes: nam quemadmodum et dicitur 'si multa iacias, alias dispariter iacis', et in hiis hoc accidit» (Aristoteles, De divinatione per somnium, 2 [463b12-22], il testo è tratto dalla traduzione rivista da Guglielmo di Moerbeke). Si noti, tuttavia, che la medesima concezione aristotelica di quest'opera è in contrasto con quanto egli aveva affermato nel De philosophia, fr. 12, dove poneva i sogni profetici a dimostrazione dell'esistenza del divino. Sulla questione si veda Gregory, I sogni e gli astri, p. 118; per le interpretazioni medievali rimando a Kruger, Dreaming in the Middle Ages, pp. 84-85.

105 «L'homme prévoit l'avenir: en langage contemporain, on dirait qu'il est un projet d'avenir. Son attention ne se limite pas au moment présent: il délibère sur ce qu'il y a à faire et sur le moment où il faut le faire. N'est-ce pas là aussi une forme de transcendence? Les moments du temps se suivent de telle façon que le glissement d'un instant dans le passé est la condition inévitable de l'apparition du moment suivant. Et pourtant, l'homme ne se contente pas de vivre les moments de son existence dans leur apparition successive, attendant que l'avenir devienne présent avant de s'intéresser à lui» (Verbeke, Le «De anima» d'Avicenne, p. 17).

106 «Hominum autem quidam sunt verorum somniorum: quod fit cum anima eius consuevit dicere verum et vincere fallacem imaginationem. [. . .] Dicemus ergo quod omnia quae in mundo sunt praeterita, praesentia et futura, habent esse in sapientia creatoris et angelorum intellectualium secundum aliquid, et habent esse in animabus quae sunt angeli caelorum secundum aliud» (Avicenna, De anima, IV, II, pp. 25-28).

107 Cfr. Kruger, Dreaming in the Middle Ages, pp. 86-89.

108 «Regina Machyr dicitur habuisse sub se militem unum nomine Iordanem, qui filium habebat nomine Solernium, qui continuo infra diem naturalem XxIII oris continuis usque ad etatem annorum xx dormiebat. Capud erat crossissimum et oculi rubei et inflati et cum excitabatur super se subsistere non valebat, et cum eo tempore quo non dormiebat diceretur ei: "Et quomodo poteris filii statum tuum augere?”, dicebat Deum magnum se continuo videre in sompniis qui mirabilia offerebat sibi et promictebat, igitur non erat ei expediens laborare. Mater 
l'eventualità di una corretta applicazione delle tecniche oniromantiche e del loro effetto positivo sugli atti umani, forse in accordo con quelle posizioni dottrinali che giustificavano i sogni veritieri sulla base della prescienza divina e attraverso l'ampia manualistica sull'interpretazione dei sogni. ${ }^{109}$ Tuttavia, i luoghi del Decretum che si occupano di aruspicina dimostrano che il Barberino era pienamente a conoscenza dell'inquadramento della questione nella letteratura giuridica: infatti, nei brani di Doc. Am., I, sub Docilitate, doc. XxIV, v. 1639 (vol. I, p. 328) in cui si assimilano gli auspici e gli auguri alla superstizione Francesco si era servito dei canoni che rigettavano qualsiasi pratica divinatoria, inclusa l'oniromanzia. ${ }^{110}$

In base al percoso delineato finora sulla maniera in cui nei Documenti si intrecciano divinazione, necessità di non incorrere nel mendacium e strutturazione del discorso oratorio è possibile rileggere sotto un'altra ottica l'exemplum del predicatore Alberico della Caprafica, la cui attività viene presentata dal valdelsano quasi in maniera rendicontale, prima mediante l'enumerazione degli argomenti oggetto del sermo e poi accennando agli effetti dell'actio sull'uditorio. La struttura e il contenuto di tale inserto esemplare mettono in luce una lista di auctores, considerati come meri espedienti di sottigliezza filosofica e inadatti alla «gente grossa». La loro confutazione da parte di frate Albertico diviene dunque un'operazione inutile:

Restat modo solum de exemplo huius regule videre quod est tale. Frater Albericus de la Caprafica, missus semel ad predicandum in villas, cum esset apud Domodossele et astarent sibi rustici, et rustice multi volens apparere, cum novitatibus cepit dicere quomodo Aristotiles erravit ponendo «quod non sit possibilis resurrectio mortuorum», et «quod nullo modo duo corpora possunt esse in eodem loco». Item quomodo Averois erravit di-

autem eius dicebat ad eum sepissime huius regule testum et similia verba iuvans etiam illum consilio medicorum, propter que devenit in melius ut solo medio sue vite tempore dormiret; cum quoque cerneret in XXV anno tempus dormitionis quod cessari poterat perditum fore magistrum quesivit et didicit arma ferre. Is quoque dicitur postea strenuissimus extitisse in armis et vicisse illuc missus postmodum a regina rogata magnam partem Turchie» (Doc. Am., II, sub Industria, doc. v, reg. XCII, v. 2756 [vol. II, pp. 193-194]). Nel brano sono stati emendati offerabat in offerebat, ed didicit in et didicit e nimis in armis, cfr. Barb. lat. 4076, c. 48ra.

$109 \mathrm{Si}$ veda, a titolo di esempio, l'ampia diffusione manoscritta greca, latina e volgare del più celebre prontuario di simboli onirici, ovvero il Somniale Danielis, studiato da Cappozzo, Dizionario dei sogni nel Medioevo, a cui rimando anche per la bibliografia pregressa.

110 In particolare, nella glossa Francesco da Barberino menziona il canone Si quis ariolos di Decr., C. 26, q. 5, c. 1 (vol. I, col. 1027), un brano tratto dai Capitularia regum Francorum dove vengono condannati esplicitamente i sogni divinatori con richiamo a quanto espresso in Deut., 18, 10-11: «Nec inveniatur in te qui lustret filium suum aut filiam ducens per ignem aut qui ariolos sciscitetur et observet somnia atque auguria ne sit maleficus ne incantator ne pythones consulat ne divinos et quaerat a mortuis veritatem». Si veda supra, nota 60 e ancora Kruger, Dreaming in the Middle Ages, pp. 11-13. 
cens «quod angelus nichil potest movere immediate nisi celeste corpus», et «quod Deus non cognoscit singularia». Item quomodo Avicenna erravit dicens «quod anima per ymaginationem suam operatur in corpore alieno», et «quod prophetia est naturalis». Item quod Alkindus erravit dicens «quod simpliciter omnia futura dependent ex conditione supercelestium corporum» et «quod omnia de necessitate contingunt». Item quod Rabi Moisis erravit dicens «quod verbum dicitur in Deo essentialiter solum»; et «quod corpora supercelestia sunt animata», et «quod Deus non potest facere accidens sine subiecto». Et multos istorum et aliorum qui erraverunt errores recitabat et inutiliter explicabat. Cumque ibi esset ex casu quidam valens homo qui hec michi postea et alia recitavit et stetisset in deformi habitu, sicut per partes illas transeunt viatores post predicationem, habuit fratrem et redarguit eum $<$ v>alde inter cetera dicens ei testum regule presentis. ${ }^{111}$

I brani richiamano in forma compendiata una silloge di autori, probabilmente già presente nella summa da cui le citazioni sono tratte e fedelmente riprodotta dal valdelsano, come accade in altri passi simili in cui si dimostra il ricorso massivo agli Errores Philosophorum attribuiti ad Egidio Romano. ${ }^{112}$ Tra i personaggi menzionati spiccano sicuramente gli esponenti dell'aristotelismo e, in particolare, Averroè, sul quale aleggiava un fervido dibattito culminato con le celebri condanne di Étienne Tempier del 1270 e 1277, rivolte non solo ai campioni dell'averroismo, come Sigieri di Brabante, ma anche ad opere differenti per pubblico e funzioni ed ugualmente considerate eterodosse, tra cui i manuali di geomanzia, negromanzia e demonologia, nonché il De Amore di Cappellano. ${ }^{113}$

111 Doc. Am., II, sub Industria, doc. v, reg. XVII, v. 2335b (vol. II, p. 109). Nel testo di Albertazzi ho emendato l'erroneo passibilis in possibilis, già in Barb. lat. 4076, c. 41va e in Egidi.

112 Si vedano i sondaggi di Panzera, Francesco da Barberino tra Andrea Cappellano e Averroè, pp. 196-200. Per l'importanza di tale testo cfr. Mandonnet, Sigier de Brabant et l'averrö̈sme latin, vol. 2, pp. 1-25.

113 La tesi n. 65 della condanna di Tempier è affine alla lista di errori enunciata nei Documenti («quod Deus uel intelligentia non infundit scientiam anime humane in sompno, nisi mediante corpore celesti», cfr. La condamnation parisienne de 1277, p. 100), un dato significativo se si considera che tra i difensori della posizione eterodossa figurerebbe proprio Sigieri di Brabante, come ha evidenziato Hissette, Enquête sur les 219 articles, pp. 270-271. L'accostamento tra il De Amore e i manuali di divinazione è nell'epistola che fa da prologo al sillabo, in cui si ricorda per incipit anche l'anonimo Estimaverunt Indi: «Librum etiam "de amore”, siue "de deo amoris", qui sic incipit: "Cogit me multum, etc.”, et sic terminatur: "Caue igitur, galtere, amoris exercere mandata, etc.”; item librum geomantie qui sic incipit: "Estimauerunt indi, etc.”, et sic terminatur: "Ratiocinare ergo super eum, et inuenies, etc.”; item libros rotulos seu quaternos nigromanticos aut continentes experimenta sortilegiorum, inuocationes demonum, siue coniurationes in periculum animarum, seu in quibus de talibus et similibus fidei orthodoxe et bonis moribus euidenter aduersantibus tractatur» (La condamnation parisienne de 1277, pp. 76-78). 
Com'è noto, la condanna dell'averrosimo, dell'aristotelismo radicale e del determinismo astrologico ${ }^{114}$ ebbe notevoli ripercussioni sia sulla cultura accademica, sia sulla religiosità colta e popolare del Due e Trecento: un esempio in tal senso è rappresentato dall'opera di Ramon Llull, che dedicò parte della sua attività letteraria alla reprobatio delle tesi antidottrinali giungendo a partecipare con posizioni antiaverroistiche al Concilio di Vienne del 1311-1312, ovvero negli stessi anni in cui Francesco da Barberino si accingeva alla stesura dei Documenti. ${ }^{115}$ Il dibattito generato dalle 219 tesi di Tempier, ben vivo anche nel secolo successivo, portò a un'estrema diffusione del Sillabo approntato dal vescovo parigino, con il quale si intendeva colpire non solo quanto professato nella Faculté des Arts, ma anche la condotta libertina invalsa tra gli studenti e il generale traviamento dei costumi. ${ }^{116}$ Panzera ha recentemente avanzato l'ipotesi che il Barberino agisca con prudenza nei Documenti per non incorrere in accuse di eterodossia, specialmente perché l'allegoria dell'amore ivi proposta sarebbe potenzialmente assimilabile a quella del Cappellano; ${ }^{117}$ mi sembra tuttavia eccessivo riscontrare nei Documenti simili cautele, e a maggior ragione se si considera che la carriera di notaio episcopale e inquisitore dei francescani poteva già di per sé condurre il valdelsano su posizioni avverse all'aristotelismo radicale, anche al di là dal veto imposto dalle proposizioni di Tempier. ${ }^{118}$

114 La difesa del libero arbitrio in contrasto con il determinismo astrale e con l'influenza delle sfere celesti è uno degli argomenti principali anche della Declaratio Raimundi per modum dialogi edita, in cui Llull nega tuttavia anche l'unicità dell'intelletto, al fine di marcarne ulteriormente la libertà. Cfr. Lulle et la condamnation de 1277, Introduction, pp. XXX-XXXII. Per il testo della Declaratio si veda CCCM, vol. LXXIX, pp. 219-402, in particolare i capitoli 74, 112, 142-143, 170, 207-207.

115 Si veda Bonafede, La condanna di Stefano Tempier. Sulle accuse di eresia a Llull e sulla controversia con Eymerich cfr. Perarnau i Espelt, De Ramon Llull a Nicolau Eymerich; Spruit, Llull, Ramon.

116 L'inserimento della letteratura cortese nell'Epistola del Tempier rivela «la dépravation des moeurs qui sévit dans les milieux universitaires. Il confirme donc que de profonds désordres moraux et disciplinaires allaient de pair avec les troubles doctrinaux auxquels le syllabus a tenté de porter remède» (Hissette, Enquête sur les 219 articles, p. 14). Sulla questione si vedano anche Bianchi, Il vescovo e i filosofi, pp. 21-22 e p. 153; La condamnation parisienne, pp. 231-236).

117 Secondo Panzera, Francesco da Barberino tra Andrea Cappellano e Averroè, pp. 150-151 la condanna del De Amore da parte di Tempier avrebbe influito anche sulla stessa divulgazione dei Documenti da parte dell'autore. Gli esempi delle premure dottrinali risiederebbero nell'impiego delle fonti (cfr. ivi, p. 125) e sarebbero evidenti fin dal Proemio, dove l'autore rassicura sulla correttezza dottrinale del libro (come ad esempio in Doc. Am., Prohemium, De dubiis que possunt insurgere super Ecclesiaste libro in variis [vol. I, p. 37]). Ma si vedano le puntualizzazioni di Montefusco, Recensione a Panzera, pp. 397-398.

118 Va rilevato che i lacerti dello Stagirita e dei suoi commentatori ma anche altri brani inclusi nella lista di frate Alberico erano stati ampiamente discussi da Tommaso d'Aquino il cui pen- 
Francesco da Barberino seleziona tra gli argomenti della predicazione di Alberico non le tesi averroistiche contro l'immortalità dell'anima, che avrebbero imposto al frate una confutazione totalmente incentrata su questioni teoretiche, bensì quei passi che approcciano la conoscenza delle cose future, come dimostrano la presenza di Avicenna e gli accenni al determinismo puro di Alkindi e Rabi Moisis Maimonide ${ }^{119}$ e che, per questo motivo, potevano presentare dei risvolti pratici sia mediante le differenti tecniche divinatorie, sia a livello procedurale, con riferimento all'attività inquisitoriale. La pregnanza di quest'ultima applicazione è testimoniata dal fatto che il compendio di errori discussi da frate Alberico rappresenta una tappa intermedia tra le proposizioni di Tempier e gli errori poi confluiti nelle più note compilazioni manualistiche ad uso degli inquisitori, ovvero il Directorium Inquisitorum di Nicolau Eymerich e il Malleus maleficarum di Heinrich Institor Kramer, entrambe di ambiente domenicano. ${ }^{120}$ La glossa dei Documenti, in sostanza, testimonia come il vivissimo dibattito me-

siero, pur non essendo il principale bersaglio di Tempier, venne ritenuto in continuità con alcune proposizioni del Sillabo e fu sottoposto a uno stretto revisionismo specialmente negli ambienti minoritici. Si vedano in particolare il lacerto «quod nullo modo duo corpora possunt esse in eodem loco» sembra molto vicino al commento di Simplicio alle Categorie di Aristotele, per il quale si veda Simplicius, Commentaire sur les Catégories d'Aristote (in CLCAG, vol. 5, p. 587, 82-93), ma il brano sulla compresenza di due corpi nel medesimo luogo potrebbe anche derivare dal commento di Themistius al De anima, per il quale cfr. Thémistius, Commentaire sur le traité de l'âme d'Aristote, liber II (in CLCAG, vol. 1). Per quanto riguarda Tommaso si vedano almeno Tommaso d'Aquino, Summa theologiae, Ia, q. 52, a. 3 (vol. V, pp. 28-29); Ia, q. 105, a. 2 (vol. V, pp. 472-473); Ia, q. 14, a. 11 (vol. IV, pp. 183-184); Ia, q. 78, a. 4 (vol. V, pp. 255-257); De Veritate, q. 12, a. 3 (vol. XXII, 2/1, pp. 373-380). Sulle correzioni di Tommaso cfr. Bianchi, Il vescovo e i filosofi, pp. 27-29.

119 Tommaso d'Aquino dedica alla disquisizione sulla natura e la validità delle profezie una consistente dimostrazione in Summa Theolologiae, IIa, IIae, q. 171 (vol. X, pp. 365-376).

120 Nella sezione del Directorium Inquisitorum denominata De erroris philosophorum priscorum confluiscono quasi tutte le citazioni riportate nella glossa dei Documenti d'Amore, opportunamente differenziate per autore. In particolare: l'errore aristotelico «quod non sit possibilis resurrectio mortuorum» è a p. 238, n. 9; i due errori di Avicenna si trovano rispettivamente a p. 239, n. 11 e n. 16; le citazioni di Alkindi sono riferite a p. 240, n. 1 e 2; i brani di Rabbi Moises confluiscono a p. 240, n. 3 e 4 e a p. 241, n. 7 (faccio riferimento all'edizione F. Nicolai Eymerici ordinis praedicatorum, Directorium Inquisitorum). Relativamente al Malleus maleficarum, ho riscontrato la confutazione dell'errore aristotelico «quod nullo modo duo corpora possunt esse in eodem loco» in p. I, q. X, 60A, p. 322, che tuttavia riproduce Tommaso d'Aquino, De Malo, q. 16, a. 11, arg. 9 (t. XXIII, p. 329); e il primo errore di Avicenna in p. I, q. II, 14C, p. 231: «Multotiens autem anima operatur in corpore alieno, sicut in proprio, quemadmodum est opus oculi fascinantis et estimationis operantis» (l'edizione di riferimento è Heinrich Institoris, Jacobus Sprenger, Malleus Maleficarum). Per la discussione sulla paternità del trattato rinvio a Di Simplicio, Malleus maleficarum. 
dievale sull'eredità del pensiero aristotelico e sulla divinazione sia penetrato attraverso sillogi e compendi nei vari livelli di cultura, e quindi ben al di là degli ambienti accademici ed ecclesiastici parigini, dalla predicazione popolare, a sua volta riversatasi nella glossa giuridico-letteraria dei Documenti, per poi acquisire risvolti procedurali nei manuali inquisitoriali. In tal senso il punto di vista del Barberino appare per certi versi radicale: se infatti la confutazione di errori filosofici non era adatta alle folle accorse a Domodossola per assistere ai sermones di frate Alberico, essa sarebbe stata maggiormente in sintonia con i lettori della glossa latina dei Documenti. L'interesse del valdelsano è però tutto rivolto alla discrepanza tra discorso sottile e pubblico rude, un problema che rende l'expositio difatti inutile («et multos istorum et aliorum qui erraverunt errores recitabat et inutiliter explicabat»), vanificando al contempo tutto l'impianto dell'orazione, dall'inventio all'actio. In questo senso credo che le chiose barberiniane non intendano tanto puntare il dito contro gli errori comunicativi di frate Alberico né contro l'ignoranza degli uditori, ${ }^{121}$ quanto costringere a una riflessione sulla necessità di rendere il sapere accessibile e intelligibile anche a livello popolare e al di fuori degli studia, moderando tuttavia la curiositas affinché l'ermeneutica non corrisponda alla ybris, una tematica a cui l'autore affida la chiusa dell'intera opera. In questo tentativo di allargamento del pubblico e di 'democratizzazione' delle conoscenze si riconoscono gli effetti dell'insegnamento retorico del Brunetto volgarizzatore sulla Firenze duecentesca, vivi a distanza di qualche decennio negli scritti valdelsano il quale, essendo legato sia al milieu ecclesiastico, a cui la predicazione va ricondotta, che a quello cittadino, operava in un fervido ambiente intellettuale nelle doppie vesti di notaio e poeta proprio come il Latini. ${ }^{122}$

Resta da chiarire, infine, la coerenza interna delle posizioni espresse dal Barberino, che sembra rigettare la possibilità dell'oraculum nei versi volgari, per poi ammettere nella glossa, con Avicenna e mediante l'apologo del soldato Solernio, che alcuni sogni siano rivelatori della veritas. Ulteriormente ambiguo è l'atteggiamento nei confronti dello stesso Avicenna, autore la cui onirologia viene inizialmente contrapposta a quella di Aristotele, ma che viene poi incluso nella lista dei

121 Quest'ultima è la tesi accennata da Antognoni, Un contemporaneo di Dante, p. 78.

$122 \mathrm{Su}$ questa straordinaria stagione intellettuale rimando al fondamentale saggio di Coccia, Piron, Poésie, sciences et politique; per Francesco e Brunetto si veda ancora Montefusco, Bischetti, Prime osservazioni. Mi pare emblematica anche la collaborazione del Barberino con un altro poeta-notaio come Lapo Gianni, attestata da alcune pergamene fiorentine e, soprattutto, dal registro delle imbreviature di Lapo (AsFi, Notarile Antecosimiano 11484), in cui entrambi compaiono spesso in documenti attigui. Cfr. Azzetta, Tra gli amici e cultori di Dante; Marchesini, Tre pergamene autografe. 
filosofi oggetto della reprobatio di frate Alberico per le posizioni in merito alla «prophetia naturalis». L'apparente contraddizione può essere forse risolta ricorrendo a Cicerone e a Tommaso d'Aquino. Nel De divinatione, infatti, Cicerone espone la suddivisione dei metodi divinatori in due distinte categorie, rigettandole entrambe: la 'divinazione artificiale', basata sull'impiego di pratiche fortemente standardizzate come quelle degli indovini, e la 'divinazione naturale', in cui l'anima riceve la predizione del futuro in maniera immediata e sotto impulsi sganciati dal vincolo corporeo, come ad esempio durante il sogno. ${ }^{123}$ Nella prima categoria vengono quindi incluse la geomanzia, gli auspici e gli auguri, ovvero tutte quelle tecniche sconfessate dal Barberino su base canonistica in Doc. Am., I, sub Docilitate, doc. XxIV, ma anche l'astrologia, considerata da Cicerone mera superstizione al pari delle altre pratiche per la predizione del futuro.

Tommaso sembra affrontare il problema assumendo una posizione intermedia tra la condanna assoluta della divinazione naturale e la sua legittimazione come oracolo divino: all'interno delle Quaestiones, pur prendendo le distanze dalle tesi avicenniane, ${ }^{124}$ egli situa la profezia naturale a metà tra sogno premonitore, considerato un caso particolare della prima, e profezia divina. ${ }^{125}$ Nel dimostrare tale tesi, egli aveva inoltre associato la prescienza del futuro alla predizione medica e astrologica, operando dunque una netta differenziazione tra tali discipline:

Fuit igitur quorundam opinio quod prophetia esset naturalis primo modo quia dicebant «animam habere in se ipsa quandam vim divinationis», ut Augustinus narrat XII Super Genesim ad litteram; sed hoc ipse ibidem improbat quia si hoc esset, tunc in potestate sua haberet anima quandocumque vellet futura praecognoscere, quod manifeste apparet esse falsum. Et praeterea hoc apparet esse falsum quia natura mentis humanae nullius cognitionis naturaliter potest esse principium in quae non possit pervenire per principia per se nota quae sunt prima instrumenta intellectus agentis, ex quibus principiis in cognitionem

123 Si veda Cicerone, De divinatione, I, LVI-LVII.

124 Cfr. Tommaso d'Aquino, De Veritate, q. 12, a. 3, arg. 9 (t. XXII, 2/1, p. 374): «Praeterea, ad prophetiam non requiruntur nisi tria; scilicet claritas intelligentiae, et perfectio virtutis imaginativae et potestas animae, ut ei materia exterior oboediat, ut Avicenna ponit in VI De Naturalibus; sed haec tria possunt accidere naturaliter; ergo naturaliter potest aliquis propheta esse», e la confutazione di tale tesi in De Veritate, q. 12, a. 3, ad. 9 (t. XXII, 2/1, pp. 378-379): «Ad nonum dicendum quod illorum trium unum non potest naturaliter animae competere, ut scilicet sit tantae virtutis quod ei materia exterior subdatur, cum etiam nec ipsis angelis ad nutum deserviat materia corporalis, ut Augustinus dicit; et sic in hoc non est sustinendum dictum Avicennae, vel cuiuslibet alterius philosophi. Ex aliis vero duobus quae tangit obiectio, secundum quod naturaliter homini proveniunt, causatur prophetia naturalis, non illa de qua loquimur».

125 «Et sic patet quod prophetia naturalis media est inter somnium et prophetiam divinam; unde et somnium dicitur esse pars vel casus prophetiae naturalis, sicut et prophetia naturalis est quaedam deficiens similitudo prophetiae divinae» (Tommaso d'Aquino, De Veritate, q. 12, a. 3, co. [t. XXII, 2/1, p. 377]). 
futurorum contingentium perveniri non potest nisi forte per inspectionem aliquorum signorum naturalium, sicut medicus praecognoscit sanitatem vel mortem futuram et astrologus tempestatem futuram vel serenitatem; talis autem futurorum praecognitio non dicitur esse divinationis vel prophetiae sed magis artis. ${ }^{126}$

Il brano dell'Aquinate mostra non una sconfessione del determinismo medico e astrologico, ${ }^{127}$ bensì un suo ridimensionamento disciplinare: inquadrare la medicina e l'astrologia come artes, ovvero pratiche derivanti dallo studio dei fenomeni naturali e fortemente connesse nelle metodologie e negli intenti, ${ }^{128}$ equivale a concedere loro una dignità scientifica rifiutandone, al contempo, qualsiasi valore metafisico, in contrasto dunque con le posizioni ciceroniane che volevano l'astrologia assimilata alla superstizione. Tale approccio pare essere in sintonia con la complessa trattazione dei Documenti, dove la presenza di Cicerone è costante, come ad esempio nella definizione della prudentia-previdentia; tuttavia, le tesi de De divinatione sono accolte solo per quanto riguarda aruspicina, oracoli e auguri, mostrando segni di apertura sia nei confronti dell'oniromanzia, sia in riferimento all'astrologia, come vedremo a breve. L'influsso dell'Aquinate potrebbe inoltre essere comprovato anche dal fatto che tra le uniche tre menzioni esplicite nei Documenti una riguarda proprio l'impiego della medicina. Nella prima parte precettistica sub Docilitate il valdelsano si rivolge infatti ai servitori, i quali non dovrebbero dispensare consigli medici durante la somministrazione dei pasti al proprio signore, configurando nuovamente le discipline e o artes scientifiche nel segno delle norme di conversazione. ${ }^{129}$ Infine, nella lista di auctoritates abbondantemente analizzate per Doc. Am., II, sub Industria, doc. v, reg. XCII Francesco parte dalla riflessione sul sogno divinatore come veritas per approdare a un'autocitazione della sezione sub Prudentia, una sezione dei Documenti in cui egli affronta più nel dettaglio questioni di determinismo, specialmente riguardo al legame tra disposizione astrale e preveggenza. Tale richiamo lega difatti l'oniromanzia che si avvaleva del sapere co-

126 Tommaso d'Aquino, De Veritate, q. 12, a. 3, co (t. XXII, 2/1, pp. 375-376).

127 Si noti infatti che poco oltre Tommaso risponde alle obiezioni contro l'astrologia ribadendone i fondamenti, ovvero il legame tra corpi celesti e condizione umana (Tommaso d'Aquino, De Veritate, q. 12, a. 3, ad. 7, [t. XXII, 2/1, p. 378]).

128 D'altronde il legame tra medicina e astrologia attraversa l'antichità e il Medioevo e trova riscontro anche nella cultura dell'estremo oriente, con risvolti di vario tipo. A questo proposito rimando alla bella raccolta di interventi contenuta in Astro-Medicine. Astrology and Medicine.

129 Il testo volgare recita: «Dispiàcemi chi serva / parlar di medico a signor servendo: / se non forse ubidendo, / quand'esso l'à da .llui in mandamento» (Doc. Am., I, sub Docilitate, doc. XxII, vv. 1313-1316 [vol. I, p. 266]), versi così commentati nella glossa: «Isto medico indigerent ad mensam aliqui cogitantes ad alia commedendo qui sepissime quantum vel quid commederint non attendunt, in quod dicitur frater Thomas de Aquino sepius incidisse: non enim ad ciborum delectationem cogitabat» (ivi, v. 1315 [vol. I, p. 266]). Si noti inoltre che l'impiego della medi- 
smologico a una generale possibilità che l'astrologia possa essere intesa come ars funzionale all'interpretazione di categorie di segni e fenomeni. Anche riguardo a tali questioni non è rintracciabile nei Documenti una condanna in assoluto del determinismo e dell'astrologia giudiziaria, una disciplina per la quale l'attività e il pubblico dei predicatori rivestono un ruolo chiave costituendo a loro volta un ulteriore livello ermeneutico delle artes.

\section{L'astrologia giudiziaria: l'ars della sottigliezza}

I primi accenni al rapporto tra astrologia e interpretazione dei sogni mediante il ricorso al De anima di Avicenna sono quindi lo spunto per una trattazione più esaustiva riguardo all'attività degli astrologi nel proemio della settima parte dei Documenti. Anche in questo caso, come si è osservato per l'oniromanzia, scompaiono completamente i richiami al Decretum di Graziano sulla predizione degli avvenimenti futuri, sostituiti dalla descrizione allegorica dell'immagine di Prudenza, la quale «guarda in una spera / per dimostrar che vera / maniera è di tenere / denançi provedere». ${ }^{130} \mathrm{Al}$ testo viene affiancata una raffigurazione della virtù che presiede a questa sesta parte dei Documenti, divisa verticalmente in due sezioni affrontate, ma che presentano alcune discrepanze nei due testimoni manoscritti dell'opera. In entrambi, tuttavia, Prudenza viene collocata sul lato sinistro e ritratta come una donna di trent'anni, in abito verde e in posizione seduta che si porta la mano sul capo per riparare gli occhi dalla luce mentre osserva le sfere celesti, che costituiscono la metà destra della miniatura (Figg. 12 e 20). ${ }^{131} \mathrm{Al}$ di sotto delle sfere concentriche viene aggiunta una breve ekphrasis nella quale è riassunto l'ordinamento dei pianeti dalla cosmologia egizia fino agli stessi $\mathrm{Docu}$ menti. Anche la didascalia, come le miniature, differisce lievemente nei due testimoni dell'opera:

Barb. lat. 4076, c. 69v: «Egiptii quos secutus est Plato sic posuerunt ordinem planetarum: nam dixerunt Solem statim esse post Lunam, supra eum Mercurium et supra Mercurium Venerem. Caldei, quos secutus est Tullius, et comuniter astrologi posuerunt ut in alia figura que est infra rationes moventes utrosque ponuntur in glosis».

cina verrà discusso nella VII parte sotto il magistero di Prudenza, nel doc. xV, ovvero in una sezione dei Documenti in cui trova ugualmente spazio la trattazione astrologica.

130 Doc. Am., VII, sub Prudentia, Proemio, vv. 4220-4223 (vol. III, pp. 44-45).

131 Cfr. Egidi, Le miniature dei codici barberiniani, pp. 82-83; sui notevoli scarti tra l'illustrazione di tale allegoria nei due testimoni dei Documenti si veda Nardi, Le illustrazioni dei 'Documenti d'amore', pp. 83-85. 
Barb. lat. 4077, c. 58v: «Egiptii quos secutus est Plato sic posuerunt ordinem planetarum, ut in hac presenti figura Caldei autem, quos secutus est Tullius, et comuniter omnes ut in figura inferiori rationes moventes, utrosque videbis in glosis prohemii partis huius». ${ }^{132}$

A prescindere dalle proposte sulla datazione dei due codici e sulla loro successione temporale, ${ }^{133}$ ciò che qui ci interessa notare sono le integrazioni apportate nel Barb. lat. 4076, non «un codice d'archivio o un brogliaccio, ma il codice originale definitivo dell'opera», ${ }^{134}$ dove appunto l'immagine dei cieli viene descritta anche in riferimento all'opinione degli astrologi, assenti nell'iscrizione del Barb. lat. 4077 ma accostati a Cicerone nel testimone completo. In entrambi i casi, inoltre, si rinvia a un'altra figura posta più avanti nell'opera, ovvero la dettagliata rappresentazione della Circumspectio (Barb. lat. 4076, c. 101r), in cui al centro tra le sfere concentriche che contengono i cieli e quelle che rappresentano la dimensione oltremondana viene posta una donna nell'atto di osservare l'intero cosmo, dai cui occhi si diramano due tubi che abbracciano Inferno, Purgatorio e Limbo e si congiungono nella parte inferiore del cerchio, sul modello della sirena dalla coda biforcata che allegoricamente rappresentava l'Eternità. ${ }^{135}$ Come ha recentemente rilevato Ciccuto, la figura della Circumspectio è un'immagine che testimonia la visualità del realismo giottesco, come è evidente dalla simile raffigurazione di tale allegoria della Cappella degli Scrovegni di Padova. ${ }^{136}$ Essa, inoltre, «ci fa intendere che la cultura visuale, la figuratività, l'uso delle immagini, delle figure con pari dignità significante a ridosso delle partiture verbali si sono radicati sull'orizzonte culturale del primo '300 nella declinazione del primato della pittura per scientiam et cognitionem», ${ }^{137}$ un'iconografia che si fonde con quella della Prudentia non solo nei Documenti, ma anche nel Reggimento, ${ }^{138}$ testimoniando la necessità di dare corpo visivamente all'idea della preveggenza e l'evoluzione delle forme artistiche dalla pittura giottesca fino alle miniature barberiniane. ${ }^{139}$

132 Per il testo di entrambe faccio riferimento all'edizione dei Documenti curata da Egidi, vol. IV, p. 94, n. 16 e nota 8, modificandone tuttavia le grafie e la punteggiatura secondo l'uso moderno. Si noti che l'iscrizione del Barb. lat. 4077 era anche in Egidi, Le miniature dei codici barberiniani, p. 83.

133 Per la bibliografia sulla questione rimando alle note 26 e 89 di questo contributo.

134 Petrucci, Minima barberina, p. 1009.

135 Cfr. Egidi, Le miniature dei codici barberiniani, p. 83.

136 Per un raffronto con la raffigurazione della Prudenza in Giotto si veda Frojmovič, Giotto's Circumspection, pp. 205-206.

137 Ciccuto, Francesco da Barberino: un pioniere del Bildercodex, p. 90. Ma su tale raffigurazione si veda ancora Frojmovič, Giotto's Circumspection, pp. 195-210.

138 Cfr. Regg., XX, p. 217.

139 Cfr. Frojmovič, Giotto's Circumspection, p. 201. 
Nella descrizione di Prudentia è evidente la crescente commistione tra oniromanzia e sapere cosmologico, tra ars coniectoris e astrologia, discipline che hanno l'uguale compito di decifrare i signa di cui è intessuta la realtà. ${ }^{140}$ Tale associazione era già presente in Tolomeo e diverrà preponderante negli scritti di Alberto Magno e Michele Scoto, in cui trova espressione la tecnica araba di interpretazione dei sogni; ${ }^{141}$ nei Documenti, tuttavia, l'autore si appoggia a una serie di auctoritates classiche e patristiche, per poi pervenire alle formulazioni di Boezio, Macrobio e Albertano da Brescia. Come ha evidenziato Marruzzo, per definire il sistema di virtù dei Documenti Francesco da Barberino si serve principalmente di due opere, ovvero il Moralium dogma philosophorum attribuito a Guglielmo di Conches e il De virtutibus et de vitiis et de donis Spiritus Sancti di Alano di Lilla. ${ }^{142}$ Le recenti ricerche di Panzera hanno inoltre permesso di inserire il Breviloquium de virtutibus antiquorum principum et philosophorum del predicatore francescano Giovanni di Galles, a sua volta dipendente dai Moralium dogma, tra i punti di riferimento di numerose sezioni della glossa barberiniana, e infatti si nota che alcune delle citazioni inserite dall'autore nel proemio sono tratte proprio da questa compilazione, fortemente connotata da un punto di vista politico, da cui il valdelsano estrae quasi esclusivamente i lacerti di autori classici, che costituiscono di gran lunga il principale modello del Gallese. ${ }^{143} \mathrm{Se}$ dunque appare significativo che il Barberino attinga a piene mani da un compendio di exempla messo a punto da un predicatore francescano, è ugualmente sintomatica l'opera di rielaborazione a cui tali brani vengono sottoposti. Trat-

140 «Fra gli eventi del mondo sublunare e i sogni si stabilisce un rapporto speculare una volta ricondotti agli stessi principi: di qui la stretta connessione fra astrologia e oniromanzia, perché l'una legge negli astri i destini dell'uomo e del cosmo che l'altra ritrova nelle cifre e nelle metafore delle fantasie oniriche» (Gregory, I sogni e gli astri, p. 135).

141 Oltre al saggio appena citato di Gregory si vedano Caroti, L'astrologia; Federici Vescovini, Medioevo magico, pp. 225-275.

142 Alano di Lilla è inoltre menzionato nella glossa ben sedici volte, venendo dunque a rappresentare un'auctoritas di sicuro pregio agli occhi dell'autore (cfr. Marruzzo, Composizione e significato de «I Documenti d'amore», p. 226). Riguardo al Moralium dogma philosophorum credo sia essenziale sottolineare che esso è fonte prediletta anche per la descrizione della prudenza di Albertano da Brescia, a cui lo stesso Barberino rinvia glossando il v. 4206. Cfr. Hiltz, De amore et dilectione Dei, pp. 268-270. Per il testo di Alano di Lilla si veda Lottin, Le Traité d'Alain de Lille.

143 Cfr. Panzera, Francesco da Barberino tra Andrea Cappellano e Averroè, pp. 124-130. In particolare, sono affini alla Summa di Giovanni di Galles il brano ciceroniano che apre il proemio («Prudentia est rerum bonarum et malarum neutrarumque scientia etc.»), presente nella Summa alla c. CCVIr, cap. 3, nonché l'intera sezione contentente le citazioni di Macrobio (da «prudentie insunt ratio» a «consilio premunire»), che si rifà a c. CCVIIIr, cap. 6. Per l'edizione del Breviloquium faccio riferimento a Summa Iohannis Valensis (il Breviloquium è alle cc. 200v-217r). Sulla preponderanza delle fonti classiche nel Breviloquium si veda Swanson, John of Wales, pp. 59-62. 
tando della prudenza la Summa del Gallese non maschera l'intenzione di attribuirle risvolti politici, intendendola come capacità di comprendere e anticipare gli avvenimenti futuri e di indirizzare in tal modo l'azione dei governanti; ${ }^{144}$ ad essa fa da contrappeso la commistione tra immagini e glossa dei Documenti, che porta a intendere la stessa prudenza come ars che si avvale della cosmologia, e viene quindi assimilata alla previdentia. Tale idea è veicolata non solo dalla selezione di fonti invocate o sottese alla glossa barberiniana, ma anche dalle annotazioni linguistiche ed etimologiche che connotano prudentia e previdentia, trasponendo l'atto della visione su un piano metaforico e intendendolo come capacità di scrutare gli eventi futuri:

Prudentia est per quam preterita, si male sunt acta corrigimus presentia, ordinate dirigimus et in futurorum cautelam actenter ac vigilanter inspicimus et vigilantes tuemur. Unde autem dicatur, dic breviter quod prudens videns componitur cum porro et dicitur prudens quasi porro, idest longe videns futura, usu doctus, calidus exercitatione, artis instructus, considerator. Facundus, qui facile fari potest, ut in Catholicon: a prudente igitur tolle prudentiam. ${ }^{145}$

L'idea che gli avvenimenti subiscano l'influsso astrale e che la loro previsione possa essere effettuata mediante la tecnica diviene palese nelle sezioni successive della glossa, che integrano quanto già accennato nella didascalia della miniatura. L'operato degli astrologi è infatti menzionato quasi parafrasando quanto sostenuto nell'ekphrasis, prima di cedere il passo a una digressione puramente cosmologica sulla conformazione delle sfere, che Francesco da Barberino trae dal De philosophia mundi di Guglielmo di Conches:

Ut notetur quod optime doctrina in custodiendis quesitis est in futura conspicere unde ad similitudinem astrologorum qui nituntur ad vicenda futura ipsa in superiora vertit oculos suos. Sed quia Egitii, quos secutus est Plato, sic posuerunt, ut in superioribus circulus figuratur eo quod dixerunt solem statim esse post Lunam, supra eum Mercurium et supra Mercurium Venerem. Et Caldei quos secutus est Tullius posuerunt post Lunam Mercurius, supra eum Venerem, supra Venerem Solem. Ecce quod secundum istorum ultimorum oppinionem figuram hanc tibi seu speram aliam represento, ut ex ipsis duabus superiori vi-

144 «It is clear from the very title of the work that he was interested in rulers and philosophers, and the text shows that he knew a considerable amount about the ancient world. He tells his stories for a moral purpose; he is not acting as a historian and makes no attempt to criticise his material» (Swanson, John of Wales, p. 46).

145 Doc. Am., VII, sub Prudentia, Prohemium (vol. III, p. 43). Secondo Marruzzo tale definizione sarebbe dipendente da Cicerone, De inventione, II, 53, 160, che tuttavia è la fonte non di questo brano nello specifico ma della definizione trascritta come dipendente dal secondo libro della Retorica ciceroniana all'inizio del Proemio. Cfr. Marruzzo, Composizione e significato de «I Documenti d'amore», pp. 236-237. 
delicet et presenti quam malueris eligas causas autem que moverunt utrosque ante quam ad expositionem sequentium descendamus adducam. ${ }^{146}$

In questo caso l'allegoria femminile di Prudentia osserva le sfere celesti esattamente come fanno gli astrologi, che si rivolgono alle stelle per trovarvi segni mediante i quali interpretare il futuro. Rispetto alle proposizioni astrologiche che rientravano nell'ambito degli errori filosofici qui la prospettiva appare rovesciata, prevedendo un'apertura nei confronti di tale disciplina, del tutto distante dalle pratiche magiche e oracolari che appartenevano al novero della divinazione artificiale. Le posizioni del valdelsano in merito furono già ben comprese dall'Ubaldini: nella Tavola che chiude l'edizione dei Documenti del 1640 questi infatti sottolineava l'ostilità del Barberino nei confronti dell'astrologia «vietata di predicarsi, riguardando non tanto la giudiciaria, quanto le vane quistioni», ${ }^{147}$ ovvero le sottigliezze impiegate dai predicatori per fare presa sull'uditorio. A supporto delle sue tesi il segretario pontificio citava Par. XXIX, 94-105 (erroneamente indicato come Purg. XXIX), ${ }^{148}$ ovvero i versi danteschi che criticano coloro che divulgano favole e falsità forzando l'interpretazione della Scrittura e arrecando danno e traviamento presso gli incolti, ${ }^{149}$ contro i

146 Doc. Am., VII, sub Prudentia, Prohemium, v. 4220 (vol. III, p. 44). Segnalo per precisione che prima di vicenda il manoscritto espunge superiora (Barb. lat. 4076, c. 69vb), come regolarmente segnalato da Egidi. Per quanto riguarda il testo citato Albertazzi, lo rintraccia in Guglielmo di Conches, De philosophia mundi, II, 23-24.

147 Ubaldini, Tavola, in Id., Documenti d'amore, s.v. Astrologia.

148 «Per apparer ciascun s'ingegna e face / sue invenzioni; e quelle son trascorse / da' predicanti e 'l Vangelio si tace. / Un dice che la luna si ritorse / ne la passion di Cristo e s'interpuose, / per che 'l lume del sol giù non si porse; / e mente, ché la luce si nascose / da sé: però a li Spani e a l'Indi / come a' Giudei tale eclissi rispuose. / Non ha Fiorenza tanti Lapi e Bindi / quante sì fatte favole per anno / in pergamo si gridan quinci e quindi» (Par. XXIX, 94-105).

$149 \mathrm{Si}$ veda ad esempio l'interpretazione dell'Ottimo: «Qui l'Autore riprende li predicanti moderni, che ignorano e dispregiano la Santa Evangelica Scrittura e, a malatioso intento favoleggiando e trovando dubbi e gavillationi, per li quali credono essere stimati dal volgo sapientissimi; e solo a questo fine fanno tali invenzioni. E quando dicono queste favole, ridono le persone, e questi gonfiano il cappuccio e spurgansi; quasi dicano: "io sono una saputa persona”. Altri mostrano di sapere lo corso de' cieli, dicendo come la Luna nella passione di Cristo, ch'era quintadecia, sì si venne ad interporsi linealmente al Sole di subito; per la quale interpositione il lume del Sole non venne giuso, sì che fu eclissi e alli spagnuoli e alli indi e alli giudei, che stanno a questi due stremi per meza regione. La quale positione, per lo modo ch'eglino favoleggiano, non è vera, però ch'è impossibile che la Luna in uno stante corresse sei segnali. [. . .] Onde sì fatte inventioni non solo dannificano li uditori in perdere tempo, ma eziandio diminuisce la fede e quella gratia della quale il principale Padre non ha voluto essere scarso. Per la quale colpa, l'autore mette quelli predicanti in compagnia di quello maledetto uccello che per superbia cadde di cielo» (Par. XXIX, 94, in Ottimo commento, vol. III, p. 1838). 
quali Dante inveisce facendo riferimento proprio alla predicazione («Non disse Cristo al suo primo convento: / 'Andate, e predicate al mondo ciance'», Par. XXIX, 110-111). Il passo dei Documenti richiamato dall’Ubaldini propone alcune riflessioni precettistiche sulla maniera in cui i predicatori devono modulare $\mathrm{i}$ contenuti delle proprie orazioni in base all'uditorio:

\author{
E pon[i] predicatori \\ ta[gl]i, che .ll'ovra gli onori, \\ ché mal predic'a gente \\ che è per sé nocente. \\ $\mathrm{E}$ costor dèn pensare \\ di non mai predicare \\ a pompe o vanagloria, \\ se voglion di ciò gloria. \\ Né già d'astrologia \\ predicar alchun dìa, \\ dov'è grossi auditori: \\ che per lor son migliori \\ le cose piane e grosse, \\ per chui sol Dio le mosse. \\ Così per simigliança \\ togli d'ongni sottilgliança, \\ ma tra sottigli poranno \\ usar quel che savranno. ${ }^{150}$
}

Nei versi si richiama l'idea delle orazioni costruite «a pompe o vanagloria», in cui il primo termine, come si è visto precedentemente per Doc. Am., I, sub Docilitate, doc. XXIII, v. 1437, traduce l'idea di grosseggiare, rimarcata anche dal riferimento ai «grossi auditori» - i rudes auditores dell'autotraduzione - identificabili idealmente con il pubblico delle orazioni di Alberico della Caprafica. Secondo Francesco l'astrologia sarebbe quindi sconsigliata tra coloro che sono privi di ingegno, per i quali sarebbero più appropriati discorsi privi di 'sottigliezze' interpretative: la pratica di tale disciplina viene allora inquadrata non come arte divinatoria, ma nella sua portata verbale e performativa. Ne risulta una prevalenza della funzione dell'actio a discapito dell'inventio, da cui conseguentemente si deduce che le insidie della predicazione astrologica risiederebbero non tanto nelle prescrizioni giuridiche che ne limitavano le applicazioni e che ne screditavano la materia, quanto piuttosto nella sua trasformazione in discorso divulgativo. A conferma di ciò con-

150 Doc. Am., VII, sub Prudentia, doc. XI, vv. 5778-5795 (vol. III, pp. 205-206). 
corre la glossa latina, in cui le fonti giuridiche e dottrinali vengono chiamate in causa per disciplinare l'operato dei predicatori:

Nam: «Inter cetera, que ad salute spectant populi Christiani, pabulum verbi Dei permaxime sibi noscitur necessarium, quia, sicut corpus materiali, sic anima spirituali cibo nutritur, eo quod "Non in solo pane vivit homo, sed in omni verbo, quod procedit ex ore Dei” (Extra, "De officio ordinarii”, capitulo "Inter cetera”). ${ }^{151}$

La chiosa riproduce l'incipit di una decretale dal Liber extra di Gregorio IX, una raccolta che simboleggia non solo la maturità del diritto canonico dopo la svolta di Graziano, ma anche le mutate condizioni sociali in cui la Chiesa operava nel XIII secolo e che rendevano necessarie nuove norme tra cui, appunto, quelle aventi come oggetto la predicazione. ${ }^{152} \mathrm{Nel}$ brano è riconoscibile il celebre versetto del Vangelo di Matteo in cui si associano pane terreno e celeste, ovvero il nutrimento spirituale costituito dalla Scrittura. Si tratta di un luogo cruciale per tutta la classificazione del peccato di gola nel Medioevo in quanto attraverso la bocca passano il sostentamento fisiologico e quello spirituale: pertanto, l'assenza di moderazione in entrambi i casi è artefice sia del peccatum oris, sia del peccatum linguae, ed è a questa voluta ambiguità che il Barberino fa riferimento nella precettistica rivolta agli oratori. ${ }^{153}$ La decretale del Liber extra, infatti, disciplina proprio la necessità di offrire una pubblica esegesi della parola divina e la possibilità per i vescovi che siano impossibilitati ad adempiere a tale compito per impedimenti di vario tipo di ricorrere a dei supplenti, affinché ai fedeli sia garantita un'adeguata e costante esposizione della Scrittura. ${ }^{154}$

Nella chiosa ai versi sull'astrologia giudiziaria è rilevante che Francesco da Barberino non abbia interesse a stabilire i limiti del determinismo astrologico il quale, come abbiamo visto, era stato bersaglio delle condanne inquisitoriali di Tempier e presentava problemi anche a livello dottrinale, al punto da dover essere disciplinato nel Decretum. L'apertura nei confronti dell'astrologia dimostra

151 Doc. Am., VII, sub Prudentia, doc. XI, v. 5778 (vol. III, pp. 210-211). La punteggiatura è stata ritoccata rispetto all'edizione di Albertazzi, seguendo Barb. lat. 4076, c. 82ra.

152 Corrisponde a X.1.31. 15 (vol. II, col. 192).

153 «Che il vizio di gola possa comportare conseguenze molteplici e pericolose l'aveva spiegato Gregorio, quando nella genealogia dei vizi le aveva attribuito cinque figlie: sciocca allegria, scurrilità, perdita della purezza, multiloquio e ottundimento dei sensi» (Casagrande, Vecchio, I sette vizi capitali, p. 135).

154 Il sommario della decretale recita: «Episcopi, qui per se non possunt, tenentur assumere idoneos, qui suppleant suo loco quoad praedicationes, visitationes et confessionum auditiones; et ut possint episcopi reperire tales, praecipit in ecclesiis cathedralibus et collegiatis tales institui» (X. 1. 21. 15, vol. II, col. 192). 
quindi che l'obiettivo precipuo del valdelsano a questa altezza dell'opera è quello di radicalizzare il divario tra rudes e subtiles:

Licet ista sit permissa scientia et aliquando in predicationibus per exempla supercelestium trahantur animi audientium, tamen aliqua sunt in ea que non sunt omni rudi populo predicanda. Ita et in natura, ita et in theologia. Sunt enim rudes instruendi per plana, ut dicitur de fide que planis verbis est exponenda, ut notatur supra in glosis prohemii circa formam Amoris. ${ }^{155}$

Il brano che commenta l'impiego dell'astrologia giudiziaria rinvia alla portata educativa degli exempla tratti da tale disciplina e all'esigenza che i «grossi auditori» abbiano a disposizione un'esegesi fondata su plana verba e non sulle sottigliezze. Tale problema mi pare sia la colonna portante di tutto l'impianto allegorico, linguistico, pedagogico e dottrinale dei Documenti e, parallelamente, anche di quello del Reggimento. Lo stesso Francesco vi richiama l'attenzione in più occasioni, a partire dal Proemio, esplicitamente evocato nel brano appena citato, in cui egli travasa un consistente passo sui signa per la previsione del futuro dal Dragmaticon philosophiae di Guglielmo di Conches, già riconosciuto come fonte di varie sezioni dei Documenti, ${ }^{156}$ e, soprattutto, chiarisce da quale lato dell'uditorio egli intende collocarsi:

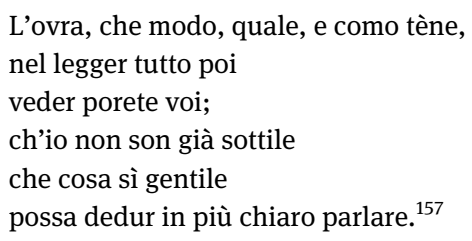

Sempre all'interno del Proemio, sono dirimenti tutti quei luoghi nei quali l'autore giustifica l'impiego delle «due penne», ovvero l'alternanza tra «i due codici linguistici, utilizzati appunto in maniera simultanea, senza che venga stabilito tra essi un rapporto gerarchico», ${ }^{158}$ ma differenziati in quanto diretti a tipologie di pubblico distinte, nel tentativo di soddisfare anche coloro che non avevano accesso

155 Doc. Am., VII, sub Prudentia, doc. XI, v. 5786 (vol. III, p. 211). Nel testo ho corretto l'erroneo aequa in aliqua, ripristinando la lezione di Barb. lat. 4076, c. 82ra, già in Egidi.

156 Un consistente blocco testuale di Doc. Am., Prohemium, v. 78 (vol. I, pp. 29-31) è tratto quasi fedelmente da Guglielmo di Conches, Dragmaticon, I, 5, 3-10, in CCCM, vol. CLII, pp. 18-21. Sul rapporto tra i Documenti e il Dragmaticon si veda Scarpati, Francesco da Barberino e Guglielmo di Conches, pp. 163-170.

157 Doc. Am., Prohemium, vv. 87-92 (vol. I, pp. 28-29). E si noti che tale premura era posta anche in apertura del Regg., Proemio, vv. 28-32, p. 1.

158 Panzera, Francesco da Barberino tra Andrea Cappellano e Averroè, p. 72. 
allo studio del latino ma desideravano comunque usufruire degli ensenhamens barberiniani:

Latinum autem, quod pluribus est comune, voluit omni rationabilitati conformare. Metricum autem summere non curavi, tum quia eadem ratione qua rime vitiis eget aliquibus vel non caret, tum quia prosa hodie magis placet et prodest magisque comunis est, tum et quia de poetarum sinu in Trutanorum usum versuum fabricatio noscitur devoluta. Rimas autem vulgares ad nobilium utilitatem de patria mea, qui latinum non intelligunt, scribere volui. ${ }^{159}$

In questa differenziazione alle ragioni linguistiche si sommano inoltre quelle giuridiche: se infatti le sezioni in volgare sono destinate ai nobili, si può supporre che quelle latine siano indirizzate agli ecclesiastici i quali, appunto, avevano una pratica costante della grammatica. La bipartizione rispecchia anche la professione dell'autore, doctor sia in diritto civile che in diritto canonico e dunque strettamente in contatto sia con le istanze dei nobili che con quelle del clero. ${ }^{160} \mathrm{Il}$ binomio latino/volgare che attraversa i Documenti sarà poi traslato a livello metrico nel Reggimento nel problematico dualismo prosa/rima, un'operazione che mette nuovamente in atto una differenziazione tra le tipologie di lettori ma che, allo stesso modo, è tesa all'inclusione di un'altra categoria sociale, ovvero il pubblico femminile. All'interno di quest'ultimo Francesco opera tuttavia delle distinzioni, come si evince dal proemio del Reggimento in cui programmaticamente egli esplicita quali saranno le scelte linguistiche alla base della trattazione:

Non vo' che sia lo tuo parlare oscuro, acciò ch'aver è a mente con ogni donna possa dimorare; né parlerai rimato, acciò che non ti parta, per forza di rima, dal proprio intendimento; ma ben porrai tal fiata, per dare alcun diletto a chi ti legerà, di belle gobbolette seminare, e anco poi di belle novellette indurrai ad exemplo. E parlerai sol nel volgar toscano, e porrai mescidare alcuni volgari, consonanti con esso, di que' paesi dov'hai più usato, pigliando i belli e' non belli lasciando. ${ }^{161}$

Francesco da Barberino si ripropone di trattare alcuni argomenti in prosa piuttosto che in poesia, in quanto il verso rappresenterebbe un vincolo metrico poco adatto all'esposizione piana e distesa, che invece è compito delle glosse

159 Doc. Am., Prohemium, De dubiis que possunt insurgere super Ecclesiaste libro in variis (vol. I, pp. 35-36). Ho reinserito la maiuscola su Trutanorum, già in Egidi e in Barb. lat. 4076, c. 4rb, eliminata da Albertazzi sulla base di una erronea ricostruzione etimologica del significato, in realtà ben esplicito già in Du Cange, s.v. Trutanus, Trudanus.

160 Per tale aspetto cfr. Marruzzo, Composizione e significato de «I Documenti d'amore», pp. 246-249.

161 Regg., Proemio, p. 5. Ma sui problemi metrici posti da tale passo riguardo alla struttura formale dell'opera cfr. Giunti, Il Reggimento di Francesco da Barberino, pp. 43-74. 
attuare. ${ }^{162}$ Lo stesso argomento veniva impiegato anche da Brunetto Latini nel Tesoretto nei luoghi in cui l'autore si richiama a delle sezioni in prosa, probabilmente mai composte o comunque non pervenuteci, ma che permettono di ipotizzare che il poemetto fosse stato inizialmente concepito come un prosimetro e che il ricorso al volgare rimarcasse l'intenzione di selezionare il pubblico dei lettori, allargando così la ricezione anche a coloro che non conoscevano il francese e che dunque non potevano avere accesso al Trésor. ${ }^{163}$ La mutua complementarità tra verso e prosa del Reggimento si rispecchia ulteriormente nella struttura complessiva dei Documenti, una «maison à trois étages», come la definì Thomas, ${ }^{164}$ che si appella a tre differenti livelli di comprensione. Ne risulta, tuttavia, che il piano meno dotto ed erudito costituito, nel caso dei Documenti, dai versi volgari, e corrispondente nel Reggimento alle «belle gobbolette», non viene affatto svalutato o messo in secondo piano rispetto al latino, come hanno sostenuto lo stesso Thomas e più recentemente Minnis, ${ }^{165}$ ma risulta invece valorizzato in più occasioni attraverso una costante e reiterata attenzione nei confronti di un uditorio non istruito, incapace di dirimere complicate questioni filosofiche e dottrinali ma al quale, nell'ottica del Barberino, va garantita la possibilità di intendere correttamente ogni tipo di sapere. A riprova di ciò si può addurre anche il frammento acefalo e anepigrafo tràdito dal codice Alexianus I.3, considerato da Sansone una primissima redazione prosastica del Reggimento, poi abbandonata, ma da ritenersi senza dubbio un compendio seriore di entrambi i trattati del Barberino realizzato

162 Su questi aspetti si veda Montefusco, Bischetti, Prime osservazioni, pp. 201-202. Cfr. anche Regg., IV, p. 33: «Ivi è uno testo volgar per la gente / ch'a più non è intendente, / e, intorno a quello, un testo letterale / per chi più sa e vale; // e poi, intorno ancor di questi due, sono chiose letterali, dove s'aducon tutte simiglianze e concordanze di molti altri detti di savi e di filosafi della divina legge e dell'umana». Su questo passo rimando anche a Goldin, Testo e immagine, p. 133.

163 Si tratta di Brunetto Latini, Tesoretto, vv. 411-426 (in Poeti del Duecento, t. II, p. 190): «Ma perciò che la rima / si stringe ad una lima / di concordar parole / come la rima vuole, / sì che molte fiate / le parole rimate / ascondon la sentenza / e mutan la 'ntendenza, / quando vorrò trattare / di cose che rimare / tenesse oscuritate, / con bella brevetate / ti parlerò per prosa, / e disporrò la cosa / parlandoti in volgare, / che tu intende ed apare». Per un ragguaglio complessivo sulla struttura formale del Tesoretto rimando a Berisso, Tre annotazioni sul «Tesoretto». Il legame tra il proemio del Reggimento e il Tesoretto era stato messo in luce da Ortiz, Francesco da Barberino e la letteratura didattica neolatina.

164 Thomas, Francesco da Barberino et la littérature provençale, p. 59.

165 Cfr. ivi, pp. 59-60 e Minnis, Amor and Auctoritas, pp. 39-40. 
da un compilatore. ${ }^{166} \mathrm{Al}$ di là del valore ecdotico di tale testimone ai fini della constitutio textus, il dato più rilevante che si può trarre dal testo riguarda la ricezione della coppia Documenti-Reggimento in un periodo prossimo alla stesura. Scrive infatti il compilatore riassumendo i contenuti di entrambe le opere:

Et questo trattato dividerò in tre parti ordinarie et in una extraordinaria. Indella prima parte porremo certa dottrina per amaestramento delle donne di qualunque etade o condizione sieno, con molti belli exempli; indella seconda, ad amaestramento di ciascuno uomo vulgare, porremo molte belle auctoritadi e detti di molti savi uomini in volgare; indella terza, per coloro che sanno gramatica, porremo molte universali auctoritati di savi auctori in gramatica. Indell'ultima extraordinaria, porremo generalmente di molte cose utili e dilettevoli in gramatica, che non si convegnano a ogna maniera di gente. ${ }^{167}$

L'intento di voler comporre un'opera totale, che si adatti ai livelli di istruzione e al ruolo sociale di ciascun destinatario, sembra quindi evidente anche in questo lacerto proemiale, in cui la graduale distinzione della materia e delle auctoritates viene operata con una prospettiva linguistica, di genere e teleologica al contempo, ma senza che ne traspaia un giudizio di valore sulla superiorità di uno specifico codice linguistico né di una singola componente rispetto alle altre parti che compongono l'architettura dell'opera barberiniana. Il binomio Reggimento-Documenti è già percepito come indissolubile, speculare e complementare, e in tale organigramma gli ammaestramenti ricoprono un ruolo di primissimo piano che deve essere sorretto mediante exempla e auctoritates.

Il divario tra grossi e sottili, in sostanza, non rappresenta per Francesco da Barberino una maniera per rivendicare l'esclusione dei primi dall'accesso al sapere a beneficio dei secondi. Il taglio precettistico-oratorio fornito alla tematica astrologica nei Documenti svela infatti che Francesco non intende deprecare l'ignoranza, bensì ammaestrare gli oratori sull'atteggiamento da adottare per non incorrere negli errori di Alberico della Caprafica e catturare di conseguenza le

166 Il codice, segnato Alexianus I.3 e conservato presso l'ex Collegio Internazionale S. Alessio Falconieri di Roma (ora Istituto Storico Ordine dei Servi di Maria), fu segnalato da Besutti, Il «Reggimento e costumi di donna», e poi edito in Appendice all'edizione del Reggimento di Sansone, pp. 275-307 (ma precedentemente pubblicato in Sansone, La prima redazione del «Reggimento e costumi di donna»). Si leggano a questo proposito le severe critiche mosse da Brambilla Ageno, Recensione a Francesco da Barberino, Reggimento e costumi di donna, e poi in Ead., L'edizione critica dei testi volgari, pp. 114-115; e da Battisti, Recensione a Francesco da Barberino, Reggimento e costumi di donna; Caretti, Interrogativi filologici; Margueron, Recensione a Francesco da Barberino, Reggimento e costumi di donna, e si veda ora Giunti, «Né parlerai rimato", pp. 73-74.

167 Regg., Appendice, p. 275. 
attenzioni di ogni tipologia di uditorio. Se infatti già nella prima parte l'autore additava la crossitas dei «copisti ignoranti e incapaci, denunciandone la mancanza di comprensione dei testi e gli errori grossolani nei tentativi di correzione» ${ }^{168} \mathrm{e}$ individuando in essi un difetto di cultura scritta, ben diverso è l'atteggiamento quando egli si trova ad esporre quali siano i «viçi nel parlare» ${ }^{169}$ e le relative regole volte a disciplinare la conversazione. In questo caso non sono racchiusi giudizi di valore ma piuttosto alcuni spaccati della realtà cittadina, in cui cui gli ensenhamens rivestono una funzione pratica e pertanto vengono modulati non solo in base alle varie professioni, ma anche con riferimento alle qualità umane del singolo, un concetto sublimato retoricamente mediante l'icastica metafora della limatura. ${ }^{170}$

La stessa diade interpretativa grossezza/sottigliezza, quasi una cifra stilistica dei Documenti, si riscontra ulteriormente nella sezione dei mottetti dove le indicazioni per coloro che si dedicano alla speculazione filosofica sono modulate in base alle competenze dell'uditorio:

168 Petrucci, Scrivere il testo, p. 224. L'affermazione è in Doc. Am., I, sub Docilitate, doc. vI, vv. 355-356 (vol. I, p. 95): «Et que ibi notantur istorum scriptorum aliqui v[itium] quoddam maximum patiuntur. Nam dum eis occurrunt subtilia que animis eorum applicari non possunt, suo quodam intellectui crosso conformant ut credant se intelligere scribentes, ac credentes corrigere corrumpunt. Sufficiant igitur eis pingere quod non intelligent, nec Phylosophie se faciant corruptores».

169 Doc. Am., I, sub Docilitate, doc. v, v. 222 (vol. I, p. 60). E si noti che nel documento successivo viene esplicitato il ricorso al latino come maniera di rendere la trattazione più chiara rispetto al volgare: «ista lictera in vulgari testu videatur obscura, latinum tamen eodem loco est clarum» (Doc. Am., I, sub Docilitate, doc. vI, v. 335 [vol. I, p. 91]).

170 «Et sic de hominibus, nam alii quadrati, ut crossi et rudes, alii plani, ut semplices et boni, qui non utuntur duplicitate. Alii rotundi ut malitiosi, et astuti, et cauti, quos sequendo per circulum raro capere poteris. Alii magis rodentes, ut violenti et superbi, alii minus ut minus superbi, et qui verbis detrahunt solum, et facta non audent. Alii absque sono, ut illi qui se fingunt bonos et nocent, alii cum rumore ut tediosi et displicibiles. Alii ad reformandum ut moriginati et boni, alii ad destruendum ut impii et nequam. Et sicut limarum diversi sunt effectus, ita et homines diversis artibus utuntur» (Doc. Am., I, sub Docilitate, doc. vI, v. 295 [vol. I, pp. 82-83], ma segnalo che nel brano, che trascrivo dall'edizione Albertazzi come di consueto, ho emendato untur e discibiles ripristinando le lezioni utuntur e displicibiles del Barb. lat. 4076, c. 8rb, già presenti nell'edizione di Egidi). 
Se tu fili, fila grosso, o non troppo sottil mai! Quando volpe, quando vai.
"“Sit ut breviter transeas si tu filas, idest si tu tendis ad phylosophiam fila grossum, idest non erres in hiis que sunt veritatis et fidei seu nunquam nimium subtile modo temperat illam dictionem crossum, quia etiam crosso modo intelligendo posset aliquis ita errare, sicut nimium subtiliçando". Quandoque etc.: debes scire quod sicut vulpes sunt sagaces, ita vari sunt simplices et rudes, unde sic expone: quandoque tempus est ut sis vulpis et exquiras omnia et quandoque non. Nam in invenienda veritate quando prees ad iudicandum hic ponitur omnis cura. In investigando autem subtilia et investigabilia maiestatis non plus sapere quam opportet sapere». ${ }^{171}$

L'autore impiega nel testo volgare due metafore concrete, ovvero quella della filatura, a cui si addicono gli aggettivi grosso e sottile, nonché la contrapposizione tra volpi e scoiattoli ( $v a i)$, relegando alla chiosa il compito di esporre il significato: la filatura 'sottile' evidenzierebbe quindi la possibilità di incorrere nell'errore speculativo, cosa che non accadrebbe in caso di filatura 'grossa', da esporre di fronte a «simplices et rudes», caratteristiche che appartengono ai vai. Poiché quindi le volpi sarebbero rinomate per la loro sagacia, chi si dedica alla speculazione filosofica dovrebbe tendere ad esse piuttosto che alla rozzezza dei $v a i$, e a maggior ragione, in quanto gli sforzi della 'filatura' hanno come obiettivo la ricerca della verità («in invenienda veritate»). ${ }^{172}$ Non è escluso, infine, che dietro la scelta dei vai si nasconda una lieve polemica nei confronti di un uditorio autorevole e istruito, «simbolo di un milieu cortese e borghese nello stesso tempo», ${ }^{173}$ ma in realtà incapace di comprendere pienamente le 'sottigliezze' e interessato solo alle ricchezze derivanti dall'esercizio di determinate professioni, un'interpretazione resa possibile dal fatto che in epoca medievale con la pelliccia di scoiattolo venivano realizzati copricapi o indumenti «distintivi di personaggi eminenti, di dottori, di magistrati, di membri di ordini cavallereschi». ${ }^{174}$ Tale controversia, che potrebbe trovare riscontro anche in altri luoghi dei Docu-

171 Doc. Am., II, sub Industria, doc. vI, mot. XLI, vv. 3294-3296 (vol. II, pp. 291-293).

172 Un'altra similitudine attinta dal mondo animale, che in questo caso contrappone falconi e pecore, compare poco dopo col medesimo intento di rappresentare diverse tipologie umane: cfr. Doc. Am., II, sub Industria, doc. v, reg. LXXIV, vv. 2658-2660 (vol. II, pp. 172-174).

173 Goldin, Un gioco poetico di società, p. 288; tuttavia per l'autrice il termine sarebbe impiegato da Francesco da Barberino in senso letterale, senza alcun legame metonimico con la classe sociale di appartenenza.

174 GDLI, vol. XXI, p. 628, s.v. vàio ${ }^{2}$. 
menti, ${ }^{175}$ rispecchia quindi il costante impegno di Francesco da Barberino nel rendere la scienza e la dottrina intellegibili a un bacino di lettori più ampio, ma sottintende anche una precisa differenziazione sociale dello stesso, evidente sia negli insegnamenti rivolti a padroni e servitori, sia nelle sezioni in cui traspare tutta la vitalità delle occupazioni quotidiane e dei vari «gradi e stadi» delle donne e degli uomini calati nella realtà cittadina. ${ }^{176}$ In questo senso l'invito ad adottare un linguaggio meno oscuro si pone in continuità con l'opera del Brunetto volgarizzatore a cui si è precedentemente accennato, con l'attività di celebri predicatori come Giordano da Pisa, ${ }^{177}$ ma anche con simili esortazioni affidate alla lirica amorosa, tra cui vanno menzionati almeno il sonetto di Guido Orlandi a Guido Cavalcanti Per troppa sottiglianza il fil si rompe o la tenzone tra Bonagiunta Orbicciani e Guinizelli, inaugurata dal sonetto del lucchese Voi, ch'avete mutata la mainera a cui fa eco la risposta Omo ch'è saggio non corre leggiero, tra i testi più copiati della letteratura volgare. L'Orbicciani, infatti, rimproverava a Guido di aver sensibilmente stravolto gli stilemi della poesia amorosa attraverso la «sottigliansa» (v. 9), ovvero gli artifici ed enigmi che ne rendevano difficile la comprensione, e «traier canson' per forsa di scrittura» (v. 14) equivaleva a riversare nel dettato poetico i sintomi di un intellettualismo vigente in seno a una realtà accademica e culturale come quella di Bologna. Questa inutile indulgenza al trobar clus denotava però anche la limitatezza espressiva e un certo conservatorismo dell'Orbicciani. ${ }^{178}$ Nell'ambito della cosiddetta linea Bonagiunta-Guinizelli il Barberino sembrerebbe tuttavia posizionarsi dalle parti di quest'ultimo, come dimostrerebbero i riferimenti all'auctoritas del bolognese in svariati luoghi sia del Reggimento che dei Documenti, ${ }^{179}$ e forse proprio perché Guinizelli rispose al lucchese con un ensenhamen in cui richiama l'atten-

175 Si veda ad esempio Doc. Am., I, sub Docilitate, doc. vI, v. 324 (vol. I, p. 86) dove, parlando di coloro che anelano al nome di filosofi, Francesco da Barberino afferma: «Pauci hodie remaserunt qui ad hoc nomen anelent habendum, sed eorum loco insurrexerunt studentes non ut sint sed ut appareant, volentes potius videri quam esse. Et non ut mentem ornent, sed ut copulent aurum auro et ut scientiam vendent. Et nos, ingrati Deo et mundo, religiosos contempnimus qui, abnegantes semet ipsos, temporalia contempxerunt et phylosophie studio se dederunt». Cfr. Panzera, Francesco da Barberino tra Andrea Cappellano e Averroè, pp. 200-201. 176 E valga come esempio il noto passo di Regg., XV, pp. 169-172.

177 Sulla strutturazione delle prediche intorno al binomio grossi/sottili e sulla riverberazione nella predicazione duecentesca cfr. Muzzarelli, Pescatori di uomini, pp. 44-52.

178 Si vedano Giunta, La poesia italiana nell'età di Dante, pp. 75-100; Id., Versi a un destinatario, pp. 167-169; Borsa, La nuova poesia di Guido Guinizelli, pp. 103-145. Per l'iconicità di tali esempi cfr. Ciccuto, Guinizzelli e Guittone, pp. 77-87; per un profilo intellettuale della Firenze duecentesca si veda ora Montefusco, La linea Guittone-Monte.

179 Guinizelli viene esplicitamente citato infatti in Regg., I, p. 11 e anche in numerosi luoghi dei Documenti, tra cui mi sembrano significativi la menzione in prima battuta nella presentazione latina nel paragrafo Primum omnium expositio (vol. I, p. 9) o il suo inserimento nel canone di 
zione sui «despari senni e intendimenti» (v. 13) che caratterizzano gli uomini e che quindi guidano la penna del poeta, in perfetto accordo con la struttura globale che il notaio valdelsano conferisce alla coppia Reggimento-Documenti.

Tornando quindi ai riferimenti all'astrologia giudiziaria all'interno dei $D o$ cumenti mi sembra innegabile che la peculiarità dell'approccio barberiniano risieda nella maniera in cui tale disciplina viene inquadrata nel novero degli argomenti di predicazione e conversazione e ricondotta alla messa in pratica di un'ars interpretativa, capace di fondere téchne ed ermeneutica e di produrre responsi dotti, adatti a un pubblico erudito, ma dei quali tuttavia non viene messa in dubbio la veridicità. ${ }^{180}$ Il taglio interpretativo stupisce perché, come si è più volte sottolineato, Francesco conosce perfettamente le controversie giuridiche inerenti alla divinazione e non dovette essere indifferente nemmeno alle ripercussioni della condanna inquisitoriale parigina o alla diffusione dell'aristotelismo radicale. Malgrado ciò, egli ammette l'impiego dell'astrologia giudiziaria in quanto ars di fronte ai sottili, distingue tale pratica da tecniche pagane quali la geomanzia, la negromanzia o l'ornitomanzia e, nell'enunciare quali siano le discipline impiegabili nella predicazione, non ha interesse a mettere in relazione l'operato degli astrologi con il binomio veritas/falsitas, che pure aveva contraddistinto molteplici passi sulla divinazione in generale e sull'oniromanzia nel dettaglio.

Infine, al di là del richiamo agli astrologi come studiosi dell'ordinamento cosmologico delle sfere celesti nell'immagine miniata di Prudenza, all'altezza del doc. XI Francesco da Barberino non fa riferimento a nessuno strumento effettivamente impiegato da essi per la predizione del futuro. Tale atteggiamento si distacca da quei luoghi della glossa in cui egli lasciava le considerazioni sulla divinazione al personaggio-interlocutore Garagraffulus Gribolus, un vero e proprio alter ego che ricorre negli inserti novellistici o in passi caratterizzati da uno stile dialogico, e a cui spesso il valdelsano affibbia il ruolo di personaggio scabroso, burlone, una concessione al comico-realistico che anticipa lo spirito del Decameron e che avrebbe potuto trovare riscontro anche nel perduto Fiore di novelle a cui egli accenna nell'opera. ${ }^{181}$ Ad esempio, al resoconto orale di Garagraffulus Gribolus è

poeti volgari di Doc. Am., I, sub Docilitate, doc. vi, vv. 389-390 (vol. I, p. 100) e di Doc. Am., II, sub Industria, doc. II, v. 1932 (vol. II, p. 35). Cfr. Giunta, La poesia italiana nell'età di Dante, p. 251. 180 Ma se la precisione della predizione astrologica basata sul calcolo matematico era l'argomento principale di coloro che ne difendenvano l'esattezza e l'affidabilità, per contro tutti gli avversari dell'astrologia ne sottolineavano il carattere fallace, dovuto all'instabilità dei fenomeni osservati. Su tale contrapposizione cfr. Federici Vescovini, Medioevo magico, pp. 234-236.

181 Il peso di Garagraffulus Gribolus nella composizione dei Documenti era già stato rilevato dall'Ubaldini nella Vita di Messer Francesco da Barberino acclusa alla sua edizione, dalla quale apprendiamo che un personaggio «che da lui per beffa vien'appellato Garagraffolo Gribolo» aveva ripetutamente censurato l'opera, annotazione riprodotta quasi fedelmente anche nell'Istoria 
affidata la dettagliata descrizione dello specchio magico col quale sarebbe possibile determinare non solo gli avvenimenti futuri, ma anche comprendere ciò che pensano le persone e riconoscerne le menzogne, di cui il Barberino fornisce anche una raffigurazione miniata a c. $17 \mathrm{v}$ del Barb. lat. $4076 .{ }^{182}$ Tracce di dialoghi con tale personaggio compaiono inoltre sia nel proemio dell'opera, in cui si ribadisce la natura divina di Amore, sia in corrispondenza della ricca glossa che introduce la virtù della Pazienza dove, trattando degli oracoli sibillini e della figura di Cassandra, Francesco da Barberino dimostra una solida conoscenza della letteratura profetica, traslata su un impianto stilistico che si richiama a una pluralità di generi letterari. ${ }^{183}$

Ciò che emerge da questo lungo viaggio nella concezione barberiniana dei problemi relativi alla predizione del futuro è quindi un graduale sbilanciamento dell'intera riflessione sull'actio, ovvero sull'uso performativo di alcune discipline, laddove in più luoghi l'attività degli indovini veniva condannata e bandita a livello giuridico e dottrinale. Se quindi in molti casi la divinazione non sarebbe da includere nel processo di inventio, ovvero nella ricerca di argomenti pertinenti all'orazione, in quanto Agostino, confluito poi nel Decretum, ne faceva un'attività tacciabile di paganesimo, l'approccio del Barberino prevede anche una riconsiderazione dell'aspetto performativo da cui traspare tutta la vitalità della predicazione medievale, che confluirà in esempi notissimi per teatralità come quello di Bernardino da Siena. In tal senso, stupisce come all'astrologia giudiziaria venga ritagliato uno spazio autonomo che prescinde dalle cogenti problematiche riguardanti la conciliazione tra libero arbitrio e determinismo, l'influsso degli astri nell'operato umano o la delimitazione del ruolo della Fortuna, temi che pure cominciavano ad affacciarsi nella lirica amorosa del Due e Trecento con

della volgar poesia del Crescimbeni (vol. III, p. 92). Per alcuni spunti interpretativi su tale figura rimando a Goldin Folena, Il commento nella pagina autografa, p. 276 e n. 31; qualche accenno si trova anche in Verlato, Schede di lessico. Riguardo alle novelle inserite nei Documenti cfr. Antognoni, Un contemporaneo di Dante, mentre per la menzione del Fiore di novelle si veda ad esempio Doc. Am., I, sub Docilitate, doc. viII, v. 594 (vol. I, p. 134).

182 Il passo si trova in Doc. Am., I, sub Docilitate, doc. XIV, v. 865 (vol. I, pp. 188-189). Panzera ha richiamato l'attenzione sull'aspetto negromantico dell'oggetto, sottolineando come la testimonianza sia preziosa perché precede cronologicamente quella degli specchi magici di Floron e Rostock, del secolo successivo. Cfr. Panzera, Francesco da Barberino tra Andrea Cappellano e Averroè, pp. 201-202. La singolarità della miniatura era stata messa in luce anche da Egidi, Le miniature dei codici barberiniani, p. 94. Aggiungo che, più o meno negli stessi anni in cui Francesco da Barberino sta lavorando ai Documenti d'Amore, lo specchio di Floron compare nel commento alla Sphera Mundi di Cecco d'Ascoli, punto di partenza anche per la letteratura successiva sul tema (per un ragguaglio anche bibliografico mi permetto di rinviare a Ferrilli, Divinazione, astrologia, pp. 24-26). 183 Si tratta di Doc. Am., Praesentatio, De Amoris forma (vol. I, p. 14) e di Doc. Am., IV, sub Discretione, doc. III, v. 3780 ma in realtà pertinente al v. 3778 (vol. II, pp. 377-380). Su quest'ultimo passo cfr. Goldin Folena, Il commento nella pagina autografa, pp. 279-282. 
risvolti tracciabili anche nelle tre cantiche dantesche. Nei Documenti si riverberano invece gli effetti dei manuali di retorica e delle diffusissime artes praedicandi, il cui sviluppo va di pari passo con la crescita della pubblica esegesi, che ugualmente pongono l'accento su questioni metodologiche e sulla reciproca influenza di contenuto e azione, di Verbum e verba, di exempla e loro ricezione presso le folle. ${ }^{184}$ Il risultato è un organismo multisfaccettato e che trasversalmente abbraccia tutte le forme e i contenuti, dove coesistono i grossi e i sottili e il sermo humilis diviene legittimo strumento di elevazione culturale al pari della glossa accademica.

\section{Conclusioni: i Documenti d'Amore come exemplum precettistico-formale}

Al termine di questo lungo excursus, che spesso ha puntato la lente sui microaspetti del problema, restano tuttavia da definire quali considerazioni di carattere più generale la divinazione contribuisca a mettere in luce nell'opera di Francesco da Barberino. I risvolti teologici, filosofici e giuridici inerenti alla predizione del futuro hanno permesso di attraversare al contempo forma e materia della sua opera; ne sono emerse alcune questioni che resteranno aperte ad altri sondaggi, come ad esempio l'annoso problema delle fonti, ma anche la possibilità di uno sguardo d'insieme che entri nel tessuto strutturante degli scritti barberiniani per dispiegarne il valore documentario. In primo luogo, resta di difficile definizione il genere letterario a cui appartengono i Documenti d'Amore e il complementare Reggimento: se infatti nel secondo caso le attenzioni della critica hanno investito precipuamente fattori di ordine metrico-retorico e il suo inserimento nel dominio della letteratura comportamentale destinata alle donne, il problema risulta notevolmente più complesso per quanto riguarda i Documenti, in cui la vastità di argomenti trattati, l'impianto allegorico, l'esposizione che procede su due codici linguistici che si equivalgono senza sovrastarsi vicendevolmente, nonché l'inscindibilità tra le singole parti e tra testo e apparato figurativo rendono l'opera a ragione un tentativo di inglobare e far convivere tra loro tutte le forme retoriche e qualsiasi tipo di destinatario. ${ }^{185}$ L'operazione editoriale dell'Ubaldini, che scisse il testo volgare dall'autotraduzione e dalla glossa latina, risulta agli occhi del lettore moderno un tentativo

184 Su questo aspetto cfr. Muzzarelli, Pescatori di uomini, pp. 15-19.

185 Marruzzo ha fatto riferimento all'utilità dell'arte nel completare il valore pedagogico del testo come pratica legittimata anche dal diritto. Cfr. Marruzzo, Composizione e significato de «I Documenti d'amore», pp. 232-233. Si ricordi che lo stesso Francesco da Barberino intende con- 
di isolarne una peculiarità pure importante, ovvero l'esemplarità del volgare, ma non riesce a circoscrivere le ragioni che rendono difatti l'organigramma complessivo dei Documenti un unicum della letteratura medievale.

Come si è già detto, resta aperta anche la questione delle fonti. Nel caso della divinazione il valdelsano si mostra un abile modulatore di auctoritates di vario tipo, tra le quali si riconoscono le impronte dello studioso di diritto, del notaio episcopale e futuro inquisitore, ma anche quella dell'intellettuale calato in un contesto cittadino che aveva già goduto dell'operato di Brunetto, maestro di retorica e 'digrossatore' dei rozzi fiorentini, secondo la nota definizione del Villani. Anche al di là dei numerosi compendi a cui il valdelsano attinge, la cifra stilistica dei Documenti risiede proprio nell'alternanza di codici, registri e piani ricettivi e nella capacità di alternarne gli aspetti senza che il ricorso alle fonti risulti una mera riproduzione meccanica di testi. Come l'analisi ha ampiamente dimostrato, Francesco piega costantemente la materia di trattazione alle proprie esigenze, così come invita a più riprese i predicatori a fare lo stesso con le folle. Se quindi il compito del predicatore è quello di ammaestrare e rendere intellegibile il Verbum divino ai più, quello del valdelsano si situa a monte e intende conchiudere nel medesimo apparato formale sia le piazze, sia i predicatori stessi. Si tratta di un'operazione pedagogica che si avvale degli stessi strumenti didattici in uso nei centri della cultura accademica e della manualistica che presiedeva all'oratoria religiosa e civile, e che nell'esemplarità e nella figurabilità linguistica e per immagini trovava il suo fondamento. ${ }^{186}$ Francesco da Barberino raccomanda agli oratori di variare gli argomenti e la profondità della trattazione al variare degli uditori e, nel farlo, compone un'opera che attua la medesima strategia. Come egli stesso annuncia nel proemio sotto la scorta di Agostino, Sapienza ed Eloquenza sono due aspetti indissolubili, ${ }^{187}$ e come tali

notare la sua opera come un trattato etico, dando quindi ampiamente risalto alla forma precettistica. Cfr. MacLaren, Shaping the Self in the Image of Virtue, p. 73.

$186 \mathrm{Su}$ tale aspetto aveva richiamato l'attenzione lo stesso autore in Doc. Am., VI, sub Spe, Prohemium, v. 4029 (vol. III, p. 7): «Modo convertit se ad formam, predicens quod absque figuris lectura sola plene res hec intelligi non valeret. Sed hoc est verum. Respondes ita: quo ad novitios, quo autem ad alios, id scriptura operatur quod pictura ydiotis». Si veda di nuovo MacLaren, Shaping the Self in the Image of Virtue, p. 94: «This echo does not mean that the images are primarily for those who cannot read. Instead, Francesco states that the images are useful for everyone; reading the accompanying text alone is not enough».

187 «De qua primo dic quod Eloquentia est virtus seu gratia clare ac ornate proferens, que concipit intellectus humanus unde, ad denotandam in ea claritatem, fit capite discoperto et in tunica tantum. Et stat recta super pedes suos, tum quia est coram Factore suo tum quia est magis apta locutioni. Ed dic virtus sive gratia ideo quia eleganter loqui et eloquentiam habere si a natura gratia est, si ex studio et per accidens virtus est. Sed nichilominus omnis virtus aut collata aut 
vengono rappresentati lungo i Documenti. Lo stesso Amore, l'unico a cui sia concesso di presiedere e chiudere il libro, viene inoltre raffigurato già nella cornice proemiale nell'atto di donare agli uomini un'eloquenza plurilingue, che fa ricorso a una perizia retorica che ne consenta l'attuazione. ${ }^{188}$ Tale binomio si traduce in una commistione di forme metriche a cui fa eco una sapiente strutturazione disciplinare e contenutistica, nella quale è ben evidente il ruolo dell'autore come organizzatore e selezionatore della materia. Alla mescidanza disciplinare non sfugge nemmeno lo stesso Francesco, che inserisce sé stesso come presenza costante a cui fare riferimento, sia mediante i richiami interni dei Documenti, sia attraverso quelli incrociati che legano questi ultimi al Reggimento, all'Officiolum e ai testi menzionati ma non pervenutici, come i Fiori di novelle. Viene dunque da chiedersi se il valdelsano non intenda replicare sotto altri auspici il monumentale esperimento portato a termine da Graziano per il diritto, in cui l'opera di selezione ed organizzazione del materiale canonistico rivela già di per sé l'apporto dell'auctor, fino ad assumere valore normativo.

L'esplicitazione delle fonti non si configura dunque come accostamento obbligato di lacerti testuali che egli traeva da altre compilazioni, e in questo senso andrebbero approfondite non solo le dinamiche intertestuali, ma anche quelle interdiscorsive che governano la composizione dei Documenti. Nella raffigurazione delle pratiche divinatorie è infatti emerso il ruolo non marginale delle artes praedicandi, che confluiscono nel testo anche sottoforma di ritratti attinti dalla quotidianità, come l'exemplum di Alberico della Caprafica ha ampiamente mostrato. A tali istanze si sommano i reiterati tentativi di trovare un canale di comunicazione tra religione colta e religione popolare, ovvero tra due differenti modelli ricettivi del Verbum divino. Nella seconda metà del XII secolo la predicazione popolare aveva infatti marcato l'«esigenza di povertà e di partecipazione femminile ai movimenti», ${ }^{189}$ aspetti che sembrano ripercuotersi sull'ideazione della coppia

permissa descendit ex gratia. De ista eloquentia dicit Augustinus in IV libro De doctrina Christi: "Sapientiam sine eloquentia parum prodesse cuilibet, eloquentiam vero sine sapientia nimium obesse plerumque, prodesse michi nunquam visum est” (Doc. Am., Prohemium, v. 9 [vol. I, pp. 21-22]. Nel testo ho ripristinato nichilominus del manoscritto al posto di nihilominus, nonché cuilibet contro civitatibus, adottato da Albertazzi in quanto riscontrabile nella fonte agostiniana. Cfr. Barb. lat. 4076, c. 3ra). Si veda anche Marruzzo, Composizione e significato de «I Documenti d'amore», p. 229.

188 Si veda Doc. Am., Prohemium, De dubiis que possunt insurgere super Ecclesiaste libro in variis (vol. I, p. 35), ma anche il lungo excursus sull'origine delle lingue e su questioni di fonetica, grammatica e sulle varie discipline retoriche di Doc. Am., I, sub Docilitate, doc. Xxxiv, v. 1502 e v. 1547 (vol. I, pp. 302-306 e 312). Cfr. Panzera, Francesco da Barberino tra Andrea Cappellano e Averroè, pp. 44-45.

189 Manselli, Il soprannaturale e la religione popolare, p. 95. 
Documenti-Reggimento e sull'autorappresentazione della propria missione poetica. In tal senso, la forte componente didascalica di entrambe le opere risulta nuovamente coerente con quanto Francesco da Barberino raccomandava a coloro che si accingevano alla predicazione: intendendo limitare al minimo le possibilità di fraintendimento e di indurre i rudes in errore, egli compone quindi un'opera pluristratificata, capace di declinare la stessa materia secondo differenti gradi di approfondimento, e passibile di far coesistere enciclopedismo e precettistica, in modo che vi possano ricorrere ugualmente rudes e subtiles. La letteratura degli exempla confluisce dunque nei Documenti come ipotesto e come fine ultimo, come raccordo tra le varie parti dell'opera e modello da superare, conferendo al sistema incrociato dei due trattati un valore normativo e al contempo esemplare.

Riletta alla luce di tali considerazioni anche la trattazione sulla predizione del futuro assume risvolti ben precisi, specialmente per quanto riguarda i destinatari. Il valdelsano sembra infatti marginalizzare il dibattito cosmologico e dottrinale su libero arbitrio, Fortuna e determinismo, che pure aveva interessato i lirici coevi, a favore di una sua trasposizione indirizzata appunto agli aspetti inerenti alla sua divulgazione: il ricorso massivo alle auctoritates, espediente che caratterizza sia la glossa giuridica che la predicazione, viene infatti attuato in tutti quei luoghi in cui il Barberino riflette sulla questione da un punto di vista teoretico, mentre per i risvolti performativi, ovvero per il discorso agito, che trova la sua realizzazione fattuale, egli introduce una serie di differenziazioni di facile comprensione. Esse sono l'opposizione tra veritas e falsitas, o tra verbum e Verbum, in seno ad un pubblico che è suddiviso dicotomicamente in grossi e sottili e in cui i rudes non vanno esclusi dal disegno intellettuale complessivo, bensì coinvolti e istruiti con un sapere che sia esposto in maniera tale da non indurli in errore. È grazie a tali presupposti che nella fittissima glossa latina possono convivere un manuale metrico che prende in esame le forme della poesia volgare, così come brani in lingua d'oc o in lingua di sì, autori classici, patristici e canonistici ma anche gli inserti narrativi affidati a Garagraffulus Gribolus e che avrebbero dovuto trovare piena espressione nella perduta silloge novellistica. Siamo dunque ben lontani da quegli esempi di intellettualismo ed elitismo culturale che avevano visto in Guittone e nei frati Gaudenti un connubio particolarmente efficace tra azione politica e religiosa, volto a favorire un determinato milieu nella partecipazione cittadina. Francesco da Barberino, pur perfettamente calato nelle vicende della Firenze magnatizia ed ecclesiastica, intende dunque conchiudere un progetto alternativo e più vicino alle istanze popolari, in cui forma, contenuto e immagine si alternano ed equivalgono nel 'digrossare' i ceti meno intellettuali. Per questo, sembra che il valdelsano intenda spostare l'asticella del pubblico brunettiano un po' più in là, coinvolgendo anche coloro che avevano accesso al sapere solo in forma orale come le masse destina- 
tarie della predicazione popolare. Un tentativo i cui effetti, ben lontani dal magistero retorico inaugurato da Brunetto, meritano tuttavia di essere riconsiderati al fine di allontanare dal valdelsano l'infausta etichetta villaniana di 'semi-poeta'.

\section{Bibliografia}

\section{Sigle}

CCCM = Corpus Christianorum. Continuatio Mediaevalis, voll. 1-346, Turnhout 1966 sgg.

$C C S L=$ Corpus Christianorum. Series Latina, voll. 1-213, Turnhout $1953 \mathrm{sgg}$.

CLCAG = Corpus Latinus Commentariorum in Aristotelem Graecorum, Leiden $1957 \mathrm{sgg}$.

CSEL = Corpus Scriptorum Ecclesiasticorum Latinorum, editum consilio et impensis Academiae

Scientiarum Austriacae, Vindobonae $1866 \mathrm{sgg}$.

$D B I=$ Dizionario Biografico degli Italiani, Roma $1960 \mathrm{sgg}$.

Du Cange $=$ Charles du Fresne du Cange (et alii), Glossarium mediae et infimae latinitatis,

Niort 1883-1887 (online all'URL: http://ducange.enc.sorbonne.fr/).

$E D=$ Enciclopedia dantesca, Roma 1970.

GDLI = S. Battaglia, Grande Dizionario della Lingua Italiana, Torino 1961-2002.

MGH = Monumenta Germaniae Historica, online all'URL: http://www.dmgh.de/;

$P L=$ Patrologiae cursus completus, Series II, Ecclesia Latina, a cura di J. P. Migne, voll. 1-221

Paris, Garnier, 1844-1855, online all'URL: http://www.documentacatholicaomnia.eu/

1815-1875,_Migne,_Patrologia_Latina_01._Rerum_Conspectus_Pro_Tomis_Ordinatus, MLT.html.

$T L I O=$ Tesoro della Lingua Italiana delle Origini, online all'url: http://tlio.ovi.cnr.it/.

\section{Fonti}

Dante Alighieri, La Commedia secondo l'antica vulgata, a cura di G. Petrocchi, Milano 1966-1967.

Dante Alighieri, Convivio, a cura di F. Brambilla Ageno, Firenze 1995.

Giovanni Crocioni, Le rime di Pietro Alighieri, con cenni biografici, Città di Castello 1903.

Aristoteles, De somno et vigilia liber, adiectis veteribus translationibus et Theodori Methochitae commentario, edited by H.J. Drossaart Lulofs, Leiden 1943.

Aristoteles, De insomniis et De divinatione per somnium, a New Edition of the Greek Text with the Latin Translations, edited by H.J. Drossaart Lulofs, Leiden 1947.

Aristotle, Parva naturalia, a revised text with introduction and commentary by Sir D. Ross, Oxford 1955.

Aristoteles Latinus, Union Académique Internationale, Turnhout 2003.

Aristotelis Fragmenta selecta, recognovit brevique adnotatione instruxit W.D. Ross, Oxford 1958. 
Avicenna Latinus, Liber de anima seu Sextus de Naturalibus, édition critique de la traduction latine médiévale par S. Van Riet, introduction sur la doctrine psychologique d’Avicenne par G. Verbeke, Louvain-Leiden 1968-1972.

Graziolo Bambaglioli, Commento all'«Inferno» di Dante, a cura di L.C. Rossi, Pisa 1998.

Biblia sacra iuxta vulgatam versionem, adiuvantibus B. Fischer, I. Gribomont, H.F.D. Sparks, $W$. Thiele, recensuit et brevi apparatu critico instruxit R. Weber, editionem quintam emendatam retractatam praeparavit R. Gryson, Stuttgart 2007.

Francesco da Barberino, I Documenti d'Amore secondo i manoscritti originali, I-IV, a cura di F. Egidi, Roma 1902-1927.

Francesco da Barberino, I Documenti d'Amore / Documenta Amoris, a cura di M. Albertazzi, 2 voll., Lavis $2011^{2}$ [l ed. 2008].

Francesco da Barberino, Reggimento e costumi di donna, ed. critica a cura di G.E. Sansone, seconda ed. riveduta, Roma 1995.

Bonagiunta Orbicciani da Lucca, Rime, edizione critica e commento a cura di A. Menichetti, Firenze 2012.

Le chiose ambrosiane alla Commedia, edizione e saggio di commento a cura di L.C. Rossi, Pisa 1990.

La condamnation parisienne de 1277, nouvelle édition du texte latin, traduction, introduction et commentaire par D. Piché, avec la collaboration de Claude Lafleur, Paris 1999.

Corpus iuris civilis, vol. 1 , Institutiones, recognovit P. Krueger, Digesta, recognovit

T. Mommsen, Berolini 1872.

Corpus iuris civilis, vol. 2, Codex lustinianus, recognovit P. Krueger, Berolini 1877.

Corpus iuris canonici, editio lipsiensis secunda post Ae.L. Richteri curas ad librorum manu scriptorum et editionis romanae fidem recognovit et adnotatione critica, instruxit Ae. Friedberg (pars prior, Decretum Magistri Gratiani; pars secunda, Decretalium Collectiones), Lipsiae 1879.

F. Nicolai Eymerici ordinis praedicatorum, Directorium Inquisitorum, cum commentariis Francisci Pegnae, Romae, in aedibus Populi Romani apud Georgium Ferrarium, 1587. Indices titulorum et legum totius Corporis iuris canonici et civilis, curantibus X. Ochoa et A. Diez, Roma 1964-1965.

Heinrich Institoris, Jacobus Sprenger, Malleus Maleficarum, edited and translated by C.S. Mackay, Cambridge 2006.

Martini Episcopi Bracarensis, Opera omnia, edidit C.W. Barlow, New Haven 1950.

Ottimo commento alla Commedia, a cura di G. Boccardo, M. Corrado e V. Celotto, Roma 2018.

Le rime di $M$. Francesco Petrarca estratte da un suo originale. Il trattato delle virtù morali di Roberto re di Gerusalemme. Il Tesoretto di ser Brunetto Latini, con quattro canzoni di Bindo Bonichi da Siena, in Roma, nella stamperia del Grignani, 1642.

Poeti del Duecento, a cura di G. Contini, Milano-Napoli 1960.

Lucio Anneo Seneca, Dialoghi, a cura di P. Ramondetti, Torino 1999.

L. Annaei Senecae, Ad Lucilium Epistulae Morales, recognovit et adnotatione critica instruxit L.D. Reynolds, Oxford 1965.

Simplicius, Commentaire sur les Catégories d'Aristote, traduction de Guillaume de Moerbeke, édition critique par A. Pattin, vol. II, en collaboration avec W. Stuyven, Leiden 1971-1975.

Summa lohannis Valensis de regimine vite humane, seu Margarita doctorum ad omne propositum prout patet in tabula, impressum Lugduni 1511. 
Vincentii Burgundi ex ordine praedicatorum venerabili Episcopi Bellovacensis Speculum Quadruplex: Naturale, Doctrinale, Morale, Historiale, Duaci, ex Officina Typographica Baltazaris Belleri, 1624 (ristampa: Graz 1964-1965).

Thémistius, Commentaire sur le traité de l'âme d'Aristote, traduction de Guillaume de Moerbeke, édition critique et étude sur l'utilisation du commentaire dans l'oeuvre de Saint Thomas par G. Verbeke, Leiden 1973.

Sancti Thomae de Aquino, Opera Omnia, iussu Leonis XIII p. m. edita, cura et studio Fratrum Praedicatorum, Roma-Parigi 1884-2000.

Federico Ubaldini, Documenti d'amore di messer Francesco Barberino, Roma, Vitale Mascardi, 1640.

Philippi Villani De origine civitatis Florentie et de eiusdem famosis civibus, edidit G. Tanturli, Padova 1997.

Wilhelm von Conches, Philosophia, herausgegeben, übersetz und kommentiert von G. Maurach, unter Mitarbeit von H. Telle, Pretoria 1980.

\section{Studi critici}

E. Abramov-van Rijk, Parlar cantando. The Practice of Reciting Verses in Italy from 1300 to 1600, Bern 2009.

0 . Antognoni, Le glosse ai 'Documenti d'Amore' di M. Francesco da Barberino e un breve trattato di ritmica italiana, in «Giornale di Filologia Romanza», 4 (1883), pp. 78-98.

O. Antognoni, Un contemporaneo di Dante e i costumi italiani, in Id., Saggio di studj sopra la Commedia di Dante, Livorno 1893, pp. 59-79.

Astro-Medicine. Astrology and Medicine, East and West, edited by A. Akasoy, C. Burnett and R. Yoeli-Tlalim, Firenze 2008.

L. Azzetta, Tra gli amici e cultori di Dante: documenti per Francesco Da Barberino, Lapo Gianni, Andrea Lancia, in «Per beneficio e concordia di studio». Studi danteschi offerti a Enrico Malato per i suoi ottant'anni, a cura di A. Mazzucchi, Cittadella 2015, pp. 61-71.

F. Barberini, Francesco Barberini e l'edizione seicentesca dei Documenti d'Amore, in «Xenia antiqua», 2 (1993), pp. 125-148.

C. Battisti, Recensione a Francesco da Barberino, Reggimento e costumi di donna, ed. critica a cura di G.E. Sansone, in «Lingua Nostra», 19 (1958), pp. 30-32.

M. Berisso, Tre annotazioni sul «Tesoretto», in «Filologia italiana», 11 (2014), pp. 15-40.

F.M. Bertolo, T. Nocita, Apocalissi figurata. Per l'interpretazione del testo allegorico in appendice all' 'Officiolum' di Francesco da Barberino, in «Studi e testi italiani», 7/15 (2005), pp. 55-64.

F.M. Bertolo, T. Nocita, L''Officiolum' ritrovato di Francesco da Barberino. In margine ad una allegoria figurata inedita della prima metà del Trecento, in «Filologia e Critica», 31/1 (2006), pp. 106-117.

R. Bertuzzi, II dibattito sul libero arbitrio tra XIII e XIV secolo: la "nobile virtù" tra prescienza divina e problema del male, in «ll mondo errante». Dante fra letteratura, eresia e storia, Atti del convegno internazionale di studio (Bertinoro, 13-16 settembre 2010), a cura di M. Veglia, L. Paolini e R. Parmeggiani, Spoleto 2013, pp. 81-98. 
G.M. Besutti O.S.M., Il «Reggimento e costumi di donna» ed altre opere trecentesche in un codice della Biblioteca S. Alessio Falconieri, in «Studi storici dell'Ordine dei Servi di Maria», 7 (1955), pp. 9-29.

L. Bianchi, Il vescovo e i filosofi. La condanna parigina del 1277 e l'evoluzione dell'aristotelismo scolastico, Bergamo 1990.

G. Billanovich, M. Prandi, C. Scarpati, Lo «Speculum» di Vincenzo di Beauvais e la letteratura italiana dell'età gotica, in «Italia Medioevale e Umanistica», 19 (1976), pp. 89-170.

G. Biscaro, Inquisitori ed eretici a Firenze (1319-1334), in «Studi medievali», n. s. 2 (1929), pp. 347-375; 3 (1930), pp. 266-287; 6 (1933), pp. 161-207.

D. Blume, Francesco da Barberino. The Experience of Exile and the Allegory of Love, in Images and Words in Exile. Avignon and Italy during the First Half of the $14^{\text {th }}$ Century, edited by E. Brilli, L. Fenelli and G. Wolf, Firenze 2015, pp. 171-192.

D. Bommarito, Boezio e la fortuna di Dante in Inf. VII, 61-96, in «L'Alighieri», 20/1 (1979), pp. 42-56.

G. Bonafede, La condanna di Stefano Tempier e la 'Declaratio' di Raimondo Lullo, in «Estudios Lulianos», 4 (1960), pp. 21-44.

P. Borsa, La nuova poesia di Guido Guinizelli, Firenze 2007.

F. Brambilla Ageno, Recensione a Francesco da Barberino, Reggimento e costumi di donna, ed. critica a cura di G.E. Sansone, in «Romance Philology», 12/3 (1958), pp. 314-324.

F. Brambilla Ageno, L'edizione critica dei testi volgari, Padova $1984^{2}$.

J. Brams, La riscoperta di Aristotele in Occidente, Milano 2003.

E. Brilli, A. Fontes Baratto, A. Montefusco, Sedurre l'imperatore. La lettera di Francesco da Barberino a Enrico VII a nome della corona romana (1311), in «Italia Medioevale e Umanistica», 57 (2016), pp. 37-89.

G. Brunetti, S. Gentili, Una biblioteca nella Firenze di Dante: i manoscritti di Santa Croce, in Testimoni del vero. Su alcuni libri in biblioteche d'autore, a cura di E. Russo, Roma 2000, pp. 21-48.

F. Bruni, Semantica della sottigliezza. Note sulla distribuzione della cultura nel Basso Medioevo, in Id., Testi e chierici del Medioevo, Genova 1991, pp. 91-133.

M.C. Camboni, Il sonetto delle origini e le «glosse metriche» di Francesco da Barberino, in "Studi di filologia italiana», 66 (2008), pp. 13-34.

M.C. Camboni, Cantus/Cantilena, Sonum fabricantis, Discordium/Concordium: nota sulla terminologia metrica del primo Trecento, in «Studi mediolatini e volgari», 62 (2016), pp. 5-13.

J. Canteins, Francesco da Barberino: l'homme et l'oeuvre au regard du soi-disant fidèle d'amour, Milano 2007.

G. Capocaccia, F. Macchioni, Statuto della città di Bagnoregio del MCCCLXXIII, Bagnorea 1921.

V. Cappozzo, Dizionario dei sogni nel Medioevo. Il 'Somniale Danielis' in manoscritti letterari, Firenze 2018.

L. Caretti, Interrogativi filologici, in «Letterature moderne», 9/1 (1959), pp. 93-100.

S. Caroti, L'astrologia, in Federico /l e le scienze, a cura di P. Toubert e A. Paravicini Bagliani, Palermo 1994, pp. 138-151.

C. Casagrande, S. Vecchio, I peccati di lingua. Disciplina ed etica della parola nella cultura medievale, Roma 1987.

C. Casagrande, S. Vecchio, I sette vizi capitali. Storia dei peccati nel Medio Evo, Torino 2000. 
M.G. Ciardi Dupré Dal Poggetto, Nuove ipotesi di lavoro scaturite dal rapporto testo-immagine nel Tesoretto di Brunetto Latini, in «Rivista di storia della miniatura», 1-2 (1996-1997), pp. 89-98.

M. Ciccuto, Francesco da Barberino: un pioniere del 'Bildercodex' tra forme del gotico cortese e icone della civiltà comunale, in «Letteratura e arte», 9 (2011), pp. 83-95.

M. Ciccuto, Guinizzelli e Guittone, Barberino e Petrarca: le origini del libro volgare illustrato, in «Rivista di storia della miniatura», 1-2 (1996-1997), pp. 77-87.

C. Ciociola, Rassegna stabiliana (Postille agli atti del convegno del 1969), in «Lettere Italiane», 30/1 (1978), pp. 97-123.

C. Ciociola, «Visibile parlare»: agenda, Cassino 1992.

C. Ciociola, Scrittura per l'arte, arte per la scrittura, in Storia della letteratura italiana, diretta da E. Malato, vol. II, Il Trecento, Roma 1995, pp. 531-580.

E. Coccia, S. Piron, Poésie, sciences et politique. Une génération d'intellectuels italiens (1290-1330), in «Revue de synthèse», 129/4 (2008), pp. 549-586.

O. Condorelli, Bartolomeo da Brescia, in Dizionario biografico dei giuristi italiani (XII-XX secolo), a cura di I. Birocchi, E. Cortese, A. Mattone, M.N. Miletti, Bologna 2013, vol. I, pp. 182-183.

R. Cristiani, La questione cronologica nelle opere di Messer Francesco da Barberino, in Raccolta di studi di storia e critica letteraria dedicata a Francesco Flamini, Pisa 1918, pp. 3-21.

R. Davidsohn, Un libro di entrate e spese dell'inquisitore fiorentino (1322-1329), in «Archivio storico italiano», s. V, 27 (1901), pp. 346-355.

C.T. Davis, The Early Collection of Books of S. Croce in Florence, in «Proceedings of the American Philosophical Society», 107 (1963), pp. 399-414.

B. Degenhart, A. Schmitt, Corpus der Italienischen Zeichnungen 1300-1450, Teil I, Süd und Mittelitalien, 1. Band, Katalog 1-167, Berlin 1968.

I. Del Lungo, Federico Ubaldini e le Vite Ubaldiniane, in «Archivio Storico Italiano», s. V, 48 (1911), pp. 391-394.

G. Desideri, "Et indefessa vertigo". Sull'immagine della ruota della Fortuna: Boezio, "Lancelot" e "Commedia", in «Critica del testo», 8/1 (2005), pp. 389-426 (volume monografico dal titolo Sensi, sensazioni, sentimenti, a cura di S. Bianchini, A. Landolfi e A. Punzi).

O. Di Simplicio, Malleus maleficarum, in Dizionario storico dell'Inquisizione, diretto da A. Prosperi, con la collaborazione di V. Lavenia e J. Tedeschi, Pisa 2010, vol. II, pp. 965-968.

A. Dunlop, Painted Palaces. The rise of secular art in Early Renaissance Italy, University Park Pa. 2009.

F. Egidi, Le miniature dei codici barberiniani dei 'Documenti d'amore', in «L'arte», 5 (1902), pp. 1-20; 78-95.

F. Egidi, L'argomento barberiniano per la datazione della "Divina Commedia", in «Studi Romanzi», 19 (1928), pp. 135-162.

G. Federici Vescovini, Medioevo magico. La magia tra religione e scienza nei secoli XIII e XIV, Torino 2008.

E. Fenzi, Ancora a proposito dell'argomento barberiniano (una possibile eco del "Purgatorio" nei “Documenti d'Amore" di Francesco da Barberino), in «Tenzone», 6 (2005), pp. 97-120. 
S. Ferrilli, Cino da Pistoia, Francesco da Barberino e l'astrologia giudiziaria: tra poesia, politica e cultura giuridica, in Poesia e diritto nel Due e Trecento italiano, a cura di F. Meier e E. Zanin, Ravenna 2019, pp. 105-124.

S. Ferrilli, Divinazione, astrologia e profetismo politico in Cecco d'Ascoli, in «Linguistica e Letteratura», 45/1-2 (2020), pp. 17-49.

E. Frojmovič, Giotto's Circumspection, in «The Art Bulletin», 89/2 (2007), pp. 195-210.

G. Gatti, Del Caput Africae nella seconda regione di Roma, in «Annali dell'Instituto di corrispondenza archeologica / Annales de l'Institut de correspondance archéologique», 54 (1882), pp. 191-220.

M. Giansante, G. Marcon, Giudici e poeti toscani a Bologna: tracce archivistiche fra tardo stilnovismo e preumanesimo, Bologna 1994.

M. Gilardi Zanone, In margine alle chiose dei ‘Documenti d'Amore' di Francesco da Barberino, in Studi testuali, Alessandria 1984, pp. 65-81.

C. Giunta, La poesia italiana nell'età di Dante. La linea Bonagiunta-Guinizzelli, Bologna 1998.

C. Giunta, Versi a un destinatario. Saggio sulla poesia italiana del Medioevo, Bologna 2002.

C. Giunti, Il Reggimento di Francesco da Barberino: prosa ritmica o versi sciolti?, in «Studi e problemi di critica testuale», 63 (2001), pp. 43-74.

C. Giunti, «Né parlerai rimato». Sulla struttura formale del Reggimento e costumi di donna di Francesco da Barberino, in «Studi e problemi di critica testuale», 81/2 (2010), pp. 71-111.

D. Goldin, Un gioco poetico di società: $i$ «mottetti» di Francesco da Barberino, in «Giornale Storico della Letteratura Italiana», 150 (1973), pp. 259-291.

D. Goldin, Autotraduzione latina nei 'Documenti d'Amore' di Francesco da Barberino, in «Atti dell'Istituto Veneto di Scienze, Lettere ed Arti», 133 (1975), pp. 371-392.

D. Goldin, Testo e immagine nei 'Documenti d'Amore' di Francesco da Barberino, in «Quaderni d'italianistica», 1/2 (1980), pp. 125-138.

D. Goldin Folena, Il commento nella pagina autografa di Francesco da Barberino, in Intorno al testo. Tipologie di corredo esegetico e soluzioni editoriali, Atti del Convegno di Urbino (1-3 ottobre 2001), Roma 2003, pp. 263-282.

T. Gregory, I sogni e gli astri, in I sogni nel medioevo, Seminario Internazionale (2-4 ottobre 1983), a cura di T. Gregory, Roma 1985, pp. 111-148.

C. Guimbard, Francesco da Barberino e la scelta del volgare, in Il volgare come lingua di cultura dal Trecento al Cinquecento, Atti del Convegno Internazionale (Mantova, 18-20 ottobre 2001), a cura di A. Calzona, F.P. Fiore, A. Tenenti, C. Vasoli, Firenze 2003, pp. 9-23.

S.L. Hiltz, De amore et dilectione Dei et proximi et allarum rerum et de forma vite. An edition, PhD Dissertation, University of Pennsylvania, 1980.

R. Hissette, Enquête sur les 219 articles condamnés à Paris le 7 mars 1277, Louvain 1977.

G. Indizio, L'argomento barberiniano: «dossier» di un'attribuzione, in «Studi Danteschi», 72 (2007), pp. 283-297; ora in Id., Problemi di biografia dantesca, Ravenna 2013.

G. Indizio, Gli argomenti esterni per la pubblicazione dell" "Inferno" e del "Purgatorio", in «Studi Danteschi», 68 (2003), pp. 17-47, ora in Id., Problemi di biografia dantesca, Ravenna 2013, pp. 223-246.

G. Izzi, Ubaldini, Federigo, in ED, Roma 1970, vol. v, p. 771.

E. Jacobsen, Francesco da Barberino Man of Law and Servant of Love, in «Analecta Romana Instituti Danici», 15 (1986), pp. 87-115; 17 (1987), pp. 75-106.

L. Kéry, Canonical collections of the Early Middle Ages (ca. 400-1140). A bibliographical guide to the manuscripts and literature, Washington 1999. 
J. Keshiako, Dreams and Visions in the Early Middle Ages. The Reception and Use of Patristic Ideas, 400-900, Cambridge 2015.

E.I. Kouri, A.I. Lehtinen, Disputed Questions on Aristotle's De iuventute et senectute, De respiratione and De morte et vita by Henricus de Alemannia, in Sic itur ad astra. Studien zur Geschichte der Mathematik und Naturwissenschaften. Festschriften für den Arabisten Paul Kunitzsch zum 70. Geburtstag, herausgegeben von M. Folkerts und R. Lorch, Wiesbaden 2000, pp. 362-375.

S.F. Kruger, Dreaming in the Middle Ages, Cambridge 1992.

S. Kuttner, Repertorium der Kanonistik (1140-1234), Prodromus Corporis Glossarum, I, Città del Vaticano 1937 («Studi e testi», vol. LXXI).

S. Kuttner, Bernardus Compostellanus antiquus. A study in the Glossators of the Canon Law, in «Traditio», 1 (1943), pp. 277-340.

S. Kuttner, B. Smalley, The Glossa Ordinaria to the Gregorian Decretals, in «English Historical Review», 60 (1945), pp. 97-105.

J. Leclercq-Marx, La syrène dans la pensée et dans l'art de l'antiquité et du Moyen Age. Du mythe païen au symbole chrétien, Bruxelles 1997 (online all'URL: http://www.koregos. org/fr/jacqueline-leclercq-marx-la-sirene-dans-la-pensee-et-dans-l-art-de-l-antiquite-etdu-moyen-age/).

J. Le Goff, I sogni nella cultura e nella psicologia collettiva dell'Occidente medievale, in Id., Tempo della Chiesa e tempo del mercante, Torino 1977.

J. Le Goff, Le christianisme et les rêves (Ile-VIle siècles), in I sogni nel medioevo, Seminario Internazionale (2-4 ottobre 1983), a cura di T. Gregory, Roma 1985, pp. 171-218.

J. Le Goff, Sogni, in Dizionario dell'Occidente medievale. Temi e percorsi, a cura di J. Le Goff e J.C. Schmitt, Torino 2004, vol. II, pp. 1087-1105.

O. Lottin, Le Traité d'Alain de Lille sur les Vertus, les Vices et les Dons du Saint-Esprit, in «Mediaeval Studies», 12 (1950), pp. 20-56, riedito in Id., Psychologie et morale aux XIIe et XIIle siècles, vol. 6, Problèmes d'histoire littéraire de 1160 à 1300, édition de 0. Lottin, Gembloux 1960, pp. 27-92.

Lulle et la condamnation de 1277. La Déclaration de Raymond écrite sous forme de dialogue, traduction du latin avec notes et appendices C. Bonmariage et $\mathrm{M}$. Lambert, avec la collaboration de J.M. Counet, introduction C. Bonmariage, Louvain-Paris 2006.

F. Macchioni, Storia civile e religiosa della città di Bagnoregio dai tempi antichi sino all'anno 1503, Viterbo 1956.

S. MacLaren, Shaping the Self in the Image of Virtue: Francesco da Barberino's I Documenti d'Amore, in Image and Imagination of the Religious Self in Late Medieval and Early Modern Europe, edited by R. Falkenburg, W.S. Melion and T.M. Richardson, Turnhout 2007, pp. 71-95.

P. Mandonnet, Sigier de Brabant et l'averroïsme latin au XIIIe siècle, Louvain 1908-19112.

R. Manselli, Il soprannaturale e la religione popolare nel Medioevo, Roma 1985.

R. Manselli, Il sogno come premonizione, consiglio e predizione nella tradizione medioevale, in I sogni nel medioevo, Seminario Internazionale (2-4 ottobre 1983), a cura di T. Gregory, Roma 1985, pp. 219-244.

U. Marchesini, Tre pergamene autografe di ser Lapo Gianni, in «Archivio Storico Italiano», s. 5, 12/1 (1894), pp. 91-94.

C. Margueron, Recensione a Francesco da Barberino, Reggimento e costumi di donna, in «Erasmus», 13 (1960), pp. 5-10. 
C. Margueron, Francesco da Barberino, in Dizionario critico della letteratura italiana, diretto da V. Branca, con la collaborazione di A. Balduino, M. Pastore Stocchi, M. Pecoraro, Torino $1986^{2}$, vol. II, pp. 281-285.

G. Marruzzo, Composizione e significato de «I Documenti d'amore» di Francesco da Barberino, in «Giornale italiano di filologia», n.s. 5 [26], 3 (1974), pp. 217-251.

G. Melodia, Dante e Francesco da Barberino, in «Giornale Dantesco», 4/1 (1897), pp. 58-68.

G. Mezzanotte, Federico Ubaldini e gli studi provenzali nel Seicento, in «Aevum», 52/3 (1978), pp. 459-470.

G. Mezzanotte, Contributo alla biografia di Federico Ubaldini (1610-1657), in «Italia medioevale e umanistica», 22 (1979), pp. 485-503.

N. Mineo, Fortuna, libertà e volontà nell'antropologia dantesca, in «Linguistica e Letteratura», 38/1-2 (2013), pp. 9-37.

A.J. Minnis, Amor and Auctoritas in the Self-Commentary of Dante and Francesco da Barberino, in «Poetica», 32 (1990), pp. 25-42.

A. Montefusco, Rencensione a M.C. Panzera, Francesco da Barberino tra Andrea Cappellano e Averroè, in «Linguistica e Letteratura», 42/1-2 (2017), pp. 293-298.

A. Montefusco, La linea Guittone-Monte e la nuova parola poetica, in Dante attraverso $i$ documenti. II. Presupposti e contesti dell'impegno politico a Firenze (1295-1302), a cura di G. Milani e A. Montefusco, in «Reti Medievali Rivista», 18/1 (2017), pp. 1-52 (online all'URL: http://www.rmojs.unina.it/index.php/rm/article/view/5097/5742).

A. Montefusco, S. Bischetti, Prime osservazioni su ars dictaminis, cultura volgare $e$ distribuzione sociale dei saperi nella Toscana medievale, in «Carte Romanze», 6/1 (2018), pp. 163-240.

M.G. Muzzarelli, Pescatori di uomini. Predicatori e piazze alla fine del Medioevo, Bologna 2005.

V. Nardi, Le illustrazioni dei 'Documenti d'amore' di Francesco da Barberino, in «Ricerche di Storia dell'arte», 49 (1993), pp. 75-92.

R. Ortiz, Le imitazioni dantesche e la questione cronologica nelle opere di Francesco da Barberino, in «Atti dell'Accademia di Archeologia, Lettere e Belle Arti», 23 (1904), pp 231-268.

R. Ortiz, Francesco da Barberino e la letteratura didattica neolatina, Roma 1948.

A. Padovani, Il diritto, un passato "monumentalizzato"? in Roma antica nel Medioevo: mito, rappresentazioni, sopravvivenze nella 'Respublica Christiana' dei secoli IX-XIII, Atti della quattordicesima Settimana internazionale di studio (Mendola, 24-28 agosto 1998), Milano 2001, pp. 49-70.

M.C. Panzera, Per l'edizione critica dei 'Documenti d'Amore' di Francesco da Barberino, in «Studi mediolatini e volgari», 40 (1994), pp. 91-118.

M.C. Panzera, Francesco da Barberino tra Andrea Cappellano e Averroè. Poesia, immagini, profetismo, Alessandria 2016.

R. Parmeggiani, Consiliatores dell'Inquisizione fiorentina al tempo di Dante: cultura giuridicoletteraria nell'orbita di una oligarchia politico-finanziaria, in «ll mondo errante». Dante fra letteratura, eresia e storia, Atti del convegno internazionale di studio (Bertinoro, 13-16 settembre 2010), a cura di M. Veglia, L. Paolini e R. Parmeggiani, Spoleto 2013, pp. 57-79.

E. Pasquini, Francesco da Barberino, in DBI, 49, 1997, pp. 686-691. 
J. Perarnau i Espelt, De Ramon Llull a Nicolau Eymerich. Els fragments de l'“Ars amativa" en còpia autògrafa de l'inquisidor Eimeric integrats en les cents tesis antilullianes del seu “Directorium inquisitorum", in «Arxiu de Textos Catalans Antics», 16 (1997), pp. 7-129.

G. Petrocchi, Intorno alla pubblicazione dell'«Inferno» e del «Purgatorio», in «Convivium», 6 (1957), pp. 652-669.

A. Petrucci, Minuta, autografo, libro d'autore, in Il libro e il testo, Atti del Convegno Internazionale di Urbino, 20-23 settembre 1982, a cura di C. Questa e R. Raffaelli, Urbino 1984, pp. 399-414.

A. Petrucci, Scrivere il testo, in La critica del testo. Problemi di metodo ed esperienze di lavoro, Atti del convegno di Lecce (22-26 ottobre 1984), Roma 1985, pp. 209-227.

A. Petrucci, Minima barberina. I. Note sugli autografi dei 'Documenti d'Amore', in Miscellanea di studi in onore di Aurelio Roncaglia a cinquant'anni dalla sua laurea, Modena 1989, vol. III, pp. 1005-1009.

F. Petrucci Nardelli, Minima barberina. II. L'Eternità Barberina. Dalla miniatura alla stampa, in Miscellanea di studi in onore di Aurelio Roncaglia a cinquant'anni dalla sua laurea, Modena 1989, vol. III, pp. 1010-1014.

G.L. Potestà, L'ultimo messia. Profezia e sovranità nel Medioevo, Bologna 2014.

M. Prandi, Vincenzo di Beauvais e Francesco da Barberino, in «Italia Medioevale e Umanistica», 19 (1976), pp. 133-161.

R. Renier, Recensione a A. Thomas, Francesco da Barberino et la littérature provençale en Italie au Moyen Age, in «Giornale Storico della Letteratura Italiana», 3 (1884), pp. 91-104.

A. Rieger, Trobairitz. Der Beitrag der Frau in der altokzitanischen höfischen Lyrik. Edition des Gesamtkorpus, Tübingen 1991.

C. Ripa, Iconologia overo Descrittione di diverse imagini cavate dall'antichità \& di propria inventione, in Roma, appresso Lepido Facii, 1603.

G.E. Sansone, La prima redazione del «Reggimento e costumi di donna» di Francesco da Barberino, in «Filologia romanza», 3 (1956), pp. 371-435.

C. Scarpati, Francesco da Barberino e Guglielmo di Conches, in «Italia Medioevale e Umanistica», 19 (1976), pp. 163-170.

J.-C. Schmitt, Medioevo "superstizioso", Roma 1992.

J.F. von Schulte, Die Glosse zum Decret Gratians von ihren Anfängen bis auf die jüngsten Ausgaben, in «Denkschriften der philosophisch-historischen Classe der Akademie der Wissenschaften in Wien», 21 (1872), pp. 1-99.

C. Segre, Le forme e le tradizioni didattiche, in Grundriss der romanischen Literaturen des Mittelalters, vol. VI, La littérature didactique, allegorique et satirique, directeur H.R. Jauss, Heidelberg 1968-1970.

L. Spruit, Llull, Ramon, in Dizionario storico dell'Inquisizione, diretto da A. Prosperi, con la collaborazione di V. Lavenia e J. Tedeschi, Pisa 2010, vol. II, pp. 927-928.

J. Steinberg, Accounting for Dante. Urban Readers and Writers in Late Medieval Italy, Notre Dame 2007.

J. Steinberg, Dante e i confini del diritto, Roma 2016.

P. Supino Martini, Per la tradizione manoscritta dei «Documenti d'amore» di Francesco da Barberino, in «Studi Medievali», 3 (1996), pp. 945-954.

K. Sutton, The lost 'Officiolum' of Francesco da Barberino rediscovered, in «The Burlington Magazine», 147 (2005), pp. 152-164.

J. Swanson, John of Wales. A Study of the Work \& Ideas of a Thirteenth-Century Friar, Cambridge 1989. 
A. Thomas, Francesco da Barberino et la littérature provençale en Italie au Moyen Age, Paris 1883.

G. Vandelli, L'argomento barberiniano e la data della «Commedia», in «Studi danteschi», 13 (1928), pp. 5-29.

G. Verbeke, Le «De anima» d'Avicenne. Une conception spiritualiste de l'homme, in Avicenna Latinus, Liber de anima, cit., vol. II (1968).

Z. Verlato, Schede di lessico latino e volgare dai «Documenta Amoris» di Francesco da Barberino, in «Medioevo letterario d'Italia», 15 (2018), pp. 73-139.

G. Vitaletti, Intorno a Federico Ubaldini e ai suoi manoscritti, in Scritti di storia e paleografia pubblicati in occasione dell'ottantesimo natalizio di Francesco Ehrle, V, Roma 1924, pp. 489-506.

G. Vitaletti, Annotazioni alla Divina Commedia di Federico Ubaldini, in «Giornale dantesco», 26 (1923), pp. 239-252; 329-353; 27 (1924), pp. 53-67.

R. Zanni, Una ricognizione per la biblioteca di Dante in margine ad alcuni contributi recenti, in «Critica del Testo», 17/2 (2014), pp. 161-204. 